\title{
Microcirculation in the spontaneously hypertensive rat
}

Citation for published version (APA):

le Noble, J. L. M. L. (1987). Microcirculation in the spontaneously hypertensive rat. [Doctoral Thesis, Maastricht University]. Rijksuniversiteit Limburg. https://doi.org/10.26481/dis.19870925jn

Document status and date:

Published: 01/01/1987

DOI:

10.26481/dis.19870925jn

Document Version:

Publisher's PDF, also known as Version of record

\section{Please check the document version of this publication:}

- A submitted manuscript is the version of the article upon submission and before peer-review. There can be important differences between the submitted version and the official published version of record.

People interested in the research are advised to contact the author for the final version of the publication, or visit the DOI to the publisher's website.

- The final author version and the galley proof are versions of the publication after peer review.

- The final published version features the final layout of the paper including the volume, issue and page numbers.

Link to publication

\footnotetext{
General rights rights.

- You may freely distribute the URL identifying the publication in the public portal. please follow below link for the End User Agreement:

www.umlib.nl/taverne-license

Take down policy

If you believe that this document breaches copyright please contact us at:

repository@maastrichtuniversity.nl

providing details and we will investigate your claim.
}

Copyright and moral rights for the publications made accessible in the public portal are retained by the authors and/or other copyright owners and it is a condition of accessing publications that users recognise and abide by the legal requirements associated with these

- Users may download and print one copy of any publication from the public portal for the purpose of private study or research.

- You may not further distribute the material or use it for any profit-making activity or commercial gain

If the publication is distributed under the terms of Article $25 \mathrm{fa}$ of the Dutch Copyright Act, indicated by the "Taverne" license above, 
Microcirculation in the spontaneously hypertensive rat 
. 


\title{
Microcirculation in the spontaneously hypertensive rat
}

\author{
Proefschrift
}

ter verkrijging van de graad van doctor in de Geneeskunde aan de Rijksuniversiteit Limburg te Maastricht, op gezag van de Rector Magnificus, Prof. Dr. F.I.M. Bonke, volgens het besluit van het College van Dekanen, in het openbaar te verdedigen op vrijdag, 25 september 1987 om 16.00 uur

door

Jos Leonard Martin Louis le Noble geboren 1956 te Heerlen 
Promotores: $\quad$ Prof. dr. H.A.J. Struyker Boudier Prof. dr. R.S. Reneman

Co-promotores: Dr. DW. Slaaf

Dr. J.F.M. Smits

Referenten: Prof. dr. F.T. Bosman

Prof. dr. M.A.D.H. Schalekamp

Financial support by the Netherlands Heart Foundation for the publication of this thesis is gratefully acknowledged. 
In memory of my father To my mother 
1. General introduction

1. I General considerations on the aetlology

of hypertension

1.2 The pivotal role of the kidneys in the onset

of spontaneous hypertension

1.2. Nervous influences on the kidney 12

1.2.2 Afferent renal nerve activity 14

1.2. 3 Hormonal influences

1. 3 The circulatory dynamics in the

development of spontaneous hypertension

in the rat

1.4 Mictocirculation and vascular resistance 18

1.5 Wascular smooth muscle proliferation 20

1.6 Microvascular changes in spontaneous hypertension 22

1.6.1 Skeletal muscle 22

1.6.2 The splanchnic vascular bed $\quad 26$

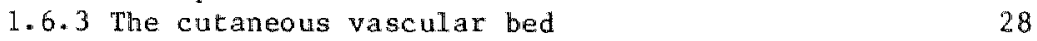

1.6.4 Cerebral microvasculature $\quad 28$

$\begin{array}{ll}1.6 .5 \text { Renal inicrovasculature } & 29\end{array}$

1.7 Synopsis 30

1.8 The present thesis 33

2. Materials and methous 43

2. 1 Animals 43

2.2 Anesthesia 43

2.3 Blood pressure measurements 44

2.4 Adrinistration of drugs 46

2.4.1 Cannulation of the right femoral vein 47

2.4.2 Cannulation of a sma11 side-branch
of the superior mesenteric artery

2.4.3 Topical adnimistration of drugs 48

2.5 Regional blood flow measurement 48

2.5.1 Doppler flownetry 48

2.6 Posterior hypothalamus stimulation $\quad 49$

2.7 Anesthetized animal preparations 50

2.7.1 Mesentery preparation 50

2.7.2 Intestinal preparation $\quad 52$

2.7.3 Cremaster preparation $\quad 52$

2.8 Conscious animal preparation 54

2.8.1 The dorsal microcirculatory chamber 55

2.9 Intravital microscopy, illumination and
recording systems

2.9.1 Set-up for anesthetized animals $\quad 58$

2.9.2 Set-up for conscious animals 61

2.10 Microvascular measurements 61

2.10.1 Diameter measurements $\quad 62$

2.10.2 Measurement of red blood cell velocity 62

2.11 Statistical analysis 6.4

2.12. References: 65 
3. Regulation of perfusion of skeletal muscle during the early phase of spontaneous hypertension in rats:
a functional morphometric study
3.1. Introduction
3.2 Experimental protocol
3. 3 Results
3.4 Discussion
3.5 References

4. Cutaneous muscle microcirculation in adult conscious normotensive and spontaneously hypertensive rats

4.1. Introduction

4.2 Experimental protocol 90

4.3 Results 91

4.4. Discussion 95

4.5 References 99

5. Sympathetic-adrenergic stimulation of the microcirculation: a combined macro- and microcirculatory stcudy

5.1 Introduction 103

5.2 Experimental protocol 104

5.3. Results 1.07

5.4 Discussion 115

5.5 Refierences 118

6. Differential effects of general anesthetics on regional vasoconstrictor responses in the rat 121

6.1 Introduction 121

6.2 Experimental protocol 121

6.3 Results 123

6.4 Discussion $\quad 127$

6.5 References 130

7. In-vivo effects of atriopeptin IT (APII) on mesenteric nitcrovessels

7.1. Introduction

7.2. Experimental protocol 133

$\begin{array}{ll}7.3 \text { Results } & 136\end{array}$

7.4 Discussion 141

7.5 References 1.43

8. Evaluation of macromolecular leakage as a possible mechanism for the blood pressure lowering effect of 1.02-1.26 hANF

8.1 Introduction

8.2 Experimental protocol

8.3 Results

8.4 Discussion 

1. GENERAL INTRODUCTION

1.1 General considerations to the aetiology of hypertension

Chronic hypertension in man may be divided into primary and secondary forms. The latter includes hypertension of known causes such as coarctation of the aorta, pheochromocytoma, primary aldosteronism, chronic glomerulonephritis, and renovascular hypertension. However, more than $90 \%$ of patients with elevated blood pressure, have primary or essential hypertension. The term "essential" refers to the unknown cause of the disease. The disease is wide-spread with a prevalence of 15-20\% in Western countries (Society of Actuaries, 1980; Epstein, 1983; Julius and hansson, 1983). No major cause has been demonstrated for essential hypertension and its aetiology has outgrown the image of being a single homogeneous disease. Current hypotheses concerning the heterogeneous pathophysiology of essential hypertension can be sumarized as follows:

1. It is a disorder of regulation in which a complex interplay of short- and long-term blood pressure control mechanlsms are involved (e.g. endocrine, neurogenic, renal and vascular mechanisms). The disorder of regulation ultimately results in an elevated arterial blood pressure associated with an increased peripheral resistance.

2. Essential hypertension encompasses a variety of speciflc but still undefined pathophysiological disturbances, on the long run increasing resistance and thus blood pressure.

3. Essential hypertension cannot be regarded as a distinct entity because the distribution curves of blood pressure in the general population are smooth and there is no dividing If he between normal and elewated blood pressure.

The multifacetted nature of the problem is reflected by the fact that a hypertensive state can be reproduced in a whole array of experimental models (e.g. dietary, hormonal, renal, neurogente, or genetic selection). Each of these modalities can in turn be modified by a range of interventions so that the extensive data on the subject matter available in literature are difficult to synthetize into some 
genetaldzed scheme. According to Guyton (1986), two main extreme mechanlsms related to the attology of hypertension can be distingulshed. Hypertension can be the result of either fluid retention by the kidneys or by activation of vascular constrictor mechanisms. Most forms of experimental hypertenston are mixed forms and it is yet not fully clarffied to what extent each factor contributes to the increased blood pressure.

There is an important genetlc component in human hypertension (Rapp, 1983). It has long been recognized that essential hypertension cends to occur in famliles. This tendency is polygenic rather than related to a single gene (P1ckering, 1968). Although avallable evidence $i s$ difficult to quantify, it indicates that the contribution of Inherttance $1 \mathrm{~s}$ probably between one-third and two-thirds of the whole. lihe inheritance of (spontaneous) hypertension in the Okamoto-Aoki strains of the spontaneously hypertensive rat (SHR) is also polygenic, even though the number of genes involved may be relatively small (Tanase et all, 1972; Harrap, 1986). The SHR strain serves as an appropriate genetic animal model of human essential hypertension and therefiore the present thesis will be 1 imited to spontaneous hypertension in rats (Rapp, 1983).

Basically, two hypotheses have been put forward to explain the aetiology of spontaneous hypertension either related to the dominant role of the kidneys or to primary vascullar changes. Before assessing the relationship of microvascular changes to the aetiology of spontaneaus hypertension, some dominant blood pressure control mechanisms w11 be alscusaed for reasons of completeness. Most of them have been shown to be involved in the vasomotor activities of the microcirculation. Each mechanlsm wil be discussed briefly from the perspective of the macrocirculation. In the second part of this introduction, the (micro)vascular dynatics in spontaneous hypertension will be discussed. 1.2 The piwotal role of the kidneys in the onset of spontaneous

No specific pathogenic mechanism has yet been found for essen- 
tial hypertension in man nor in several animal models for hypertension. The dominance of the kidneys in the induction and maintenance of seweral forms of hypertension is well-known. Kidney transplantation from nomotensive donor rats into rats of the Milan hypertensive strain resulted in complete teversal of blood pressure (Bianchi et al, 1973, 1974). This has also been demonstrated for the spontaneously hypertensive rat and the Dahl-hypertensive rat (Dahl et al, 1974). Conversely, blood pressure increased in normotensive rats after they received kidneys from prehypertensive or from hypetcensive animals (Fox et al, 1976; Tobian, 1983).

\subsubsection{Nervous influences on the kidney}

Much attention has been paid to the role or the sympathetic nerwous system in the aetiology of hypertension. An enhanced general activity of the sympathetic nervous syster can play an important role in the onset and maintenance of hypertension (Abboud, 1982, 1984; McCarty, 1986). The primary effect of an enhanced sympathetic activity would be to increase peripheral vascular resistance. It had been shown that stimulation of renal adrenerglc mechanisms influences a variety of kidney functions. Following stimulation, renal arteriolar resistance (Block et al, 1952; Fink et a 1, 1978), renin release (Davis and Freeman, 1976) and tubular sodium reabsorption (Colindres and Gotschalk, 1978; DiBona, 1977) are reported to be increased. The thick ascending limb of the loop of Henle is under adrenergic control as we11 (DiBona and Sawin, 1982).

It has been argued that a rise 1 peripheral restatance is only the cause of hypertension, if the rise seen in vascular resistance includes the renal vasculature. The renal vascular bed is among the first to raise its resistance during the development of spontaneous hypertension (Evenwel et all, 1983). An enhanced sympathetic activity affects primarily renal afferent arterioles which show the highest sensitivity for noradrenaline as compared to efferent arterioles (Edwards, 1983). Furthermore, a sympathetically mediated increased proximal tubular reabsorption of $\mathrm{Na}^{+}$and water leads to fluid retention (DiBona, 1982; Kopp et al, 1987). Circulating blood volume and plasma volume will increase and due to the ellevation of clrculatory 
f1ll1ng pressures, the cardiac output will increase. The blood pressure urinary flow curve will shift to higher pressures as has been shown for the spontaneously hypertensive rat (Norman et al, 1978; Roman, 1986).

Other factors have to be included as well. A stressful environment and high sodiun intake increase the responsiveness of the sympathetic nervous systeril to neurogenic stimull to a greater degree in anduals with a genetic predisposittom toward hypertension and these stimuli interact synergistically (Koepke and Dibiona, 1985). In addithon, high sodiun may result in disinhibition of central sympathicoinhibitory neurons and lead to a hyperadrenergic state (Gavras, 1986) which is probably reluforced by an heritable abmormal sodium handling (Harrap, 1986) observed in the spontaneously hypertensive rat.

Several authors have shown that section of the efferent nerves prevents or delays the development of hypertension in several rat models (Liard, 1977; K1ine et a1, 1980; Winternitz et a1, 1980; Katholi et a1, 1980, 1982). In most models it has however no effect on the final hypertensive state. Blood pressure increases could not be completely blocked partly due to functional reinnervation or to structural changes of the vasculature. The role of sympathetic nerves remains controversial because hypertension develops equally rapidly in rats maintained on a high sodium diet whether the renal nerves are present or not (Norman et a1, 1984). The delay in blood pressure increase was explained on the basis of the rats ability to retain sodium and water. It should be taken into account that crucial experiments still have to be performed because no selective method to eliminate the renal sympathetic nerves was employed in these studies and renal nerves in the rats consist of afferent as well as efferent fibers (Le Noble et al, 1985; Sints et al, 1985).

\subsubsection{Afferent renal nerve activity}

The role of afferent renal nerve activity may be involved in the matintenance of a high sympathetic tone. Kidneys contain both mechano-sensitive (Nijlma, 1971, 1972) and chemo-sensitive receptors with a sensory input into the central nervous system (Recordati et al, 1980 , 1981, 1982; Zanchetti et al, 1984). These nerves are involved in 
reflex cardiovascular adjustments. Moreover, electrophysilological evidence is available for the existence of renorenal reflexes. Shortterm activation of afferent renal nerves in dogs or rats by means of chemical stimulation by substances 1 ike adenosine or bradykinin (Smits and Brody, 1984; Katholi, 1984, 1985) leads to increment of blood pressure and heart rate. Chronic stimulation of the renal afferent nerves could lead to increases in overall sympathetic activity as was shown in two-kidney, one-clip Goldblatt rats (Katholi et al, 1982).

In spontaneous hypertension, afferent renal nerwes may be part of a still unknown vasopressor mechanism (Kleinjans et al, 1984). Although ablation of renal nerves prevents blood pressure to increase following pharmacological stimulation of renal afferent sensors, no attenuation in the development of high blood pressure was seen in SHR in which afferent nerves were selectively eliminated by means of dorsal rizotomy (Janssen et al, 1987). Thus the significance of afferent renal nerwes may be linked to short-term cardiovascular adjustments rather than to a state of a chronically ellevated blood pressure.

\subsubsection{Hormonal influences}

Several hormones are involved in renal excretory function. Apart from the classically known renin-angiotensin-aldosteron system and the antidiuretic hormone, special attention will be given to some of the newly described endocrine nechanisms. These newly described hormones are the so-called natriuretic hormone and the atrial natriuretic factars (ANF). Ewidence for a natuiuretic hormone goes back to the work by De Wardener in the early sixties (De Wardener and MacGregor, 1983). He found in the rat that during blood volume expension, urinary sodum excretion increases. Plasma from a volume expanded rat causes natriuresis when infused in another rat. The natriuretic activity is caused by an ouabane-like inhibitor of renal $\mathrm{Na}^{+} / \mathrm{K}^{+}$ATPase. The inhibitor is possibly released by the central nervous system and originates from the anterowentral region of the third cerebral ventricle. Selective lesions in the preoptic hypothalamic periventricular region in the rat. reduces the natriuresis after volume expansion by decreasing the hormone-like activity in plasma. 
Evidence for the existence of natriuretic factors in the atrium which difer from the originally described natriuretic hormone, comes from the work of DeBold. In 1981, he and his co-workers demonstrated that the administration of atrial homogenates to rats results in a rapld masstwe, and short-lasting diuresis and natriuresis (DeBold et al, 1981). Later experiments led to the isolation and identification of these artrial natriuretic substances (Thibault et al, 1983). They are usually referred to as atriopeptins or atrial natriuretic factors (ANF). It soon became clear that atrial natriuretic factors are polypeptides and differ both chemically and biologically markedly from the natriuretic hormone (Maack et al, 1985). The atria contain considerable quantitles of large molecular welght prohormone forms of ANF which are derived upon exocytosis. They are released upon atrial stretch (Palluk et al, 1985). Besides natriuresis and diuresis, it produces a concomitant phosphaturia, chloriduria, magnesuria, and a slight kalluresis (Cantin and Genest, 1985). Furthermore, ANF increases the glomerular filtration rate (GFR) at high doses by increasing the glomerular capillary permeability. Recent microvascular studies of the kidney demonstrate a preglomerular dilation and postglomerular constriction in superficial cortical nephrons (Marin-Grez et a1, 1.986). ANF antagonizes vascular smooth muscle contraction induced by a variety of vaso-active agents in vitro and lowers blood pressure In the intact animal. The hypotensive effect of ANF, which has been confirmed in a variety of hypertensive models, has been attributed to the vasorelaxant effect observed in vitro, although conclusive evidence has not yet been reported. By Itself ANF have no effect on the basal wascular muscular tore and wasorelaxation 1 s independent of the presence of the endothelitur.

Moreover, injection of ANF increases the urinary excretion of cyclic GMP, an important mediator of the relaxation of vascular smooth muscle (Ohlstein et al, 1985). Attempts to demonstrate the vasorelaxant activity in intact conscious animals (e.g. instrumented for measurement of reglonal blood flows) were negative (Lappe et al, 1985). Following continuous infusions of ANF, blaod flow to the splanchnic viscera and kidneys decreased and vascular resistance increased. Recent evidence indicates that the hemodynamic responses are 
greatly dependent on the mode of drug admintistration. The same peptide applied as bolus injection caused an increase in blood flow, indicating a reduced resistance (Lappe et al, 1986). The blood pressure lowering effect and its possible mechanism of action related to nicrovascular changes 11 be discussed in chapter 7 and 8 .

The pathophysiological implications of ANF in hypertension are not clear yet. In hypertensive subjects and in animals during the established phase of spontaneous hypertension, plasma levels of ANF are markedly increased (Cantin and Genest, 1985; Takayanagi et al, 1986; Arendt et al, 1986) or normal (Yamaji et al, 1986), while atrial tissue levels of $A N F$ are reported to be lower in hypertension. The plasma concentration changes are related to the progression of hypertension. The decrease of ANF levels in the left atrium seems to be due to an increased turn-over and in the SHR hypertension can occur despite increased levels of ANE.

1.3 The circulatory hemodynamics in the development of spontaneous hypertension in the rat

In the SHR, blood pressure rises with age (Smith et all, 1979; Prewit et all, 1982; Evenwel et a1, 1983). The blood pressure is above that of normotensive control Wistar or Wistar-Kyoto rats about 3-4 weeks after birth.

The increase in blood pressure in spontaneous hypertension may be the result of an increased cardiac output or elevation of pertpheral resistance. An infiating factor in the developrant of essental hypertension seems to be the increased cardiac output. In young SHR (age 5-6 weeks), cardiac output is increased while perlpheral resistance is st111 normal (Smith and Hutchins, 1979; Evenwel et al, 1983). Flow to the kidneys is decreased probably due to increased peripheral resistance as a consequence of an enhanced aymathetic activity initially triggered by afferent renal nerves (Kopp et a1, 1987). Plasma volumes in young SHR are Increased (Evenwel et al, 1983). An excess: intravascular volume will lead to overperfuston of major vascular beds of the body. This induces a rise in tissue resistance to higher flow via autoreguliatory mechanisms as originally formulated by Borst and 
Borgt-deGeus (1963) and Guyton et al (1971). High blood pressure becomes irreversible in the sHR by a genetic facilitation of cardio vascular structural adaption affecting the vessel wall or the microvascular architecture (Folkow, 1983). By that time, maintenance is independent of the sympathetic nervous system.

In parallel wth the fincrease in cardiac output, intravascular volume becomes progressively contracted with a centripetal redistribution of Intravascular volume towards the cardiopulmonary bed, most $11 \mathrm{kely}$ assoclated with a decreased compliance at the venous side (Folkow, 1983). The splanchnic vascular bed quickly tncreases resistance to the high blood pressure and/or flow (Evenwel et a1, 1983). The last main vascular beds which increase resistance are the skin and skeletal muscle. The cerebrovascular bed shows an intermediate reaction. The microvascular features and their hemodynamic consequences will be discussed in the next sections.

\subsection{Microcirculation and vascular resistance}

No uniform definition of the microvascular bed can be given because among the several vascular beds the architectural design, branching order, configuration, vessel size and characteristics of bload flow are different. For an extensive review of microvascular beds, see Whedenan ( 1981 ).

Usually the arterial vessel that marks the entrance into the inicroctrculation is called an arteriole and these vessels are classifled by the method of Wiedeman (1963) into first, second, third and fourth order arterioles $\left(A_{1}-A_{4}\right)$. An arteriole forms a functional unit with the surcounding tissue and has a diameter less than 100-125 $\mu$ m. Arterioles terminate in precapillary arterioles which feed the capillary network. The precapillary arterioles control flow in capillaries. At the postcaptliary side, venules converge into veins and have about 2-3 times the diameter of the arterioles and small arteries in the same vascular bed.

According to Poiseuille's 1aw, the ratio of pressure drop to rate of flow is a function of all the factors that influence blood 
flow (viscostty, length and radius) (Pappenheimer, 1984). This ratio has been adopted as an expression of vascular resistance by analogy with Ohm's law for electrical circuits. The resistance of a vascular bed is defined as the difference between the pressure at the inlet of the bed and the pressure at the outlet divided by the mean blood flow and peripheral resistance at frequency $0 \mathrm{~Hz}$.

Several parameters may affect vascular resistance in hypertension. Since length of individual vessels can be regarded as constant in most beds and blood viscosity is constant under most conditions, it is evident from Poiseuille's law that resistance depends primarily on vessel radius. Resistance calculations of the microcirculatory bed are more complex. The pressure gradient within the network is a function of the diminishing diameter of the successive branching orders with the sharpest fall accurring in the region of the smallest arterioles. Recent studies, however indlcate that a major fraction of the vascular resistance lies proximal to the microvascular bed. The resistance is modulated by feeding vessels located more upstream, supplying the microvascular bed (Segal and Duling, 1986; Melninger et al, 1987). These vessels have significant tone at rest, contribute to the overall vascular resistance and pllay a significant role in the regulation of tissue blood flow. Furthermore, the magnitude of the hydrostatic force driving the blood stream througth the microvascular bed depends on the position of the microvascular bed relative to the main feed vessel (aorta).

Changes in vascular resistance are also related to the angloarchitecture of the microcirculation. Vessels may show equal diameters but an increase in vascular metwork resistance can stll be provoked by a lowered number of parallel conductance channels (artertolar segments of the same vessel order), $i$.e. rarefaction. Rarefaction is deternined either functionally or structurally. Functional rarefaction refers to an increased number of arterioles temporary closed to flow in the resting condition while structural rarefaction refers to the lowered number of arterioles (1) functionally avallable following vasodilation or (2) anatomically present.

In addition, the involvement of a complex array of factors that include vessel length, diameter, branching in serles versus parallel 
deployement as well as rheologlcal factors bave to be considered (e.g. local hematocrit, leukocyte sticking, plasma skiming).

\subsection{Vascular smooth muscle prollferation}

The heart, arteries and arterioles are able to adapt their arehitecture by wall hypertrophy and or hyperplasia when sustained elevations of transmural pressure are at hand. Vascular structural. changes in hypertension and related functional consequences have been discussed in recent review articles (Lee and Smeda, 1985, Lever, 1986; Schwartz et al, 1986). Blood vessels of all tissues are able to readi1y adapt thefr structure. This is not exclusively limited to arteries or arterioles. Also capacitance vessels show some structural adaptation that reduces venous compliance and contributes to blood volume centralization (Folkow, 1983). Morphological changes of blood vessels reducing the average inner radius of resistance vessels have important functional consequences leading to a steeper increase in vascular resistance following stimulation. The increased wall to lumen ratio results in a geometrically based vascular hyperreactivity (for a detalled discussion, see Folkow, 1983).

Vascular hypertrophy is involved in different types of hypertension (Lever, 1986). However, data on the role of vascular hypertrophy with regard to the aetiology of spontaneous hypertension remains scanty. An increased wall thickness may precede or develop as a consequence of the elevated blood pressure (Mulvany et al, 1978; Folkow, 1983; Lee, 1983, 1985). The avallable 1fterature allows to conclude that hypertrophy of resistance vessels can be divided into three categorles:

1. Pressure-dependent. In animals such as the giraffe, arteries in lower limb segments are ordinarily exposed to transmural pressures around $500 \mathrm{~mm} \mathrm{Hg}$ due to combined hemodynamic and gravitational forces and their wall to lumen ratios are enormous compared with the cranial arteries $(0.68-0.80$ versus $0.15-0.20)$ * The normalized blood flow for tissue weight is equal in skeletal muscle in the neck and in the feet (Pettersson et a1, 1986). Other evidence for pressure-dependent hypertrophy is obtained from human studies. 
Systemic veins in small children are largelly similar in arms and legs. In adults, the raised hydrostatic pressure in the erect position affects venous wall to lumen ratio proportionally to the raised transmural pressure. Also velns used for arterial grafting very rapidly develop wall thickening (Folkow, 1983).

2. Increased wall thickness elicited by trophic effects. In earlier studies, it was proposed that sympathetic nerves exert a trophic effect on the developing vascular muscle. Denervation of the ear artery in normotensive rabbits reduced the weight and medial thickness of the vessel despite a normal perfusion pressure (Bevan, 1975). In SHR and stroke-prone SHR, sympathetlc denervation prevented vascular hypertrophy of cerebral arteries and/or arterioles with a concomitantly altered autoregulation function (Hart et al, 1980; Sadoshima et a1, 1986). It was concluded that sympathetic nerves may play an important protective role during chronic hypertension by contributing to cerebral vascular hypertrophy and maintain capillary pressure in the brain.

The regulation of vascular growth is not fully understood but may be mediated by growth factors acting on specific receptors of the vessel wall. In essential hypertenston, angiotensin II, insulin or insulin-like growth factor have been proposed as major endogenous stimulants (Lever et al, 1986).

3. Intrinsic changes linked to a genetic growth abnormality. The key question to be answered is whether structural vascular adaptations occur during the early pre-hypertensive stages. When all nervous and myogenic tone is removed from the smooth muscle the restatame remaining is only due to the structure or morphology of the vessel wall itself. Even if SHR are treated with pentolinium and papaverine before onset of high blood pressure structural adaptation still occurs by the 9 th week of 1 fife as evidenced by an increased pertpheral resistance following constant maximal vasodilation (Prewte and Dowe11, 1982). Also in other studies, long term treatment wth antihypertensive agents falled or only partly inhibited cardiovascular hypertrophy (Jespersen, 1986). The components of vascular hypertrophy (DNA replication, collagen, elastin) of the hypertensive type vary from one vessel to another and depend on the vas- 
cular bed under study (Brayden et al, 1983). Vascular changes in the prehypertenstwe and early phase of spontaneous hypertension have been denonstrated for the splanchic vascular bed (Lee, 1985), renal (Pang and Scott, 1981) and carotid vessels (Gray, 1982, 1984). An increased aortic DNA synthesis before blood pressure increased has been found in renal hypertensive rats (Loeb et al. 1986)

A feature described in the prehypertensive phase of spontaneous hypertension in lare vessels is an enhanced DNA synthesis wh thout karyokinesis or cytokinesis. This results in hypertrophic, polyploid cells that account for most of the increased mass of the hypertensive vessel (Schwartz et al, 1986). Small vessels on the other hand show a true hyperplasia that is, an increase in number of diploid cells. Recent evidence inidicates that only the largest arterioles and not precapillary arterioles show structural changes of the vessel wall (Miller et al, 1987). A higher DNA replication has also been found for cardiac and renal tissue of newborn SHR (Walter and Hamet, 1986).

Evidence of vessel wall hypertrophy as an obligatory step towards the development of hypertenston is not conclusive yet. A predisposing genetic element has to be implied (Folkow, 1986).

\subsection{Microvascular changes in spontaneous hypertension}

The bastc principles by which an increased microvascular resistance may be achieved have been mentioned in section 1.4. Because there is no general format of microvascular adaptation to chronic hypertension in the SHR, the main vascular beds and their reported vascular adaptation and relative importance to the increased resistance 111 be discussed separately. The majority of experiments have been performed on anesthetized animals with externalized tissues. A summary will be given of the animal models currently used with emphasis on the studles performed in the SHR. 


\subsubsection{Skeletal muscle}

The microvasculature of skeletal muscle plays an important role in the development and maintenance of spontaneous hypertension (Evenwel et al, 1983). In the established phase of most forws of hypertension vascular resistance in skeletal muscle is elevated (Hueller, 1983) and the stiffness of resistance and capacitance vessels is increased. In addition, the minimum resistance measured after complete vasodilation is increased suggesting structural alterations of the vascular network (Mueller et al, 1983). The majority of experimental data have been obtained from the rat cremaster, gracilis and splnotrapezius muscles. These preparations are sultable because of a relatively easy surgical approach.

A $50 \%$ reduction of the number of perfused arterioles at rest in the cremaster muscle of 6 -week old SHR as compared to 6 week old WKY has been reported by Hutchins and Darne11 (1974). The reduction of the number of skeletal muscle arterioles was observed in a period when the blood pressure of the SHR is rising rapidly. These findings have been expanded in later studies to show that at 5 weeks of age not only the number of perfused arterioles is reduced, but also the total number of arterioles functionally avallable (Hutchins, 1977; Hutchins et al, 1982). However, once the spontaneous hypertension is established (12-30 weeks) the total number of cremaster arterloles is actually higher as compared to normotensive Wistar-Kyoto rats, whereas the number of patent arterioles remains below normotensive levels.

Chen et al (1981) investigated the contribution of the sympathetic nerves to the maintenance of a reduced number of perfused vessels. By using quantitative stereological techniques, they assessed whether the reduction was anatomical or functional. The capillary density was determined in addition. The results indicate that after cutting the hypogastric nerve, thus abolishing sympathetic tone, there was no increased neurogenic tone present as evidenced by enhanced arterlolar constriction in SHR as compared to WKY. In the vasodilated state no differences in maximum diameters could be decected. Therefore, structural changes of the vascular wall seem very unlkely. Chen et al (1981) concluded that a reduced number of arterioles is the on1y mechanistn involved in the increase in vascular resistance in the SHR 
cremaster wascle. The reduced capillary density should prevent an Incredsed flitration of fluid into the foterstelum, thus preventing adema formation. Artertolar diameters in the cremaster muscle showed no difference or even a tendency to be Larger in suR than in WKY at an age of 5-6 weeks (Hutching and Darne11, 1974; Dusseau et al, 1979; Chen at, 1981). Ondy one single report shows an enhanced vasodilathig capactey in the cremaster tuscle (Roy and Mayrovitz, 1982). In the graclis ascle (Prewitet al, 1982), enhanced levels of active contwetion wete seen which were age-dependent. Interestingly, in the older sher andirals the maximun diameters lncreased but the actual *allating ciacicy increased as well so that overall average tone was approximately the same. Prewtt (1982) compared this phenomenon with a tree with half of its smallest branches pruned and the larger ones reduced in dlaneter. The mechanical sigaiflcance is unknown yet.

The dynamic aspects and time course of microvascular changes during the development of spontaneous hypertension can be nicely illustrated by the results of a study by Prewit et al (1982). Similar to the finding in the cremaster muscle, capillary density was decreased in the control situation as well as in the vasodilated state in the gracl1is muscle at the age of 6-8 weeks (Prewitt et al, 1982). No evidence was obtained for arteriolar rarefaction at the age of 6-8 weeks. By 12-14 weeks, arteriolar density was reduced in the innervated condition but not after vasodilation. The vessels were present in SHR but were not available to flow. By 16-18 weeks, arteriolar density was reduced significantly in SHR even after vasadilation with sodium nitroprusside. So, the development of raretaction of arterioles proceeds from a state of no change at 6-8 weeks of age, a state of functional rarefaction at 12-14 weeks, and finally at $16-18$ weeks, a state of functional and anatomical rarefaction. Capillary density was also reduced at $16-18$ weeks but not to the same extent as arteriolar density.

Skalak and Schmid-Schönbein (1986) found a reduced capillary mesh-work density in the spinotrapezius muscle of adult SHR. Gray (1984) determined whether there are morphological alterations in skeletel muscle capillaries of the spinatrapeztus muscle as evidenced by changes in density, length, and diameter during early and late 
stages of the developmental phase of spontaneous hypertension in the rat. In neonatal (19 days old) and young adult ( $9-10$ weeks old) rats of the SHR and WKY strains, the presence of capillaries was assessed by histological and intravital microscopic techniques. In contrast to the findings in experimental animals and human hypertensives, diameters and densities are slightly increased.

The arteriolar network of the spinotrapezilus muscle was studied in detail by Engelson et al (1985). The topology of the vascuilar arrangement of the spinotrapezius muscle was investigated by means of carbon filling, thus allowing only information with regard to the vascular anatomy. Studies were performed on 16-20 week old WKY and SHR. A new branching scheme applied to the numerous arcades was introduced which accounted for all arterioles in this muscle. Analysis revealed that the length per unit volume of the SHR arcade arterloles increased and furthermore showed the presence of almost twice as many transverse trees per unit tissue volume in the SHR as compared to WKY rats. Transverse arterioles in the SHRs are shorter and show a trend towards fewer capillary endings. Smaller arteriolar diameters were only observed for arcade arterioles.

$Z$ weifach et al (1981) found that microvascular pressures were already elevated in the young hypertensive rat in the spinotrapeztus muscle, with a much sharper decline in micropressure across the arteriolar branchings of the SHR. In the cremaster muscle, similar data were obtained (Bohlen et al, 1977). In the young bypertensive rat, at the age of 7-8 weeks, micropressures were $30-35 \%$ higher than those measured in normotenstve rats. The distribution of pressure through comparable segments of the microcirculation of both stralns was essentially identical.

In contrast to genetic hypertension, arteriolar diameters are reduced in desoxycorticosterone acetate (DOCA) salt hypertension, and In the one-kidney, one-clip renowascular hypertensive and two-kidney, one-clip rats (Meiniger et a1, 1981, 1984; Prewtet et al, 1984; Joshua et al, 1984). It appeared that in renovascular hypertension an $1 \mathrm{n}^{-}$ creased arteriolar dilating capacity diminishes as structural mechanisms supersede the malntenance of peripheral resistances. By 8-10 weeks after clipping, the difference in vasoconstriction between 
hypertensive rats and controls is no longer statistically significant (Prewtet al, 1984). The fact that rarefaction occurred indicates that it 1 s not a genetic trait of rats destined to become hypertensive but a mechanism of possible regulatory importance that can be activated in a genetically normal rat.

\subsubsection{The splanchnle vascular bed}

The splanchnic circulation recelves a large portion of the cardiac output, contalns a substantial blood volume, and provides a major share of the total body 1 ymph flow and transvascular protein flux. Therefore, hypertension-induced changes in the vasculature of this reglon can play an important role in systemic hemodynamics (Ni jhof et a1, 2983). Flow digtribution data comparing SHR to normotensive control rats indicate that in SHR splanchnic vascular resistance is elevated in proportion to the increase in arterial pressure (Nishiyama et a1, 1976; Tobia et al, 1974). The status of splanchnic and intestinal (macro)circulation in several forms of hypertension have been discussed by Overbeck (1984).

It should be kept in mind that the splanchnic vascular bed is rather heterogeneous with respect to different physiological control mechanisms. The spatial organization and fine structure is adapted for the transport function of the alimentary tract (Lundgren, 1984 ). The knowledge about microvascular changes of the splanchnic bed in spontaneous hypertension is scanty and predominantly restricted to the tissues that are easily transilluminated.

Microvascular changes during the development of spontaneous hypertension were luvestigated in the intestine of $4-5$ week, and 18-21 week old SHR and WKY. Bohlen (1983) selected and analyzed the vartous modes of vascular changes and theitr relative importance to the increased intestinal vascular resistance during hypertension in SHR. observations were performed on a loop of Jejunum in pentobarbitalanesthetized rats. The intestinal vascular characteristics of young hypertensive rats exhibited no structural changes of the vascular design. By $4-5$ weeks, arteriolar dimenstons did not differ between both strains. In mature SHR a permanent loss of about $30-35 \%$ of the second order arterioles and some loss of perfused third order and 
swaller arterioles were the only evidence of rarefaction in the intestinal vasculature. Approximately $6 \%$ of the total number of third order arterioles were not avallable for flow and there was no permanent loss of small arterioles as was the case for similar vessels in skeletal muscle. The primary physical cause of increased vascular. resistance in the small intestine was vasoconstriction of the largest and smallest arterioles. In the same study, wessel wall hypertrophy was present in the $A 3$ vessels. The latter had smaller diameters in the passive state.

Furthermore, the effects of systemic arterial hypertension on intestinal microvascular pressures were assessed (Bohlen, 1983). It was of interest that despite elevated arteriolar pressures, the intestine is essentially spared from an increase of caplliary pressures during hypertension. The ratio of microvascular pressures to mear arterial pressure was elevated in the larger arterioles but disproportionally lower in the terminal portion of the vascular bed. No micropressure data were presented for young rats. In summary, in the jejunum the largests resistance increase occurred in the smallest artem rioles.

Structural differences in the mesentery microcirculation between WKY and SHR were dacumented by Henrich et al (1978) in mature rats (age approximately 20 weeks). No data were collected in young rats. A quantitative comparison was given of the entire unicrovascular network. The number of pre- and postcapillary vessels was found to be significantly reduced in SHR as compared to WKY. The capillaries were subdivided into arteriolar and venular as well as mid-ceplilaries the number of which was reduced In SHR to nearly one/third. The vasculiar network was not analyzed during vasodilation and no attents were made to differentiate between functional and structural rarefaction. Precapillary arterioles had on the average Hncreased diameters and the total vessel length of successtve branching order vessels was evidently diminished. Wall thickening was found only for the largest arterioles in diameter. Structural changes at the venular side were apparent with an equally pronounced decrease in density of the smallest venules in diameter. Microvascular pressures were measured in a separate study (Hertel and Henrich, 1982). In the rature sHR micro- 
pressures were elevated to nearly the same percentage as the arterial pressure for all types of arcerioles.

\subsubsection{Cutaneous vascular bed}

Hack et al (1980) compared the cutaneous microvessels from 5-10 week old SHR and WKY rats. A small sample of abdominal skin was extended and fixed. Following preparation the tissue was photographed and subsequently analyzed by measuring diameters and counting the number of arterioles and wenules. Structural, i.e. anatomical, differences with regard to the arteriolar density were obserwed for the fourth order arterioles in SHR which was lowered by $30 \%$. The SHR had 28.5\% fewer fourth order velins compared to WKY.

Mean internal diameters of the distal portion of the vascular bed were larger as well in SHR as compared to WKY. The mean branching angles of both arterial and venous vessels in the tissue from SHR were greater than the respective angles measured in normotensive animals, but the difference did not reach statistical significance.

\subsubsection{Cerebral microvascular changes}

A third major vascular bed is the cerebral circulation. Mechanisms to protect the exchange vasculature from elevated microvascular pressures and potential overperfusion is especilally important in the brain, where overperfusion can lead to edema and encephalopathy. Some form of protection does exist in the SHR since it is well established that in SHR cerebral. blood flow is maintained at normal or near normal levels and cerebral vascular resistance is increased (Evenwel et al, 1983). Very 1ittle data exist about microvascular changes of the cerebral microcirculation. Most observations were made in the microcirculation of the cerebral cortex of adult spontaneously hypertensive and normotenstve rats. Harper and Bohlen (1984) were not able to demonstrate either functional or structural rarefaction in the adult, 18-21 week old, SHR as compared to WKY. Arteriolar density for several vessel categorles was identical. Constriction of the larger arterioles was the major cause for the increased resistance of this part of the cfrculation, whereas arterioles with diameters less than 25 jm were not affected. In the vasodilated state, in the large arterioles a 
greater wall thickness could be observed in SHR, indicating the presence of structural changes of the vessel wall in SHR. Furthermore, arterioles had a decreased diameter following maximal dilation. Within the microvascular bed, micropressures were elevated at all levels and in SHR the greatest pressure drop advanced towards the capillary bed in the smallest arterioles (A3 and $A 4$ ).

The results of Harper and Bohlen (1984) are at variance with a later report of Sokolova et al (1985). Arteriolar and capillary networks in the brain of hypertensive and normotensive rats were analyzed in that study. Vessels were perfused with a $4 \%$ solution of gelatin in India ink with subsequent histological analysis. In a group of 3-month old rats with spontaneous hypertension, the number of third, fourth and fifth order branches was lower and their diameter smaller in hypertensive animals as compared to controls. Capillary denstty was studied rather extensively. In the same age group the intracerebral vessels were investigated. Histological examinations showed that the captllary network, as judged by a decreased length in the reticular nuclei of the medulla oblongata and the pons, was considerably smaller in the hypertensive animals.

Furthermore, Sokolova et al (1985) made an interesting observation of a rapid appearance of anatonical racefaction in developing renal hypertension. A rise of pressure and decrease in the number of vessels are already apparent 24 hr in rats with a single ligated kidney. These data do implicate that structural changes of the vascular bed can be involved in a very early phase of hypertension.

\subsubsection{Renal microvasculature}

Although the kidneys play a crucial role in the development of spontaneous hypertension, surprisingly no systematic analysto has been made thus far regarding renal microvascular changes during the development of spontaneous hypertenston using intravital microscopic technlques. 


\subsection{Synopsis}

The multifactorial character of spontaneous hypertension in rats or essential hypertension in humans as a primary disease of the vascular bed has led invest cerning the genesis of hypertension. At a systemic level different factors and neurohumoral mechanlsms can influence blood pressure and much emphasis has been put on central hemodynamic mechanisms being key lngredients of the progressive elevation of blood pressure with a concomitant rise in vascular resistance (Peart, 1983; Evenwel et al, $1983)$.

Studies focussed on the central as well as the regional hemodynamics found an increased peripheral resistance with an equally distributed cardiac output in the phase of stable hypertension. The time profile for the appearance of the increased resistance depends upon the partlcular vascular beds (Evenwel et al, 1983).

In the SHR at the age of 5 weeks the kidney is the first to increase tis reststance closely follawed by the splanchuic bed. In the adult rats (10-12 weeks) the skeletal muscle and skin have increased their reststance and blood pressure plateau to a steady-state elevated level. Interestingly, in the SHR the resistance during aging is in a way relative. In fact, during aging WKY decrease their total peripheral resistance suggesting that the SHR has a hampered vascular outgrowth.

The increase in vascular resistance should be reflected by microvascular changes. Since a steep pressure drop at a given organ will occur within the microvasculature the importance of microvascular research in order to disclose the aetiology of spontaneous hypertenston $1 \mathrm{~s}$ obvious.

The use of intravital microscopy has allowed investigators to evaluate the atatus of the microcirculation in selected tissues, primarily of parenchymal tissues (Wiedeman et al, 1981). It is difficult to fit all data into one perfectly fitting scheme because differences with regard to methodology, animal species, strains and age, and anesthesia, have to be considered.

In-vivo observation of almost every major vascular bed has been 
used to determine whether and where in the vasculature there is an unusual amount of active or passive (1.e. Increased vall to lumea ratio reducing maximal lumen size) vasoconstriction. Most studies fall to demonstrate an enhanced vasodllating capacity during the developmental phase of spontaneous hypertension (Zweifach, 1981). Another possibility is that the increased resistance is determined by small, more upstrean located arteries which are usually not observed in standard icrovascular preparations (Segal and Duling, 1986; Meininger et al, 1987). Lumen diameters tend to be increased in larger arterioles of SHR, whereas they tend to be smaller in the end arterioles (Zweifach et al, 1981). Changes in vessel morphology and a decreased distensibility of larger arterioles or arteries may occur, but seem to play a minor role in the aetiology (Hutchins et al, 1982; Miller et al, 1987). Vessel wall hypertrophy and constriction are usually incerpreted to be indicative of long existing and profound hypertension. In SHR arteriolar responsiveness to vaso-active stimuli is enhanced as we 11 by that time.

A second mechanism by which vascular resistance may be increased is rarefaction (Hutchins and Darnell, 1974; Chen, 1981; Hutchtns, 1982; Prewit et al, 1982). The number of arterioles avallable to the circulation is reduced under resting conditions in SHR. The closure may be temporary or permanent (Prewit et al, 1982). The primary underlying mechanism of anatomical arteriolar rarefaction is unknown. Although it may be attributed to a genetic predisposition leading to rarefaction and retardation in vascular growth, artertolar and capillary rarefaction will also develop in genetically normel rats with an increased blood pressure (Prewit et al, 1984; Sokolova et al, 1985 ; Meininger et al, 1986). It is yet controversial whether a functional rarefaction precedes a structural change although it is concelvable that long-term closure as a consequence of an increased arteriolar responsiveness to vaso-active stimuli will lead to irreversible closure.

In some tissues network reconstruction shows a higher density of arcade type of arterioles although not speciflc for all tissues (Engelson et a1, 1985). Furthermore, it is difficult to correlate the occurrence of rarefaction in different vascular beds and the develop- 
ment of hypertengion In the SHR. Even within the same type of tissue different microvascular derangenents are manifest at different ages.

Athough the reduction in systemic blood pressure along the vascular tree follows essentially the same profile in both SHR and

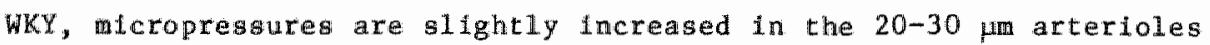
and are near normal. levels in capillaries and venules (Zweifach and Lidowski, 1984). The fall in artertolar blood pressure 1 in all beds studled in the sHR is 2 to 3 times greater than normal (Bohlen 1977, 1983; Harper and Bohlen, 1984; Zwelfach 1984).

Although a thigher than normal resistance in the small arterioles may help to minimize increased caplilary perfusion and filtration during hypertension, segmental resistance along the vascular bed may be increased more upstream and therefore not be confined to the microcirculation per se. Assuming that in adult SHR total peripheral resistance is elevated by $50 \%$, small arterioles are responsible for $10-15 \%$ of the lncrease seen in SHR (Bohlen, 1986). For the remaining 35-40\% increase in resistance small arteries and large arterioles must be considered.

In view of the existence of mechanisms subserving both systemic and local needs, it would seem plausible to assume that no singular factor can explain either the Initlating or sustaining feature of spontaneous hypertension based on microcirculatory evidence (Bohlen, 1986).

In summary, all data lead us to propose the following hypothesis with regard to vascular changes accurring in hypertension. Within the most distal part of the clrculation density of capiliaries and the gmallest arterioles w11 diminish due to an unknown factor or to a mechantsm preventing normal maturation of the vascular bed. This will result in a modest increase of arterial blood pressure. The increased blood pressure 11 affect the genetically predisposed larger vessels as well. Larger vessels are not able to undergo rarefaction, but change their functional characteristics by an increased wall thickness or hyperresponsiveness for pressor stimuli. If larger arterloles and small arteries become affected blood pressure may rise even more steeply and ultimately stabilize at a fixed level. 


\subsection{The present thesis}

Many theories have been put forward to explain the progressive rise in blood pressure with the concomitant increase in peripheral resistance in spontaneous hypertension. Factors such as renal or neurohumoral dysfunction or increased responsiveness of the vasculature can increase the peripheral resistance and have received a considerable amount of attention in the past (see general introduction; Zweifach et al, 1981).

It has been hypothesized that structural changes lead to a fixed hyperresponsiveness of the arterial vascular system and cause sustained hypertension (Folkow, 1983; Lee and Smeda, 1985; Lever, 1986). Furthermore, the design of the microvascular bed and its related physiological function may be changed and contribute to the development of spontaneous hypertension (Hutchins and Darnel1, 1974; Henrich et a1, 1978; Hutchins, 1979; Chen et a1, 1981; Prewit et al, 1982; Bohlen, 1983; Harper and Bohlen, 1984).

A large amount of research has been focussed at these mechanisms through the use of whole animal studies, organ studies and in-vitro analysis of isolated blood vessels.

Peripheral control of blood pressure and control of the microcirculation accurs at the arteriolar level of the microcirculation. Most methods currently employed to assess vascular changes only reflect these changes and do not measure them directly. It is therefore a logic consequence to attempt to study them by direct means. By using intravital microscopy, relevant parameters of microvascular hemodynamics can be measured in vivo and on-line. In this way, microvascular disturbances can directly be related to the pathophyslological proicesses involved in spontaneous hypertension.

The aim of the present thesis was to study some aspects of spontaneous bypertension related to vascular, neurogenlic and humoral microcirculatory events. The first aim of this study was to investigate the microcirculatory changes during the early developmental phase of spontaneous hypertension in a selected tissue in order to shed more light on the cause and effect relationship. In chapter 3 such a study is described for the cremaster vascular bed. In particular, the func- 
tional aspects with regard to blood flow regulation had not been studied in detali in previous studies. Therefore, special attention to this aspect 1 is given in chapter 3. In chapter 4, an attempt was made to elucidate microvascular changes involved in the maintenance phase of spontaneous hypertenston in adult rats. This study was done in conscious antmal not exposed to anesthetics. In chapter 5, we investigated whether sympathetic stimulation will result in an enhanced arteriolar tone. Sympthetic adrenergic stimuli were applied in different ways and the stimulus effect relationship was studied and correlated to corresponding microvascular changes. Studies on drug effects in the microcirculation always suffer from covariance caused by the anesthetic. We therefore describe in chapter 6 a study on the influence of several anesthetics frequently used on the control of vascular resistance in different beds. The influence of atrial peptides was studled as a hormonal mediator of cardiovascular homeostasis and blood pressure regulation. Its blood pressure lowering mechanism is only partially disclosed and its role in the development of spontaneous hypertension unknown. The microcirculatory studies on ANF described 1 chapters 7 and 8 aimed at a further analysis of the vascular effects of these hormones.

\section{9 References}

Arendt RM, Gerbes AL, Rftter D, stangl E, Bach $P$, Zähringer J. Atrial natriuretic factor in plasma of patients with acterial hypertension, heart fallure or cirrhosis of the 1iver. J Hypert 4 (supp1 2), 131-135, 1986.

Abboud FM. The sympathetic system in hypertension. State of the art revlew. Hypertension 4 (suppl 2), 208-225, 1982.

Abboud FM. The sympathetic nervous system in hypertension. Cifn Exp Hypert Theor Pract A6, 43-60, 1984.

Bevan RD. Effect of sympathetic denervation on smooth muscle cell proliferation in the growing rabbit ear artery. Circ Res 37 , $14-19,1975$.

Bianchi $G$, Fox U, Di Francesco GF, Bardi U, Radice M. The hypertensive role of the kidney in spontaneously hypertensive rats. Clin Sci Mol Med 45 (suppl 1), 135-139, 1973.

Blanchi G, Fox U, Di Francesco GE, Glovanett AM, Pagetti D. Blood pressure changes produced by kidney cross-transplantation between spontaneously hypertensive rats and normotensive rats. Clin Sc1 Mol Med 47, 435-448, 1974. 
Block MA, Wakin WG, Mann FC. Circulation through kldney during stimulation of renal nerves. An I Physiol 169, 659-669, 1952.

Bohlen HG, Gore RH, Hutchins PM. Comparison of microvascular pressure in normal and spontaneously hypertensive rats. Microvasc Res 13 , $125-130,1977$.

Bohlen HG. Intestinal mictovascular adaption during maturation of spontaneously hypertensive rats. Hypertension 5, 739-745, 1983.

Bohlen $H$. Localization of vascular resistance changes during hypertension. Hypertension 8, 181-183, 1986.

Borst JGJ, Borst-De Geus A. Hypertension explained by Starling"s theory. The Lancet $1,677-682,1963$.

Brayden JE, Halpern $W, B r a n n$ LR. Biochemical and mechanical properties of resistance arteries from normotensive and hypertensive rats. Hypertension 5, 17-25, 1983 .

Cantin $M_{3}$ Genest $J$. The heart and the atrial natriuretic factor. Endocrin Rev 6, 107-127, 1985.

Chen IIH, Prewitt RL, Dowel 1 RF. Microvascular rarefaction 1 in spontaneously hypertensive rat cremaster muscle. Am J Physiol 24l, H306-H310, 1981 .

Colindres RE, Gottschalk CW. Neural control of renal tubular sodium reabsorption in the rat; single nephron analysis. Fed Proc 37, $1218-1221,1978$.

Dahl LK, Heine $M$, Thompson $k$. Genetic lnfluence of the kidney on blood pressure. Evidence from chronic remal homografts in rats with opposite predispositions of hypertension. Circ Res 34, 94-102, 1974.

Davis Jo, Freeman RH. Mechanisms regulating renin release. Physiol Rev $56,1-56,1976$.

De Bold AJ, Borenstein HB, Veres AT, Somnenberg H. A rapid and potent natriuretic response to intravenous injection of atrial myocardial extracts in rats. Life Sci $28,89-94,1981$.

De Wardener HE, MacGregor GA. The natriuretic hormone and 1 ts posstble relationship to hypertension. In: Hypertension, physiopathology and treatment (eds: Genest $J$, kuchel 0 , Hamet $P$, Cantin M). McGraw-Hi11 Book Company, New York, 1983, pp 84-108 (ch 6).

DiBona GF. The functions of the renal nerves. Rev Physiol Biochem Pharmacol 94, 76-181, 1982.

DiBona GF, Sawin LL. Effect of renal nerwe stimulation on NaC1 and $H_{2}$ o transport in Henle"s loop of the rat. Am J Physiol 243, 1556F580, 1982 .

Dusseau JW, Hutchins PM. Stimulation of arteriolar number by salbutomol in spontaneously hypertensive rats. Am J Physlod 236, H124H140, 1979.

Edwards RM. Segmental effects of noreplnephrine and angiotensin II on isolated renal microvessels. Am J Physiol 244, F526-F534, 1983.

Engelson ET, Schmid-Schonbein GW, Zweifach BW. The microvasculature in skeletal muscle. II. Arteriolar network anatomy in normotensive and spontaneously hypertensive rats. Microvasc Res 31, 356-374, 1985.

Epstein FH. The epidemiology of essential hypertension. In: Handbook of hypertension. Clinical aspects of essential hypertension (Ed: Robertson JIS). Elsevier, Amsterdam, 1983, pp l-2l.

Evenwel RT, Kasbergen CM, Struyker Boudier HAJ. Central and reglonal hemodynamics and plasma volume distribution durlng the develop- 
went of spontaneous hypertension in rats. Clin Exp Hypert A5, $1511-1536,1983$.

Fink GD, Brody MJ. Neurogentc control of the renal circulation in hypertenston. Fed Proc 37, 1202-1208, 1978.

Folkow B. Structural factors: the vascular wall. Consequencies of treatment. Hypertension 5 (suppl 3), 58-62, 1983.

Folkow B. The structural cardiovascular factor in primary hypertension. Pressure dependence and genetic reinforcement. J Hypert 4 (supp1 3), 51-56, 1986.

Fox U, Bianchi G. The primary role of the kidney in causing the blood pressure difference between the Milan hypertensive strain (MHS) and normotensive rats. C1in Exp Pharmacol Physiol suppl 3, $71-74,1.976$.

Gavras H. How does salt raise blood pressure. Hypertension 8, 83-88, 1986.

Gray SD. Anatomical and physiological aspects of cardiovascular function in WKY and SHR at birth. Clin Sci 63 (Supp1 8), 383-385, 1982.

Gray SD. Spontaneous hypertension in the neonatal rat. Clin Exp Hypert (A) $6,755-781,1984$.

Gray SD. Muscle capillaries in hypertension. Microvasc Res 27, 39-49, 1984.

Guyton AC, Granger JH, Coleman TG. Autoregulation of the total systemlc circulation and its relation to control of cardiac output and arterial pressure. Circ Res 28 (suppl 1), 93-97, 1971 .

Guyton AC. Textbook of medical physiology ( 7 th edition). WB Saunders Company, Philadelphia, 1986, pp 264-271.

Haack DW, Schaffer JJ, Simpson JG. Comparison of cutaneous microvessels from spontaneously hypertensive, normotensive Wistar-Kyoto and normal Wistar rats. Proc Soc Exp Biol Med 164, 453-458, 1980 .

Harper SL, Bohler HG. Microwascular adaptation in the cerebral cortex of adult spontaneously hypertensive rats. Hypertension $6,408-$ $419,1984$.

Harrap SB. Genetic analys is of blood pressure and sodium balance in spontaneously hypertensive rat. Hypertension $8,572-582,1986$.

Hart MN, Heistad DD, Brody MJ. Effect of chronic hypertension and sympathetic denervation on wall-1umen ratio of cerebral vessels. Hypertension 2, 419-423, 1980.

Henrich $H$, Hertel $H$, Assmann $R$. Structural differences in the mesentery microcirculation between normotensive and spontaneously hypertensive rats. Pflugers Arch 375, 153-159, 1978.

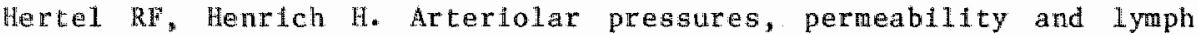
flow rate in normotensive and spontaneously hypertensive rats: contribution to the subject of fluid balance in microcirculation. In: Microvascular aspects of spontaneous hypertension (ed: Henrich H,). Hans Huber Publishers, 1982, Bern, pp 125-145.

Hutchins PM, Darne11 AE. Observation of a decreased number of small arterioles 1 tu spontaneously hypertensive rats. Circ Res 34 (supp1 1), 161-165, 1974.

Hutchins PM. Arteriolar rarefaction in hypertension. Bibl Anat 18, $166-168,1979$.

Hutchins PM, Dusseau JKW, Marr MC, Greene AW. The role of arterfolar structural changes in hypertension. In: Microvascular aspects of 
spontaneous hypertension (ed: Henrich H). Hans Huber Publishers, Bern, 1981, pp 41-53.

Janssen BJA, Debets JMM, Struyker Boudier HAJ, Smits JFM. Role of sensory nerves in the development of spontaneous hypertension in rats. Clin Exp Hypert Theor Pract, 1987, in press.

Jespersen LT, Baandrup U, Nyborg NCB, Mikkelsen EO, Lederballe 0 . Aggressive long-term anthypertensive therapy with plnacidil does not cause regression of cardiovascular hypertrophy in the sponteaneously hypertensive rat. I Hypert 4, 223-227, 1986 .

Joshua IG, Wiegman DL, Harris PD, Miller FN. Progressive microvascular alterations with the development of renovascular hypertension. Hypertension $6,61-67,1984$.

Julius $S$, Hansson L. Classification of hypertension. In: Hypertension, physiopathology and treatment (eds: Genest $J$, Kuchel $O$, Hanet $P$, Cantin M). McGraw-Hil1 Book Company, New York, 1983, pp 679-682.

Katholi RE, Naftilana, Oparil S. Importance of renal sympathetic tone in the development of DocA-salt hypertension in the rat. Hypertension 2, 266-273, 1980 .

Katholi RE, Whitlow $P L$, Winternitz SR, Oparil S. Importance of the renal nerves in the established two-kidney, one-clip Goldblatt Hypertension in the rat. Hypertension 4 (suppl 2), 166-174, 1982.

Katholi RE, Whitlow PL, Hageman GR, Woods WT. Intrarenal adenosine produces hypertension by activating the sympathetic nervous system via the renal nerves in the dog. J Hypert 2, 349-359, 1984.

Katholi $R$, McCann $W$, Woods WT. Intrarenal adenosine produces hypertension via renal nerves in the one-kidney, one-clip rat. Hypertension 7 (suppl 1), 8.8-93, 1985 .

Kleinjans JCS, Smits JFM, Van Essen H, Kasbergen CM, Struyker Boudier HAJ. Hemodynamic characterization of hypertension induced by chronic intrarenal or intravenous infusion of norepinephrine in conscious rats. Hypertension 6, 689-699, 1984.

KLine RL, Mercer PF. Functional re-innervation and development of supersensitivity to norepinephrine after renal denervation in rats. Am J Physiol 238, R353-R358, 1980.

Koepke JP, DiBona GF. HAgh sodium intake enhances renal nerve and antinatriuretic responses to stress in spontaneously hypertensive rats. Hypertension $7,357-363,1985$.

Kopp UC, Smith LA, DiBona GF. Impaired renorenal reflexes in spontaneously hypertensive rats. Hypertension 9, 69-75, 1987.

Landahl $S$, Bengtsson $C$, Sigurdsson JA, Svanborg A, Svardsudd K. Agerelated changes in blood pressure. Hypertengton 8, 1044-1049, 1986.

Lappe RW, Todt JA. Mechanism of action of vasoconstrictor responses to atriopeptin II in conscious SHR. Am J Physiol 36, 1205-1215, 1985.

Lappe $\mathbb{R W}$, Todt JA, wendt $\mathbb{R L}$. Hemodynamic effects of infusion versus bolus administration of atrial matriuretic factor. Hypertension $8,866-873,1986$.

Lee RMKW, Garfield RE, Forrest JB, Daniel EE. Morphometric study of structural changes in the wesentertc blood vessels of spontaneously hypertensive rats. Blood vessels 20, 57-71, 1983.

Lee RMKW. Vascular changes at the prehypertensive phase in the mesen- 
tertc arterles from spontaneously hypertensive rats. Blood Ves $22,105-126,1985$.

Lee RMK. Smeda JS. Primary versus secondary structural changes of the blood vessels din hypertension. Can J Physiol Pharmacol 63, $392-401,1985$.

Le Noble LML, Lappe RH, Brody WJ, Struyker Boudier HAJ, Srits JFM. selective efferent chemical sympathectony of rat kidneys. Am J Physiol 249, R496-R502, 1985.

Lever AF. Slow pressor mechanisms in hypertension: a role for hypertrophy of reslstance vessels. J Hypert 4, 515-524, 1986.

Liard JF. Renal denervation delays blood pressure increase in the spontaneously hypertensive rat. Experientia 33, 339-340, 1977.

Loeb AL, Mandel HG, Straw JA, Bean BL. Increased aortic DNA synthesis precedes renal hypertension in rats. An obligatory step? Hypertension $8,754-761,1986$.

Lundgren 0 . Milcrocirculation of the gastro-intestinal tract and pancreas. In: Handbook of physiology. The cardiovascular system. Section 2, vol IV, part l (eds: Renkin EM, Michel CC, Geiger SR). An Physiol Soc, Bethesda, MD, USA, 1984, pp 799-863.

Maack T, Camarga MJF, Kleinert HD, Laragh JH, Atlas SA. Atrial natriwret ic factor: structure and functional properties. Kidney Int $27,607-615,1985$.

Marin-Grez M, Fleming JT, Steinhausen M. Atrial natriuretic peptide causes preglomerular vasodilatation and postglomerular vasoconstriction in rat kidney. Nature $324,473-476,1986$.

McCarty. Sympathetic nerwous system development in hypertensive rats. J Hypert (suppl 3), 155-157, 1986.

Meininger $G A$, Harris $P$, Joshua $I$. Microvascular pressures in skeletal muscle of one-kidney, one-clip renovascular hypertensive rats * Microcirculation $3,237-254,1981$.

Meininger GA, Harris $\mathrm{PD}$, Joshua TG. Distributions of microvascular pressure in skeletal muscle of one-kidney, one-clip, two-kidney, one-clip, and deoxy corticosterone-salt hypertensive rats. Hypertension $6,27-34,1984$.

Meininger GA, Fehr KL, Yates MB, Borders $\Omega$, Granger HJ. Hemodynaaic characteristics of the intestinal microcirculation in renal hypertension. Hypertension $8,66-75,1986$.

Meinimger GA, renr $K L$, Xates Mis. Anatomic and hemodynamic characteristics of the blood vessels feeding the cremaster skeletal muscle in the rat. Microvasc Res $33,81-97,1987$.

Miller BG, Connors BA, Bohlen HG, Evan AP. Ce11 and wall morphology of Lntestinal arterioles from 4- to 6- and 17- to 19-week old Wistar-kyoto and spontaneously hypertensive rats. Hypertension $9,59-68,1987$.

Mueller SM. Longltudinal study of the hindquarter vasculature during development in spontaneously hypertensive and Dahl-sensitive rats. Hypertension $5,489-497,1983$.

Mulvany MJ, Hansen PK, Aalkjaer C. Direct evidence that the greater contractility of resistance vessels in spontaneously hypertensive rats is associated with a narrowed lumen, a thickened media, and an increased number of smooth muscle cell layers. Circ Res 43, 854-864, 1978.

Nifjimat A. Afferent discharges from arterial mechanoreceptors in the kidney of the rabbit. J Physiol (Lond) $219,477-485,1971$. 
Nijima A. The effect of efferent discharges in rend nerves on the activity of arterial mechanoreceptors in the kidney in rabbit. I Physiol (Lond) 222, 335-343, 1972 .

Nishiyama K, Nishiyama A, Frohlich ED. Regional blood flow in nomotensive and spontaneously hypertensive rats. An I Physiol 230, $691-698,1976$.

Norman RA, Enobakhare JA, De Clue JW, Douglas BH, Guyton AC. Arteridi pressure-urinary output relationship in hypertensive rats. Am I Physiol 23.4, R98-R103, 1978.

Nyhof RA, Laine GA, Meininger GA, Granger HJ. Splanchmic circulation in hypertension. Fed Proc 42, 1690-1693, 1983.

Ohlstein $\mathbb{E}$, Berkowitz BA. Cyclic guanosine monophosphate mediates vascular relaxation induced by atrial natriuretic factor. Hypertension $7,306-310,1985$.

Overbeck HW. Intestinal circulation during arterial hypertension. In: Physiology of the intestinal circulation (ed: Shephard AP" Granger DW). New York, 1984, p 349-360.

Palluk R, Gaida hoefke W. Atrial natriuretic factor. Life Sci 36 , $1415-1425,1985$.

Pang SC, Scott TM. Stereological analysis of the tunica media of the aorta and renal artery during the development of hypertension in the spontaneously hypertensive rat. JANAT 133, 513-526, 1981.

Pappenheimer JR. Contributions to microvascular research of Jean Leonard Marie Poiseuille. In: Handbook of phystology, section 2, vol IV, part I (eds: Renkin EM, Michel CC, Geiger SR). Am Playsiol Soc, Bethesda, MD, USA, 1984 , pp 1-10 (ch 1).

Peart WS. General review of hypertension. In: Hypertension, physiopathology and treatment (eds: Genest $J$, Kuchel 0 , Hamet $P$, Cantin M). McGraw-H111 Book Company, New York, 1983, pp 3-14 (ch 1).

Pickering $G$. The inheritance of arterial pressure in high blood pressure (2nd edition). Grune and Stratton, New York, 1968, Pp $236-273$.

Pettersson $K$, Hargens AR, M1llard RW, Johansen $K$, Gershuni DH, Burroughs $\mathbb{R}$, Meltzer DGA, Van Hoven $W$. Structural adaption to high blood pressure prevents interstitial oedema and regulates blood flow in the extremities of the giraffe. Int $J$ Microcirc. Clin Exp 5, 244, 1986.

Prewitt RL, Dowel1 RE. Pressure-flow relationship during the development of spontaneous hypertension in the rat (SHR). In: Microvascular aspects of spontaneous hypertension (ed: Herarich H). Hans Huber Publishers, Bern, 1982, pp 11-20.

Prewitt RL, Chen IIH, Dowell RF. Development of microvascular rarefaction in the spontaneously hypertensive rat. Am $J$ Phystol 243, H243-H251, 1982.

Prewitt RL, Chen IIH, Dowell RF. Microvascular alterations in the one-kidney, one-clip renal hypertensive rat. Am J Physiol 246, H728-H732, 1984 .

Rapp JP. Genetics of experimental and human hypertenston. In: Hypertension, physlopathology and treatment (eds: Genest J, Kuchel 0, Hamet P, Cantin M). McGraw-Hi11 Book Company, New York, 1983, pp $582-598$.

Recordati GM, Moss NG, Genovesi S, Rogenes PR. Renal receptors in the rat sensitive to chemical alterations of their environment. Circ Res 46, 395-405, 1980. 
Recordat GM, Moss $N G$, Genovesi $S$, Rogenes PR. Renal chemoreceptors. J Autonom Mervous Syst 3, 237-251, 1981.

Recordati $G$, Genovesi $S$, Cerati $D$. Renorenal reflexes in the rat ellcited upon stimulation of renal chemoreceptors. J Autonom Nervous Syst 6, 127-142, 1982.

Roman RJ. Pressure diuresis mechanism in the control of renal function and arterial pressure. Fed Proc 45, 2878-2884, 1986.

Roy JW, Mayrovitz HN. Microvascular blood flow in the normotensive and spontaneously hypertensive rat. Hypertension $4,264-274,1982$ *

Sadoshlma S, Yoshida F, Tbayashi S, Fujii K, Yao H, Fujishima M. Effect of chronfe sympathetic denervation on cerebral circulation during development of hypertension in spontaneously hypertensive rat. J Hypert 4 (supp1 3), 85-87, 1986.

Schmid-Schớnbein GW, Firestone $G$, Zweifach $B W$. Network anatorny of arterles fieeding the spinotrapezilus muscle in normotensive and hypertensive rats. Blood ves $23,34-49,1986$.

Schwartz SM, Campbel1 GR, Campbell JH. Replication of smooth muscle cells in vascular disease. Circ Res 58, 427-444, 1986.

Segal SS, Duling BR. Communication between feed arteries and microvessels in hamster striated muscle: segmental vascular responses are functionally coordinated. Circ Res 59, 283-290, 1986.

Skalak TC, Schmid-Schönbein GW. The microvasculature in skeletal muscle IV. A model of the capillary network. Microvasc Res 32, $333-347,1986$.

Smith TL, Hutchins PM. Central hemodynamics in the developmental stage of spontaneous hypertension in the unanesthetized rat. Hypertension 1, 508-517, 1979.

Smlts JFM, Brody MJ. Activation of afferent renal nerves by intrarenal bradykinin in consclous rats. An J Physiol 247, R.1003-R1008, 1984.

Smlts JFM, Le Noble LML, Kleinjans JCS. Role of afferent and efferent renal nerves in blood pressure control. In: Adrenergic blood pressure regulation. Proceedings of a symposium (eds: Birkenhäger WH, Folkow B, Struyker Boudier HAJ). Excerpta Medica, Ansterdam, 1985, pp 67-75.

Society of actuaries and the Association of Life Insurance Medical Directors. Blood pressure study 1979. Society of Actuarles vol 2, November, 1980.

Sokolova IA, Manukhina EB, Blinkov SM, Koshelev VB, Pineleis VG, Rodionov TM. Rarefication of the arterioles and capillary network in the brain of rats with different forms of hypertension. Microvasc Res $30,1-9,1985$.

Takayanagi $\mathbb{R}$, Imada $\mathrm{T}$, Gramer $\mathrm{RT}$, Mi sono $\mathrm{KS}$, Naruse $\mathrm{M}$, Inagani $\mathrm{T}$. Atrial natriuretic factor in spontaneously hypertensive rats: concentration changes with the progression of hypertension and elevated formation of cyclic GMP. J Hypert 4 (suppl 3), 303-307, 1986.

Tanase H, Suzuki Y, Ooshima A, Yamori Y, Okamoto K. Further genetic analysis of blood pressure in spontaneously hypertensive rats. In: Spontaneous hypertension. Its pathogenesis and complciations (ed: Okamoto K). Igaku Shoin Ltd, Tokyo, 1972, pp 9-11.

Thibault $G$, Garcia $R$, Cantin $M$, Genest J. Atrial natriuretic factor. Characterization and partial purffication. Hypertension 5 (supp1 1), $75-80,1983$. 
Tobia AJ, Walsh GM, Lee JY. Hemodynamic alterations in the young spontaneously hypertensive rat. Proc Soc Exp Blol Med 146 , $670-673,1974$.

Tobian L. Salt and hypertension. In: Hypertension, physiopathology and treatment (eds: Genest J, Kuchel $O$, Hamet $P$, Cantin M). MoGrawHill Book Company, New York, 1983, pp 73-83 (ch 5)

Walter SV, Hamet P. Enhanced DNA synthesis in heart and kidney of newborn spontaneously hypertensive rats. Hypertension 8, 520-525, 1986.

Wiedeman MP. Dimensions of blood vessels from distributing artery co collecting vin. Circ Res 12, 375-378, 1963.

Wiedeman MP, Tuma RF, Mayrovitz HN. An introduction to microcirculation. Academic Press, New York, 1981.

Winternitz SZ, Katholi $\mathrm{RL}$, Oparil S. Role of the renal sympathetic nerves in the development and maintenance of hypertension in the spontaneously hypertensive rat. J C.lin Invest 66, 971-978, 1980.

Yamaji T, Ishibashi M, Sekimara H, Takaku F, Nakaoka H, Fujii J. Plasma levels of atrial natriuretic peptide in primary aldosteronism and essential hypertension. J Clin Endocrinol Metab 63, 815-818, 1986.

Zanchetti A, Stella A, Golin $R$, Genovesi $S$. Neural control of the kidney - are there renorenal reflexes? Clin Exp Hypert Theor Pract $A 6,275-286,1984$.

Zweifach BW, Kovalcheck S, Delano F, Chen P. Micropressure-flow relationships in skeletal muscle of spontaneously hypertensive rats. Hypertension 3, 601-614, 1981 .

Zweifach $B W$. The microcirculation in experimental hypertension. Stateof-the-art review. Hypertension 5 (suppl 1), 10-16, 1983.

Zweifach BW, Lipowsky HM. Pressure-flow relations in blood and lymph microcirculation. In: Handbook of physiology, section 2, vol IV, part I (eds: Renkin EM, Michel CC, Geiger SR). Am Physiol Soc, Bethesda, MD, USA, 1984, pp 251-307 (ch 7). 


\section{MATER LALS AND METHODS}

\section{1 Animals}

In a11 studies, experiments were performed on male rats. Depending on the experimental protocol, rats derived from different strains were used. Spontaneously hypertensive rats (SHR) and Wistar-Kyoto (WKY) were obtained from the breeding colony of the central Animal Facilities of our university. Wistar rats were purchased from the Centraal Proefdieren Bedrijf, TwO (Zeist, The Netherlands). In one study presented in chapter 4, SHR and WKY were purchased from another supplier (Charles River Lab Inc, Portage, Mi, USA) but they were origlnally derived from the same strain. These rats were shlpped in pathogen-free boxes and were allowed to recover from any trauma during shipnent for $1-2$ weeks.

The SHR strain was intentionally developed as a genetic animal model of human essential hypertension by Okamoto and Aok 1 in the early sixties (Udenfriend et a1, 1976). Although there are other animal models to study hypertenstion, the SHR was chosen because of the wealth of information obtained with this model, and furthermore, it is considered to be representative of essential hypertension in man (Trippodo and Frohlich, 1981). For comparative purposes the parent WKY strain served as an adequate control.

Before and between the experiments, when using conscious animals, rats had free access to standard lab food and tap water. Regular food was obtained from Hope farms (Woerden, The Netherlands).

\subsection{Anesthesia}

A variety of anesthetics or combinations of anesthetics was used depending on the experimental design. Implantation of catheters in the femoral artery and vein was usualiy carried out under 1 ight anesthesia by ether inhalation or by an intramuscular injection of a combination of Rompun (xylazin, HCl $2 \%$ solution; Bayer $0.6 \mathrm{ml} / 100 \mathrm{~g}$ body weight) and Vetalar ( $100 \mathrm{mg} / \mathrm{ml}$ ketamine hydrochloride, Park Davis: $0.3 \mathrm{ml} / \mathrm{kg}$ ). 
The later comblnation wasi also used for the implantation of stimulation electrodes in the posterior hypothalamus.

For implantation of Doppler flow probes and of the dorsal microclrculatory chamber, the anesthetic sodiun pentabarbital (Narcovet, Apharma, Arnhem, The Netherlands) was used. Sodium pentobarbital was adrinistered intraperitoneally (1.p.) $(60 \mathrm{mg} / \mathrm{kg})$.

When using the mesentery preparation, rats were anesthetized by a slow infusion of sodium pentobarbital $(30 \mathrm{mg} / \mathrm{kg})$ through a $\mathrm{PE}-10$ catheter which had been inserted into the left femoral vein at least 3 days prior to the experiment. In some experiments, the tail vein was acutely cannulated as alternative. Following induction of anesthesia, a steady-state anesthetic depth was achieved by a slow continuous infusion of a pentobarbital solution $(60 \mathrm{mg} / \mathrm{ml})$ at a rate of $26 \mathrm{mg} / \mathrm{kg} / \mathrm{hr}$ using a Harvard infusion pump (Mil11s, Mass, USA; model $975 \mathrm{~A}$ ). With the Infusion, the rat received an additional volume load of $2.5 \mu \mathrm{l} /$ min *

The rat cremaster preparation was carried out following an intraperttoneal infection $(0.6 \mathrm{ml} / 100 \mathrm{~g}$ body welght) of a chloralose urethane mixture $(1-13.3 \%)$ dissolved in physiological saline $(0.9 \%$ NaCl). The solution had to be warmed $\left(50-60^{\circ} \mathrm{C}\right)$ to improve solubility and was cooled to a temperature of approximately $40^{\circ} \mathrm{C}$ before it was administered. Small doses of supplemental anesthesia were necessary after 2-3 hours. Urethane was purchased from Fluka AG (Buchs, Switzer1and) and alpha-chloralose from Sigma (St. Louis, Mo, USA).

Following induction of anesthesia, body temperature was kept constant $\left(37^{\circ} \mathrm{C}\right)$ by placing the rat on a waterfilled heating pad (Aquamatic K-module, Cincinnati, $\mathrm{OH}$, USA). For acute experiments, a tracheotomy was performed by cutting the trachea between two rings of cartilage and inserting a $2-\mathrm{cm}$ long section of $\mathrm{PE}-200$ tubing to a depth of $1 \mathrm{~cm}$.

\subsection{Blood pressure measurements}

In most experiments, blood pressure was measured through a catheter in the abdominal aorta. In the experiments in chapter 3 using 
the cremaster preparation, the carotid artery was camulated to exclude any induced mechanical obstruction or flow redistribution in the hindquarters.

The technique for chronic measurement of blood pressure has been extensively described el sewhere (Smits, 1980). In short, a catheter was constructed from a $9-\mathrm{cm}$ plece of $\mathrm{PE}-10$ tubing which was heatsealed to a $12-c m$ piece of $\mathrm{PE}-50$ tubing. On the other end of the PE-50 tubing, a 1-cm plece of $\mathrm{PE}-100$ tubing was heat-sealed. A 3-crit plece of vingl tubing (Serva TT 63) was slipped over it. Vinyl tubing permits frequent clampling without damaging it. For implantation of the catheter described above, it was necessary to make a small inciston in the left groin using aseptic techniques. The femoral artery was freed from connective tissue and following clamping, a small hole was cut in it with ophthalmologic scissors and the PE-10 catheter was fuserted. It was advanced for $4 \mathrm{~cm}$ into the artery so that its tip was $1 \mathrm{~cm}$ above the bifurcation and below the renal arteries. The catheter was secured to the artery and to the underlying muscles with silk sutures. When in the experiments conscious rats were required, the catheter was guided subcutaneously (s.c.n) to the neck where it was exteriorized. The catheter was then filled with heparinized saline $(250 \mathrm{IU} / \mathrm{ml})$ and closed with a metal obturator.

For chronic microwascular studies, using the dorsal microcirculatory chamber, a different approach was chosen, because it is difficult to guide the catheter subcutaneously to the neck in the presence of the chamber. The tail was sterilized and a small skin incision was made at the ventral side. The tall artery was carefully dissected and care was taken not to damage the concomitant velns. The PE-10 tubing (length $8-9 \mathrm{~cm}$ ) which had been previously sealled to PE-50 tubing (length $45 \mathrm{~cm}$ ) was inserted until its tip reached the abdominal aorta just above the bifurcation. The catheter was fixed to the tail by using 2 silk sutures. The wound was closed and covered with Steristrips. A inetal spring-stock (Instech Laboratories, Horsham, PA, USA) which served to protect the catheter from biting was secured to the tail with 2 metal stitches (Hutchins et al, 1986). The position of the catheter was veriffed post-mortem.

The carotid artery was only cannulated for acute measurement of 
blood pressure. A catheter was constructed from a 4 -cm plece of $\mathrm{PE}-1.0$ tublng and heat-sealed to a PE-50 tubing (length $30-40 \mathrm{~cm}$ ). A ventral lncision was made in the neck and the left carotid artery was dispected free from surrounding tissue. The $\mathbb{P E}-10$ catheter was inserted into itt through a small hole which was cut in the artery with ophtha1mologlc scissors. The catheter was secured to the vessel with silk sutures and exterlorized. The same type of catheter (PE 10) was used for cannulation of the jugular veln for intravenous injections of PITC-BSA after Instalment of the catheter. The wound was closed.

A low-volume displacement transducer (CP O1; CTC, Inglewood, Ca, USA) was used to measure blood pressure. To ensure patency of the catheter durlng the experiments, a continuous infusion of a Ringer solution was given ( $1 \mathrm{ml} / \mathrm{hr}$ ) using an infusion pump (Precidor Infors AG, Bagel, Switzerland) and an intra-flow device (CFS Intraflo II CF S2-03F; Sorenson Research, Salt Lake City, Utah, USA). All signals were recorded on a Grass Model 70 polygraph (Grass Instruments, Quincy, Mass, USA) or on a Schwarzer recorder model RS 348 (Schwarzer GmbH, München, GFR).

Mean arterial pressure (MAP) was obtained by low-pass filtering of the pullsatile blood pressure signal. Heart rate (HR) was determined from the pulsatile blood pressure signal by a biotachometer.

Central hemodynamic parameters (MAP, HR) during the experiments: described 1 chapter 4 were measured using a 150 PC flow thru pressure sensor (Micro Switch, Honeywe11, Freeport, II, USA) which permits a simultaneous infusion of heparinlzed saline (2 ml/day, $200 \mathrm{IU} / \mathrm{ml})$. Hemodynando parameters in these experiments were continuously monitored for $24 \mathrm{hr}$ a day (MAP, HR), using a Sanyo-MBL-550 computer and displayed on a Mitsubishi monitor. Mean values of each parameter were printed every hour and used for data analysis.

\subsection{Admintistration of drugs}

Drugs were administered by different routes. If drugs were applled systemically, the right femoral vein was used. To this purpose, bolus injections with drugs in different concentrations in a volume of 
50 ul (Hamilton Bonaduz AG, Bonaduz, Swiss) or continuous infusions with different infusion rates were performed. Between the administration of bolus injections 10 min were allowed for recovery.

Using the mesentery preparation, drugs were also applied locally via the superior mesenteric artery or topically wh the drug dissolved in Tyrode's solution.

\subsubsection{Cannulation of the right femoral vein}

The right groin of the rat was shaven and a small incision was made. The femoral vein was freed from connective tissue by gentle dissection. A small hole was cut in $1 t$ and the $P E-10$ catheter was in serted until its tip reached the inferior caval vein. The catheter was fixed to the muscle and the wound closed.

\subsubsection{Cannulation of a small side-branch of the superior mesenteric artery}

Local administration of vaso-active drugs has been successfully performed in earlier studies (Kleinjans et al, 1984; Smits and Thijssen, 1986). Therefore, in a subset of experiment using the mesentery preparation, vasopressor substances were injected into the feeding artery*

A small upper mid-abdominal incision was made, and the futestines were carefully spread to the left side of the rat and wrapped in moistened gauzes. Care was taken not to touch the coecum or the distal tleum containing the mesentery. The superior mesenteric artery could easily be recognized by its splanchnic nervous plexus and lymph vessels which $r$ un in parallel. One of the first small slde-branches of the superior mesenteric artery was dissected free of fat tussue under a stereo microscope (Wild M7S; Heerbrugg, Switzerland), using glass rods to minimize trauna. A pulled $\mathrm{PE}-10$ catheter was retrogradlely inserted into the vessel without obstructing mesentertc blood flow in the main artery. The catheter was guided outside and fixed to the abdominal wall with one 2-0 silk suture. The wound was closed. The method is basicality the same as described for cannulation of the suprarenal artery (Smits et al, 1983). To verify the location, the catheter was flushed with 200 jl indlan ink or a methylene bilue solution after the experiment. 


\subsection{Topical administration of drugs}

In case drugs were applied toplcally on the mesentery preparation, catheter (PE 50) was flrmly attached with tape to the salt water imersion objective. The regular superfusion with Tyrode's solution was stopped and within $3-5$ min a maximal volume of 40-50 ml Tyrode"s solution with the drug dissolved in it was directy superfused on the preparation, to obtain the correct drug concentration. subsequently the mesentery was superfused at the regular superfusion rate. Following completion of the protocol, superfusion with regular Tyrode's was started, first at a high rate to wash away the drug, followed by the regular superfuston rate. In these experiments $10 \mathrm{~min}$ were watted to regain base-1ine values.

\subsection{Reglonal blood flow measurement}

Doppler flownetry was chosen as a technique to assess reglonal blood flow because dynamic changes can be quantitated. Furthermore, the minute size of the Doppler flow probes, as compared to the classical bulky electromagnetic probes, enabled us to study splanchnic blood flow and to correlate this with microvascular alterations in the same preparation.

\subsubsection{Doppler flowmetry}

A $545 \mathrm{C}-3$ directional pulsed Doppler flowmeter (Bloengineering Resource Facility, University of Iowa, Iowa Clty, IA, USA) with miniaturized Doppler flow probes, positioned around the superior mesenteric artery, the renal artery and abdominal aorta, was used to measure reglonal blood flow. Following an upper midabdominal incision the origin of the superior mesenterlc artery was dissected free of surrounding tissue. The intestines were spread to the left side of the rat and were kept moistened with gauzes and wrapped in aluminum. The sliastic cuff of the probe (inner diameter $0.9 \mathrm{~mm}$ ) was fixed around the superior mesentertc artery. In some experiments, Doppler flow probes were also placed around the left renal artery $(0.6-0.8 \mathrm{~mm})$ and the abdominal aorta $(1.2 \mathrm{~mm})$ distal to the iliolumbar arteries. Flow 
through the abdominal aorta consists mainly of skeletal muscle blood flow and will be referred to as hindquarter flow. The contact of the probe with the vessel wall was improved by applying ultrasound coupling gel (ultrasound coupling gel, Ple Data Medical, Maastricht, The Netherlands). The wires were fixed at the inside of the abdominal muscles to prevent traction on the probe and were guided outside. Finally, the abdomen was closed with silk sutures. In case conscious rats were needed the wires were guided subcutaneously to a connector which was fixed to the skull with jeweller"s screws and dental cement. These rats were allowed to recover from surgery for at least 3 days before implantation of intra-arterial and intravenous catheters.

The method of measuring regional blood flow has been extenstvely described elsewhere (Haywood et al, 1981; Smits and Struyker Boudier, 1984). The Doppler frequency shift is a function of the velocity of the red blood cells and therefore provides a relative parameter of the blood flow. Relative changes in total organ vascular resistance were calculated according to the following formula:

$$
\left.\left[\frac{1+\frac{\Delta M A P}{M A P}}{1+\frac{\Delta \text { flow }}{\text { flow }}}\right] 1\right] \times 100 \%
$$

\subsection{Posterior hypothalamus stimulation}

The influence of Increased sympathetic tone on blood flow in mesenteric arterioles was investigated by electric stimulation of the posterior hypothalamus. Stimulation of this nucleus results in a general increased tone to all innervated organs (Ninomilya et al, 1970). To minimize the secondary $\mathbb{A n f l u e n c e}$ of circulating catecholamines released by the adrenals upon hypothalamic stimulation, resection of both adrenals was carried out as well.

At least three days before the experiments, animals were anesthetized and mounted in a stereotaxic frame (David Kopf, TuJunga, Ca, USA). A stainless steel bipolar electrode (MS/-303/2, Plastic Product 
Company Roanoke, VA, USA was implanted at A: $0.3 \mathrm{man}, \mathrm{L}: 0.6 \mathrm{~mm}, \mathrm{H}$ : $-2.4 \mathrm{~mm}$ according to a standard atlas (Köng and Klippel, 1963). The electrode was fixed to the akul with dental cement and the skin was closed around it. The bilateral adrenalectomy was purformed on the experimental day. To this end, two small flank incisions were made at the right and left side of the rat prior to the mesentery preparation. The adrenals were removed retroperitoneally and the wound was closed.

The bipolar electrode was connected to the stimulator (Grass, Quincy, Mass, USA) when the rat was mounted on the animal stage. Stimulations were performed with alternating voltage stimuli ( $2 \mathrm{~V}$; pulse widh of $0.5 \mathrm{~ms}$ ). Frequencies were set at $8,16,32$, and $64 \mathrm{~Hz}$, respectively. The autput of the stimulator was connected to an oscilloscope (Phll1ps PM 3540) for visual control of the stimulation parameters. Stimulation was continued until maximal effects were reached, generally for $20-50 \mathrm{~s}$. Between stimulations, 10 minutes were allowed for recovery. At the end of the experiment, the animals were sacriflced and perfused with tormaldehyde (10\%) in saline $(0.9 \% \mathrm{NaCl})$. The brains were removed and stored in $4 \%$ formaldehyde for $4-7$ days. The position of the electrode was verified by comparison af consecutive silices of the brain to the atlas of Konig and kilppel. Only experiments from animals with correct electrode location were used.

\subsection{Anesthetized antral preparations}

\subsubsection{Mesentery preparation}

The mesentery of rats is widely used for intravital milcroscopy of the microcirculation and is regarded as representative of the splanchnic vascular bed.

Following Induction of anesthesia (section 2.2), the rat was shaved at 1 tis right flank. Loose hair was removed. With a scalpel blade a small right tlank Incision (approximately $2 \mathrm{~cm}$ ) was made through the skin and underlyling abdominal muscles. Small bleeding spots were coagulated immediately.

The mesentery was exteriorized through the flank incision. The coecum and a short segment of the distal 1leum were brought outside 
and the mesentery was carefully spread with wet cotton wool sticks over a siliconized glass plate wounted on an electrically heated $\left(37-38^{\circ} \mathrm{C}\right)$ microscope stage. Care was taken not to touch or stretch the mesentery to avoid amine and prostaglandin induced vasodilation and disappearance of vasodilating capacity of arterioles (Hentich et al, 1978). The preparation was immediately superfused with Tyrode"s solution to prevent dehydration. The intestines were covered with moistened gauzes. The Tyrode's solution had the following composition in mM: $\mathrm{NaCl} 130, \mathrm{KCl} 5.6, \mathrm{CaCl}_{2}, 2.2, \mathrm{MgCl}_{2} 1.7, \mathrm{NaHCO}_{3} 24, \mathrm{NaH}_{2} \mathrm{PO}_{4} 12$, glucose 11, and saccharose 13. The pH was kept at $7.35-7.45$ by bub bling the solution with a gas nixture of $5 \% \mathrm{CO}_{2}$ and $95 \% \mathrm{~N}_{2}$ at a temperature of $36-37^{\circ} \mathrm{C}$ (Reneman et a1, 1980). The superfusion rate was 6 $\mathrm{m} 1 / \mathrm{min}$.

The mesentery of the three most distally situated loops of the ileum was inspected at low magnification. Only preparations with minimal leukocyte sticking, minimal captllary stasis and minimal microbleedings were used. The integrity of the preparation can easily be assessed by the occurence of complete arteriolar clasure following topical application of noradrenaline $\left(10^{-6} \mathrm{M}\right)$ or the absence of leakage of intravenously administered florescefn isothiocyanate bovine serum albumin (FITC-BSA) (200 $\mathrm{mg} / \mathrm{kg})$. Although the mesentery is regarded as representative of the intestinal microcirculation, its physlological role remains unknown. It may be important for fat storage and mobilization, or contribute to the overall fluld balance of the peritoneal cavity, given the large surface area of the mesentery exposed to perittoneal fluid around the mesentery. The intestinal microcirculaton including the mesentery is a rather unique microvascu$\mathbb{l}$ ar bed, because its venous drainage is wia the portal vein into the liver, i.e. coupled in series, wh the liver before flow recurns to the heart. Hence, venous pressures should be higher as compared to other vascular beds (Gore and Bohlen, 1977). Often 1 ympla vessels can be noted, which exhibit slow rhythmic contractile activity and propulsion of lymph. These vessels drain into the thoracic duct. As a rule, no vasomotion was present in all arterioles down to the precapillary vessels. Exceptionally, vasomotion could be observed in those arterioles which were directly situated between or close to fat cells 
surrounding the main arterlole feeding the intestinal loop.

In young rats with body weights lower than 270 grams, usually no mesenterlc incrovessels were present. Therefore, only rats with a minimus we 4 ht of 275 grang were used for these experiments.

\subsubsection{Intestinal preparation}

The same experimental approach for externalizing the mesentery was used when the intestinal microcirculation of the distal ileum was studled. Larger vessels are located at the outer plexus of the ileun or muscularis externa and originate from the distal branches of the superior mesenteric artery close to the mesenteric border. From the mesenteric border, wain feeding arterioles and draining venules run around the intestinal wall and end at the antimesenteric border. In contrast to the preparation technique described by Bohlen and Gore (1976), which includes dissection at the antimesenteric border of the jejunum to facilitate transillumination, the intestinal loop was left Intact and no drug had to be used to control intestinal motility.

To exclude the influence from room oxygen often reported to cause vascular constriction or loss of autoregulatory responses (House and Johnson, 1986), the intestinal loop was covered by Saran Wrap ${ }^{\mathbb{R}}$ (Dow Chemical Company, Indianapolis, Indiana, USA), a thin sheet of polyvinylidene chloride foll that has a low permeability for oxygen.

\section{7 .3 The cremaster preparation}

Striated muscle plays a pivotal role in systemic hemodynamic and blood pressure regulation in hypertension. The cremaster muscle is composed of striated muscle and is widely used to study microvascular changes in hypertension due to its accessibility and transparency. This muscle can easily be transilluminated with minimal trauma.

- The cremaster pouch is mainly composed of structural components of the external oblique and transversal abdominal muscles (Baez, 1973). The muscle composition as determined by histochemical techniques and expressed as the ratio of number of fibers per crosssectlonal. area is predominantly $(60-80 \%)$ type IIb. This muscle can be regarded histochemically as an example of skeletal muscle but not functionally (Sarelius et al, 1983), because it is not involved in 
locomotion. The muscle consists of two layers, each about four fibers thick. Sometimes, fibers run at different angles, varying between different preparations. The anteromedial part of the muscle has the highest transparency and is preferred to perform microcirculatory observations by most authors.

The cremaster auscle is directly supplied with blood by distal branches of the external spermatic artery. This artery branches of from the pudic-epigastric artery, the main feeding artery of which is the common iliac artery. The anatomic arrangement and variations in the origin of the feeding arteries of the rat cremaster microcirculation have been determined in detail by Melninger et al (1987). Due to its anatomical location, the in-situ temperature of the cremaster is reported to be a few degrees below body temperature (Hutchins and Darnell, 1974). The normal in situ temperature ranges between $34-35^{\circ} \mathrm{C}$. Cremaster exposure and dissection procedures were adapted from Baez (1973). The anterior aspect of the scrotum was shaved and loose hair was carefully removed. With the rat in the supine position, the scrotum was moderately extended by means of an anchoring silk suture $(2-0)$ through the hind pole. A longitudinal incision of skin and fascia was made in the midine over the ventral aspect of the scrotum. From the ventral surface the left testis was exposed and lifted from the scrotum and its length was measured. Tyrode's solution at room temperature was dripped on the preparation to prevent dehydration. The connective tissue was carefully stripped away with as little damage as posstble to obtain optimal clarity of the preparation. The enveloping cremaster muscle was then untrapped from the testis by making a ventral incision along the entire length of the muscle with a nicrom cauter. This incision was made directy opposite the dorsally posttioned primary arterlole and the neural connections. The testis and epldidymal fat pad were gently pulled free. The meso-epididymis was cauterized and cut with ophthalmologic scissors. The epididymis and testis were advanced into the abdominal cavity. A small cotton ball fitting into the inguinal canal prevented extruston of these organs in the course of the experiments and leakage of Tyrode's solution Into the abdominal cavity. Seven silk sutures were attached at the periphery of the cremaster and the muscle was stretched in a drum-head 
faston In the open tissue bath. The length of the muscle was adjusted to its origlinal length by applying an even tension to the cremaster. Tenston applied in this manner is sufficient to provide good visualization and to nalntaln reproducible vascular tone and reactivity (Baez, 1973). The tissue bath (volume approximately $8 \mathrm{ml}$ ) was mounted on the microscope stage. The cremaster bath was continuously perfused at a rate of 6 in $1 / \mathrm{min}$ wth a temperature-controlled Tyrode's solution, saturated with $95 \% \mathrm{~N}_{2}$ and $5 \% \mathrm{CO}_{2}\left(34.5^{\circ} \mathrm{C}\right)$. Between the antmal and the optical port, high-vacuum grease (S.A. Dow Corning, Seneffe, Belgium) Berved to seal the open organ bath. Cremaster bath $\mathrm{CO}_{2}$ and $\mathrm{O}_{2}$ partial pressures were $40 \mathrm{mmg}$ and $<30 \mathrm{mmg}$, respectively. The muscle preparation was allowed to equilibrate 45-60 min prior to the start of the experiment to allow for restoration of vascular tone and vasomotion (Le Noble et al, 1986). Occasionally, however, preparations were discarded showing slowing down of caplllary blood flow, excessive adherence of leukocytes to the venular walls or petechial bleedings.

Spontaneous, locallzed fasciculations of muscle fibers were effectively elfminated by applying topically a diluted muscle-relaxant solution (Curarin-Asta $1 \%$, Bielefeld, Germany; $250 \mu 1$ of a $1: 10$ diluted solution). This effect lasted $30-45 \mathrm{~min}$. Muscle relaxants were found not to alter vascular reactivity in cremaster muscle (Baez, 1973; Faber et al, 1982). High concentrations, however, can result in systemic drug absorption and death possibly by respiratory paralysis.

\subsection{Conscious animal preparation}

A Eew (superficial) tissues in the rat allow for direct microscoplc observations without surgical approach and the necessity of anesthetics. The microcirculatory chamber for conscious mimals was first developed for the rabbit ear which mainly consists of newly developed tissue (scar tissue) (Sandison, 1924). The technique was modified for implantation in hamsters (Endrich et al, 1980) and rats (Papenfuss et al, 1979) allowing the study of preformed sikin tissue. Recently, a new model of the dorsal microcirculatory chamber was designed which offers the possibility to study preformed muscular 
tissue in conscious rats during approximately 2 months (Snith et a1, 1985).

Before the implantation of the dorsal microcixculatory chamber, rats have to get used to handling by the investigator. A training protocal for animal restraining started at least $1-2$ weeks prior to surgery. At the end of the training protocol, rats have to sit in the restrainer loosely restrained for a period of 90-120 min. As soon as rats had recovered from surgery the training protocol was continued.

\subsubsection{The dorsa1 microcirculatory chamber (DMC)}

The study presented in chapter 4 is based upon experiments th a two-sided muscle layer preparation as originally described by Smith et al (1985). Chambers were obtained from Carolina Medical Electronics, King, NC, USA (see fig, 2.1) and consisted of two halves. Each half, consisting of a support frane and inner ring, was made of thermoneutral polycarbonate and was injection-molded. Sharp edges were smoothened to prevent animal irritation and tissue damage following implantation. The inner ring was counter-sunk to accomodate the cover slip. Cover slips, no 1.5, were obtained from Labtek diviston (Naperville, IL, USA) and were sealed with epoxy adhesive. Side $B$ of the DNC was fitted with stainless steel pins ( 0.61 in in diameter). These pins matched sackets in side $A$ and malntained al cover-glass to cover-glass distance (between $A$ and $B$ ) of 800-1000 pin preventing compression of the interposed muscular tissue. This distance was based upon a twosided muscle layer preparation. In a follow-up study conslderable increase in optical clarity was achieved by renoving the (muacle) front layer during surgery. Furthermore, resection of one layer of the muscle prevented superprojection of the underlying vessels and improved the quality of video- and photo-analysis. For a one-sided preparation, the pin length should be shortened (400-500 $\mu \mathrm{m}$ between $A$ and B). It was found that muscle thickness can vary between rats from different strains.

Rats were weighed and subsequently anesthetized with pentobarbital. To preclude the possibility of infection, each animall received penicillin $G(40.000 \mathrm{U}$ i.p.). The hair at the back was removed by means of a chemical depilatory agent. An area of approximately $6 \mathrm{~cm}$ in 

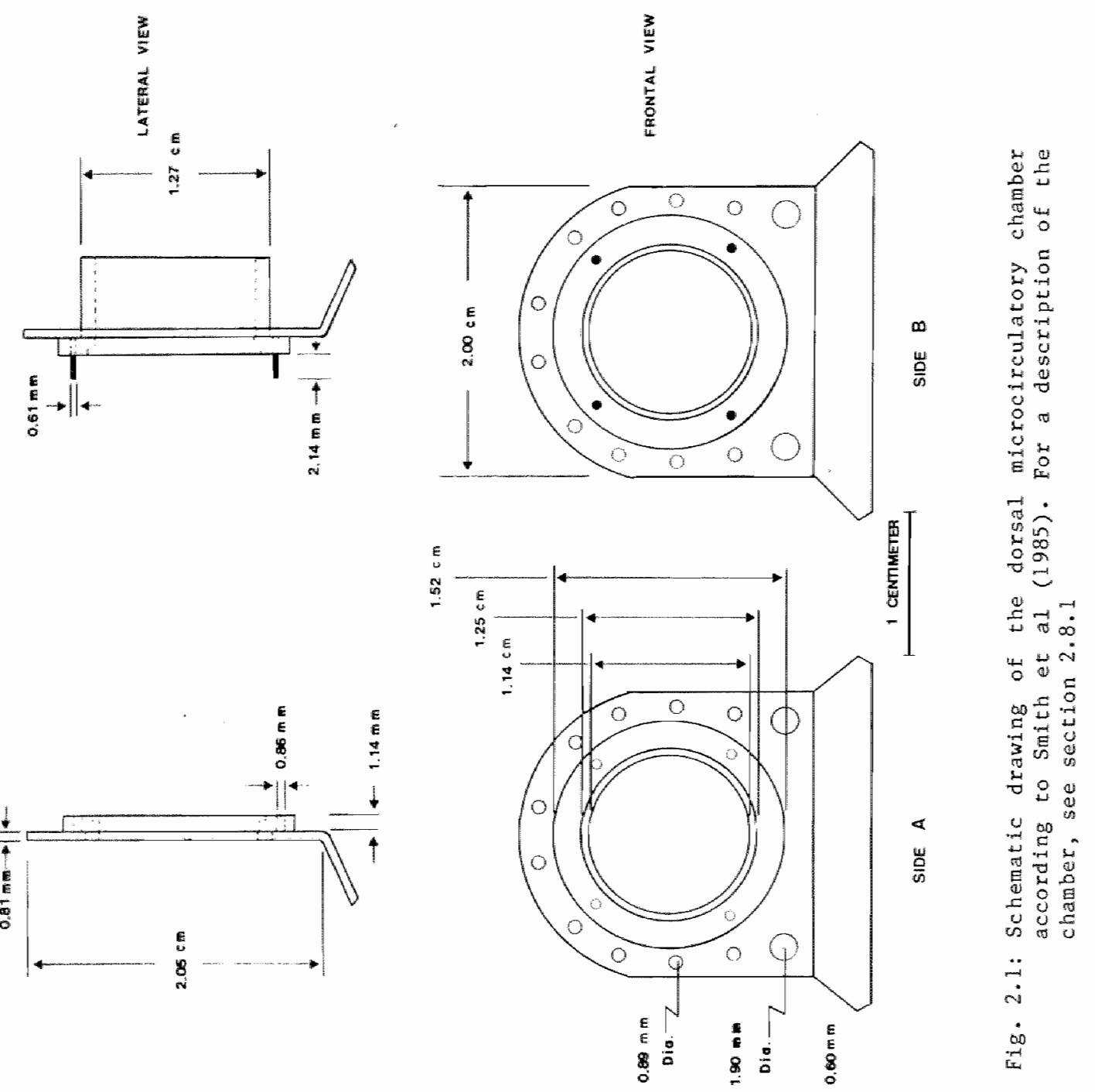
length and width beginning about 1 ch below the spine of the scapula was prepared on the dorsal side of the rat. Residues from the depilatory agent were removed. Then the area was cleansed thoroughly with an antimicrobial agent (Wiscodyne, West Chemical Products, New York, NY, USA). Surgical tools as well as the complete chamber were gas sterilized prior to surgery. The rat was placed ventral-side down on a surgery board and covered with a sterile drap to prevent contanination of the surgical field. Four 3-0 silk sutures were inserted through the skin and underlying skeletal muscle along. the length of the vertebral column. The first suture was inserted approximately 1 cn from the anterior side portion of the field and the remaining 3 sutures were spaced approximately $5 \mathrm{~mm}$ apart. The sutures were tied to a supporting D-shaped frane. The animal was rotated on its left side and extended over the surgery board. The skin was punched and a cut was made along the edge of the outline. The skin was carefully dissected from the underlying muscle. Small bleedings were treated by applying thrombin locally (Thrombin, Thrombostat). For a one-sided preparation, a round area of the underlying muscle should be removed as well.

Then side $B$ (right side) of the microcirculatory chanber was positioned and two marks indicating entry wounds for securing screws were made. Side $B$ was temporarily removed to allow for cutting out the pathways of the screws and clearing of fascia and muscle by blunt dissection. Therefore side $B$ was fitted with 1-72 Nylon screws and placed in its final position. A sterile gauze was placed over side $B$ of the chamber. The animal was flipped over on the axis of the supporting D-frame to expose its left slde. The rat was then repositioned on the board and its feet secured with tape.

Openings for the screws on the left side were cut with the scalpel blade and the screws were pushed through. The wlndow opening on the left side was marked and cut as on the right side. The stalniess steel pins of the right window were punched through the cutaneous maximus muscle with an 18 gauge needle adapter and the left window (side A) was fitted to the right window.

Air was eliminated by injecting warmed $\left(37^{\circ} \mathrm{C}\right)$ sterile physiological saline into the wound. Stainless steel nuts were fitted to the nylon screws and tightened to seal the chamber. The holding sutures 
were removed from the D-frame and the animal was placed ventral-side down on a board to complete this part of the surgery.

Five polyfilament 4-0 sutures (Vetafil Benen, South Jackson Inc., Washington DC) were inserted around the perimeter of the chamber to anchor the skin and muscle around the window and to form a seal. A minute amount of cyano-acrylate glue was applied to each suture knot to prevent untying. A petroleum-based antibacterial ofntment (Neosporin, Burroughs-Hellcome, NC, USA) was applied topically around the edges of the chamber and adjacent skin to molsturize the depilated tissue and prevent infection.

Following surgery, the andmals were kept warm by placing them on a heating pad until they were fully consclous. They were housed in separate cages in a light- and temperature-controlled room $\left(24-25^{\circ} \mathrm{C}\right)$ to which they had been previously acclimatized, and maintained on regular rat chow. Between 5-7 days were required for full recovery.

The preparation was considered to be good when:

1. No major bleedings during surgery, and no microbleedings during recovery were observed;

2. No signs of inflammation such as increasing vasodilation, neovasculartzation or edema were found. If present, infections appeared at the top side of the preparation and could be recognized by a whiteyellow discoloration; neovascularization was primarily apparent on the venous side;

3. No excessive leukocyte rolling and sticking at venular walls was present;

4. Vasomotion could be observed.

\subsection{Intravital microscopy, 111 unination and recording systems}

\subsubsection{Set-up for anesthetized animals}

Intravital microscopy has been developed as a technique for invivo studies of the microcirculation of tissues with an intact circulation and nerve supply. For the present thesis, all observations were made with a modiffed Leitz intrawital microscope except for the experiments with conscious rats, in which a different microscope system 
was employed.

The microscope and image recording equipment were mounted on wo different platforms of a large alluminu frame. The entire frame rested on a platform separated from the floor for minimizing vibrations. The microscope stage was mounted on the microscope platiorm which allows maxinum working space for the investigator. The recording system was fixed on the camera platform. The microscope was adapted to telescoplc imaging (slaaf et al, 1982). The use of a projection eye-piece ( $1 x$ or $2 \times p^{* 1}$ : Focal length $250 \mathrm{~mm} ; p^{* 2}$ : focal length $125 \mathrm{~mm}$ ) and a transfer lens (focal length 322 allows great flexibility in the vertical location of the plane of observation, while perinting rigid fixation of the recording system and transfer-lens combination. Telescopic magnification ( $M_{t e l e}$ ) is given by the ratio of the focal length of the transfer lens (FtI) and that of the projection eye-piece (Epe).

$$
M_{\text {tele }}=\frac{\mathbb{F}_{\mathrm{tl}}}{\mathrm{F}_{\mathrm{pe}}}
$$

If transillumination was performed a long worklng distance condenser lens was used (L1l, NA 0.60 or L20, NA 0.45). Mllumination was performed according to köhler prowiding highest intensity at even 111 umination. To minimize a possible artefactual influence of the illuminating light on the tissue under observation, the field ditaphragm was set in such a way that only the tissue under observation (through monitor or eye-piece) was 11 luminated. Transillumination of the mesentery preparation was performed using a Tungsten lamp (60 W). Using the cremaster preparation, images of good optical quality were obtalned by transillumithation with a "lungsten Halogen lamp (1.00 W) and heat absorbing filter (Schott KG 1, Malnz, FRG) in the light path. Power was supplied by a DC-current source (Delta E30-10) for adjusting the illumination level required.

For observation of the extramural vessels of the microcirculation of the ileum, incident fllumination was performed via a Leitz Plomopak 11 luminator 2.1 (tube factor $1.25 \mathrm{x}$ ) equipped with a mirror with $50 \%$ reflectance and $50 \%$ transmittance, placed at $45^{\circ}$ to the optical axis of the microscope, and a polarizer-analyzer cube (Ledtz Pol-cube) for minimizing the effects of strong reflections on image 
quality. The ileum was 11luminated using a Xenon lamp ( 150 h) and a Calflex heat reflecting fllter (Schote B1/K2; Malnz, FRG) in the 111umination pathway. Considerable enhancement in contrast of red blood cells was achleved by placing a blue fllter (Schott BG 38 , Mainz, FRG) in the ill wination pathway. The light level was set to the approprlate level using neutral density filters (e.g. Schott NG 5; Mainz, FRG)

Macromolecular leakage and capillary recruitment was studied using the Ploemopak 2.1 incident 111 uminator (1.25x tube factor) equipped the theitz interchangeable filter cube no I-2 (excitation filter BP 450-490; dichrolic mirror RKP 510, barrier filter LP 515) in combination with a high pressure Mercury lamp (200 W) or a Xenon lamp $(150 \mathrm{~W})$. Both lamp houses were equipped with a Calflex heat reflecting filter.

For inspection of the preparations and mapping of the entire microvasculature, low magnification abjectives (Leitz $\mathbb{1}$, NA 0.04, Leftz $4 \mathrm{x}, \mathbb{N A} 0.12$ ) were employed. Individual vessels were observed using salt water immersion abjectives with a high numerical aperture ( $\mathrm{SW} 25, \mathrm{NA} 0.60 ; \mathrm{SW} 50$, NA 1.00). In transillumination microscopy a compromise must be found between field of view and resolution. In incident fluorescence microscopy, the light gathering power, which is proportional to $\mathrm{NA}^{4} / \mathrm{M}^{2}$, becomes very important. Objectives with high NA are desirable (Slaaf et a1, 1986). Because of the low light levels present in fluorescence microcopy, the regular eye-pieces (10x) were replaced by low-power eye-pleces $(5 x)$.

A rotatable mirror placed in the ray-path above the transfer lens allowed for quick shifting from one canera to another in the course of the experiment.

Images were displayed on a 12 -inch video montcor (Siemens M21701) through a Grundig video camera (FA 32) with a 1-inch RCA silicon target tube (U1tricon; type 4532) and stored on a tape via video cassette recorder (Sony Betamax, type SL-C9ES). The video recorder was connected to a video timer (For-A, type VTG 33) for frame coding. For fluorescence microscopy, it was necessary to use a low-light level video camera. We used a high sensitivity silicon intensified target (SIT) camera (Bosch TYC 9A equipped with a 1-inch RCA STT tube (type 
4804). Sensitivity can be set either manually or automatically. The maximum sensitivity of this camera is about jo0 times higher than that of the U1tricon camera. At highest sensitivity, the images become rather noisy which can be a serious limitation for image analysis (e.g. measurement of vessel diameter).

For photographic documentation, a motorized Nikon F2 35-mm camera was mounted in addition. The camera was loaded with a sultable Kodak Ekta-chrome slide-film.

\subsubsection{Set-up for conscious animals}

For studies on conscious animals, prowided with a dorsal chamber (2.8.1), we used a modified Zelss microscope (standard model 16) with the stage attached to a heavy stable plate and mounted vertically. The preparation was transilluminated using a fiber optic light guide system and a Tungsten Halogen lamp ( $150 \mathrm{~W}$ ) with heat absorbing filter. For inspection and mapping of the preparation, zelss Plan objectives (1.25x, NA 0.04; $2.5 x, N A 0.08)$ were employed. Individual vessels were observed with a Zeiss Plan 10x (NA 0.22) long working distance objective. The video image of the microcirculatory bed was stored on tape with a Sony Betamax recorder (SL HFR 70) for further analysis. The video recorder was also connected to a video timer for frame coding. Images were displayed on a video monftor through a $2 / 3$ inch video camera (RCA, type TC $2500, \mathrm{Ca}$, USA). Total optical magnification in this study was $5 x, 10 x$, and $40 x(1.25 x, 2.5 x$, and $10 x$ objectives $)$. For photography, a Nikon F2 35-mm camera with Kodak Ekta-chrome fll $1 \mathrm{~ms}$ were used. These resulting slldes served as documentation.

\subsection{Microvascular measurements}

The tools for quantifying microvascular alterations have been refined in the last decade. With electronic methods, diameter and velocity measurements can be obtained from the microscope limages or from the recorded video images in case of off-1ine analysis. 


\subsubsection{Diameter measurements}

Diameter weasuremts were performed off-line with an imageshearlng device which was bult in our own workhop (Intaglietta and Tompkins, 1973). On the monitor, the video image could be rotated electrontcally to postition the vessel vertically. The image of the blood vessel was then sheared along a line perpendicular to the axis of the vessel. If properly callibrated the spatial translation requiled to allgn the opposite edges of the inner vessel wall is a direct measure of the diameter of the blood vessel. The mean vascular dianeter was deflned ab the linear average of this distance. The displacement represents the inner vessel diameter. By aligning vessel walls, rather than measuring the dianeter at one site, the accuracy of the measurement is in principle better than the optical resolution of the microscope.

Several factors may limit the accuracy and preciston of the diameter measurements. One problem is to accurately localize the lumenal side of the vessel wa11. A thin layer of reduced light intensity, due to a locally reduced number of red blood cells exists near the vessel wall. This layer can easily be mistaken for the intima of the vessed wall.

A second complication is rellated to the shape of the vessel itself. Arterioles can be contorted under varying conditions of vascular tone (Proctor et al, 1984) with invaginations of the vessel wall into the 1 men and therefore do not form a perfect cylinder. To assess the vascular diameter, focussing of the microscope was done by bringing into focus the widest possible image of the vessel.

Dynamic dlameter changes as occur in arterioles exhibiting vasomotion were always analyzed with a shearing montior and its output was recorded on a physiological recorder. In some experiments where vasomotion was absent, a vernier calliper was used as a reliable alternative to measure the static vessel dianeter.

\subsubsection{Measurement of red blood cell velocity}

At the present tine, no methods are avaliable to directly measure volume flow in microvessels. Most electronic methods currently In use rely on the assessment of the velocity of passing red blaod 
cells. Red blood cells are by far the most numerovs cells in the blood and are an good optical marker of flow. It is beyond the scope of this thesis to discuss the different existing methods to measure red blood cell velocity in microvessels (e.g. the dual-slit method, the spatial filtering (BDO) method, or laser Doppler velocimetry). The reader $1 \mathrm{~s}$ referred to recent surveys (S1aaf et al, 1984, 1986).

For the present thesis, velocity measurements were performed with the dual-slit method and a velocity tracking correlator (both from Instrumentation for Physiology and Medicin Inc (IPM), San Diego, CA, USA).

The circulating RBCs have a certaln distribution over the cross-sectional area of the microvessel and travel at different velocities. Applying regular microscopic techniques, the image constitutes a place- and time-dependent light intensity signal. Sensors placed on the intermediate image, collect time-dependent signals from these spots. By processing these signals in an appropriate way a measure of RBC velocity is obtained. The passing RBCs praduce characterlstic peaks in the upstream and downstream signals of the photodiodes. These signals are cross-correlated in order to determine their average delay * This delay $(\Delta t)$ is inversely proportional to the RBC velocity. The output of the velocity tracking correlator, however, is directly proportional to 1/At. Thus, inversion is avoided. After appropriate calibration of the spacing of the sensors, the velocity tracking correlator directly provides velocity. Changes in velocity should be tracked by the correlator. Within a certain range of rate of changes in velocity, velocitles are autonatically tracked. Veloctty is continuously recorded on a Schwarzer strip chart recorder. With the dual-silt method, dynamic velocity changes can be tracked over a range of a factor of 10 between velocities of $0.05-50$ man $/ \mathrm{s}$.

The two fibers in the photodiode sensor head have an actual center to center spacing of about 0.95 min and are mounted in front of the sensitive surface area of the video camera and are seen as one composite "black needle" on the video monttor. This allows for positioning of the sensors above the image of the vessel close to its centerline. This spacing should be compared to the magnified microscope image, so the spacing $d=0.50 / M \mu m$ where $M$ is the total optical 
magnification. Optial spacing is between $5-20$ fm, resulting in a required optical magnification between 50 and 200 times.

The dual-slit method relies on changes in optical density. It Is essential that changes 1 n 11 lumination power are minimized. To this end, a Tungsten lamp was connected to a stabilized DC source. The Tungsten lamp provides appropriate contrast beween red blood cells and surrounding plasma and thus a sufficient signal-to-noise ratio. Especially in larger vessels, contrast enhancement by using blue filtering hes to be avolder since it results in very weak correllograms. Since the photo-optic pick-up unit is positioned a few centimers in front of the sensitive surface camera signal-to-noise ratios, and thus velocity measurements, could be traproved by slight defocussing. However, a draw- back of this is that the simultaneous measurement of velocity and vascular diameter is not feasible anymore.

The relationship between velocity, as assessed by the dual-silt method with the sensor positioned in the centerline of the vesse1, and volume flow assessed by Baker and Wayland (1974) was calculated to be 1.6. This factor however may be affected by changes in wascular tone, the size of a given blood vessel or the local hematocrit (Pittman and Elisworth, 1986). In addition, the flow profile in vessels with laminar flow is not parabolic but blunted and varies with the vessel diameter (Tangelder et al, 1986). Moreover, the centerline velocity depends on the width of the sensor size relative to the vessel diameter (Slaaf et a1, 1986). Calculated volume blood flow based on diame-

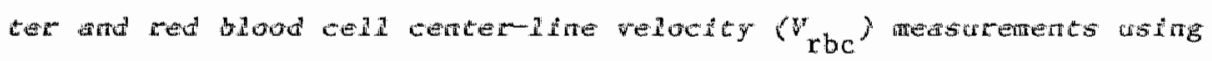
the dual-slit cross-correlation method can anly yield estimates and therefore in the present studies only $V_{r b c}$ was used.

\section{11 Statistcal analysis}

A1. data are presented as means $+S E M$, unless indicated otherwise. In chapter 3, group comparison between hypertensive and normotensive animals were made with the Mann-Whitney U-test (Johnson, 1984) using the miniltab program (Ryan et al, 1985) and a VAX computer. Base-1ine walues for MAP and HR in 3 groups in chapter 6 were compared 
with a one-way analysis of variance and a modified t-test (Wallenstein et al, 1980). Dose-response curves were compared with one-way analysis of variance as described by zerbe (1979) using a VAX computer or ANONA with repeated measures. Significance was determined at the $95 \%$ contidence leve1.

\subsection{References}

Baez S. An open cremaster muscle preparation for the study of blood vessels by in vivo microscopy. Microvasc Res 5, 384-394, 1973.

Baker $M$, Wayland $H$. On-line volume flow rate and velocity profile measurement for blood vessels in microvessels. Microvasc Res 7 , $131-143,1974$.

Bohlen $\mathrm{HG}$, Gore $\mathrm{PW}$. Technical report. Preparation of rat intestinal. muscle and mucosa for quantitative micracirculatory studies. Microwasc Res $11,103-110,1976$.

DeLano FA, Zwelfach $\mathrm{BW}$. Anesthesia and microvascular dynamics in spontaneously hypertensive rats. Am J Physiol 241, H821-H828, 1981 .

Endrich B, Asaishi $\mathbb{K}$, Götz A, Messmer $K$. Technical report - A new chamber technique for microvacular studies in unanesthetiged hamsters. Res Exp Med (Ber1) 177, 125-134, 1980.

Faber $\mathbb{J E}$, Harris PD, Wiegman DL. Anesthetic depression of microcirculation, central hemodynamics, and respiration in decerebrated rats. Am J Physiol 2543, 837-843, 1982.

Gore RW, Bohlen HG. Microvascular pressures in rat intestinal muscle and mucosal villi. Am J Physiol 233, H685-H693, 1977.

Haywood JR, Shaffer RA, Fastenow C, Fink GD, Brody M.T. Reglonal blood flow measurement with pulsed Doppler flowneter in conscious rats. Am J Physiol 241, H273-H278, 1981.

Henrich $\mathbb{H}$, Hertel $R$, Assmann $R$. Structural differences in the mesentery microcirculation between normotensive and spontaneously hypertensive rats. Pelugers Arch 375, 153-159, 1978.

House SD, Johnson PC. Milcrovascular pressures in venules of skeletal. muscle during arterial pressure reduction. An $J$ Phystol 250, H838-H845, 1986.

Hutchins PM, Darnell AE. Obserwation of a decreased number of small. arterioles in spontaneously hypertensive rats. Circ Res 34 (suppl 1), 161-165, 1974.

Hutchins PM, Osborne SW, Smith TL, Lynch CD. Continous, on-line measurement of baroreceptor activity in consclous unrestrained rats. Fed Proc 45, 187, 1986.

Intaglietta $M$, Tompkins WR. Microvascular measurements by video tmage shearing and splitting. Microvasc Res 5, 309-312, 1973.

Johnson $R$ (ed). Elementary statistics (4th edition). Duxbury Press, Boston, 1984, pp 479-486.

Kleinjans JCS, Smits JFM, Van Essen H, Kasbergen CM, Struyker Boudier 
HAJ Hemodynamic characterization of hypertension induced by chronic intratenal or intravenous infusion of norepinephrine in consctous rats. Hypertension $6,689-699,1984$.

Konlg JPR, Klippel A (eds). The rat braln. Wlllams and hilkens, Baltimore, MD, USA, 1963.

LeNoble LML, Tangelder GJ, Slaaf DW, Struyker Boudier HAJ. Vasomotion and axteriolar recruitment in cremaster muscle of anesthetized rats. Int J Mlcrocirc CIIn Exp 5, 220, 1986.

Melninger GA, Fehr KL, Yates MB. Anatomic and hemodynamic characteristics of the blood vessels feeding the cremaster skeletal muscle In the rat. Microvasc Res 33, 81-97, 1987.

Ninomiya $I$, Judy $W$, Wilson M. Hypothalamic stimulus effects on sympathetlc nerve activity. Am J Physiol 218, 453-462, 1970.

Papenfuss HD, Gross JE, Intaglietta M, Greese FA. A transparent access chamber for the rat dorsal skin fold. Microvasc Res 18, 311$318,1979$.

Pittman RN, Elssworth ML. Estimation of red cell flow in microvessels: consequences of the Baker-Wayland spatial averaging model. Microvasc Res $32,371-388,1986$.

Proctor KG, Damon DW, Duling BR. Inaccuracies in blood flow estimates in microvessels during arteriolar vasoconstriction. Microvasc Res 28, 23-26, 1984 .

Proctor KG, Busya DW. Relationshlp among arteriolar, regional and whole organ blood flow in aremaster muscle. Am $J$ Physiol 249, $1334-441,1985$.

Reneman RS, Slaaf DW, Lindbon L, Tangelder GJ, Arfors KE. Muscle blood flow disturbances produced by simultaneously elevated venous and total muscle tissue pressure. Microvasc Res 120, 307-318, 1980 .

Ryan BF, Joiner BL, Ryan TA (eds). Minttab handbook (2nd edition). PWS Publishers, Duxbury Press, Boston, 1.985.

Sandison JC. A new method for the inicroscopic study of living growing tissues by the introduction of a transparent chamber in the rabbit ear. Anat $\operatorname{Rec} 28,281-287,1924$.

Slaaf $D$, Alewijuse $R$, Wayland $H$. Use of telescoping imaging in intravital microscopy: a simple solution for conventional microscopes. Int J Microcirc 1, 121-134, 1982 .

Slaaf DW, Arts T, Jeurens IJM, Tangelder GJ, Renemen RS. electronic measurement of red blood cell velocity and volume flow in mlcrovessels. In: Investigative microtechniques in medicine and biology (eds: Chayen J, Bdtensky L), Dekker, New York, 1984, p $327-364$.

Slaaf DW, Jeurens TJM, Tangelder GJ, Rememan RS, Arts T. Methods to measure blood flow velocity of red blood cells in vivo at the microscopic Level. Ann Blomed Engin 14, 175-186, 1986a.

Slaaf DW, Jongsina FHM, Tangelder GJ, Reneman RS. Characteristics af optical systems for intravital microscopy. In: Microcirc. Technol. (eds: Nastuk WL, Rousseau D and Baker CH), Acadenic Press, $221-228,1986$.

Slaaf DW, Tangelder GJ, Reneman RS, Arts T. Dual sensor model calculations applied to blood cell velocity profiles obtained by direct observation in vivo. Microcirc Clin Exp 5, 242, 1986c.

Sinth TL, Osborne SW, Hutchins PM. Long-term macro- and microcircu1 atory measurements in consclous rats. Microvasc Res 29, 360- 
$370,1985$.

Smits JFM. The antihypertensive effect of propranolol. Thesis, Mastricht, 1980.

Sinits JFM, Kasbergen CM, Van Essen H, Kleinjans JCS, Struyker Boudier HAJ. Chronic local infusion into the renal artery of unrestrained rats. Am J Physiol 244, 304-307, 1983.

Smits JFM, Struyker Boudier HAJ. Systemic and reglonal hemodynamics following acute inhibition of angtotensin $I$ converting enzyme in the conscious spontaneously hypertensive rat. Prog Phamacol $5,40-49,1984$.

Smits JFM, Thijssen HHW. Spatial control of drug action: theoretical considerations on the pharmacokinetics of target-aimed drug delivery. In: Rate controlled drug administration and action (ed: Struyker Boudier HAJ), CRC Press, Boca Raton, CA, USA, 1986, Pp 83-114.

Tangelder GJ, Slaaf DW, Muijtjens AMM, Arts T, Oude Egbrink MGA, Reneman RS. Velocity profiles of blood platelets and red blood cells fllowing in arterioles of the rabbit mesentery. Circ Res $59,505-514,1986$.

Trippodo NC, Frohlich ED. Similarities of genetic (spontaneous) bypertension in man and rat. Circ Res 48, 309-319, 1981 .

Udenfriend S, Bumpus FM, Foster HL, Freis ED, Hasen CT, Lovenberg WM, Yamori Y. Spontaneously hypertensive (SHR) rats: Guidelines for breeding care and use. ILAR News 19: 3-20, 1976

Wallenstein S, Zucker CL, Fleiss JL. Sone statistical methods useful in circulation research. Circ Res $47,1-9,1980$.

Zerbe Go, Randomization analysis of the completely randonized design extended to growth and response curves. J. Am Statist Assoc 4, $215-222,1979$. 

3. REGULATION OF PERFUSION OF SKELETAL MUSCLE DURING THE EARLY PLASE OF SPONTANEOUS HYPERTENSTON IN RATS: A FUNCTIONAL MORPHOMETRIC STUDY

\subsection{Introduction}

Spontaneous hypertension in the rat is characterized by an in creased vascular resistance of virtually every organ system (Nishiyama, 1976; Zweutach, 1983; Evenwel et a1, 1983; Bohlen, 1986). The increased vascular resistance in spontaneous hypertension is caused by alterations at the arteriolar level as has been shown for various tissues (see chapter 1 ).

Maturation is associated with growth and development of the microvascular bed. The volume of tissues increases as well, but to a greater extent than microvascular growth. As a consequence, vascular densities will diminish as a function of age (Sarelius et al, 1981). An age-related hampered vascular outgrowth, i.e. rarefaction, may account for an increased resistance and blood pressure in SHR (Bohlen, 1986). Furthermore, during the developmental phase of spontaneous hypertension vessel lumen size may decrease. Until now evidence for a reduced vessel lumen has been obtained in in-vitro studies or in isolated perfused organs but not in direct intravital microscopic studies.

In both WKY and SHR peripheral resistance increases with age. At the age of 5-6 weeks there are no statistically significant differences between the peripheral resistance in WKY and SHR (Smith and Hutchins, 1979; Evenwel et a1, 1983) but cardiac output is unevenly distributed in SHR. The skin and skeletal muscle vascular beds receive an enhanced flow. At the same age, in SHR peripheral resistance and blood pressure start to rise progressively and stablifize at $7-9$ weeks (Evenwel et al, 1983). In addition, the peripheral resistance following complete vasodilation is also increased at 9 weeks (Prewt th al, 1982). The distribution of cardiac output is normalized at thig age.

Few studies attempted to investigate the distribution and regulation of blood flow in the early phase of hypertension. Since strlated muscle is responsible for the (ultimate) bulk of the increase in peri- 
pheral resistance the present study is focussed on local flow regulatory rechanisms in strlated mucle in the resting state and following vasodilation.

Vessel diameters were measured in the control state and following maximal. vasodilation, as achieved by adenosime, a potent endogeneous vasodlator (Proctor, 1985). From these data, vessel lumen size and nicro-vascular tone at several arteriolar levels were assessed. Micro-vascular tone was expressed in the form of a non-dinensional tone as the difference between steady-state and dilated diameter (following adenosine treatment) divided by the dilated diameter (Schmid-Schönbein et al, 1987).

under resting conditions, differences with regard to vascular densities need not to be manifest because only a fraction of functionally avallable vessels are perfused. In order to assess the flow carrying capacity, arterlolar densities at several levels within the microvascular bed were determined in the resting state and following vasodilation where all functionally avallable vessels are perfused. Furthermore, the density of plasma perfused capillaries was established by means of fluorescence microscopy.

The study was performed on the cremaster muscle of $5-6$ weeks old hypertensive rats and age-matched nomotensive control rats. This age was chosen because spontaneous hypertension is developing rapidiy.

\subsection{Experimental protocol}

\subsection{Anlmalis}

Young SHR of 5-6 weeks and age-matched WKY rats were anesthetized with alpha-chloralose urethane (see section 2.1) and the cremaster muscle prepared for intravital microscopic observations as described in detall in sections 2.7 .3 and 2.9 .1 . Central hemodynanic parameters, mean arterial pressure (MAP) and heart rate (HR), were measured via the carotid artery (section 2.3). The jugular vein was used for systemic injections of FITC-BSA (section 2.3). For a general lay-out of the experimental set-up see fig. 3.1.

Following equilibration, vessels were classified based on their 


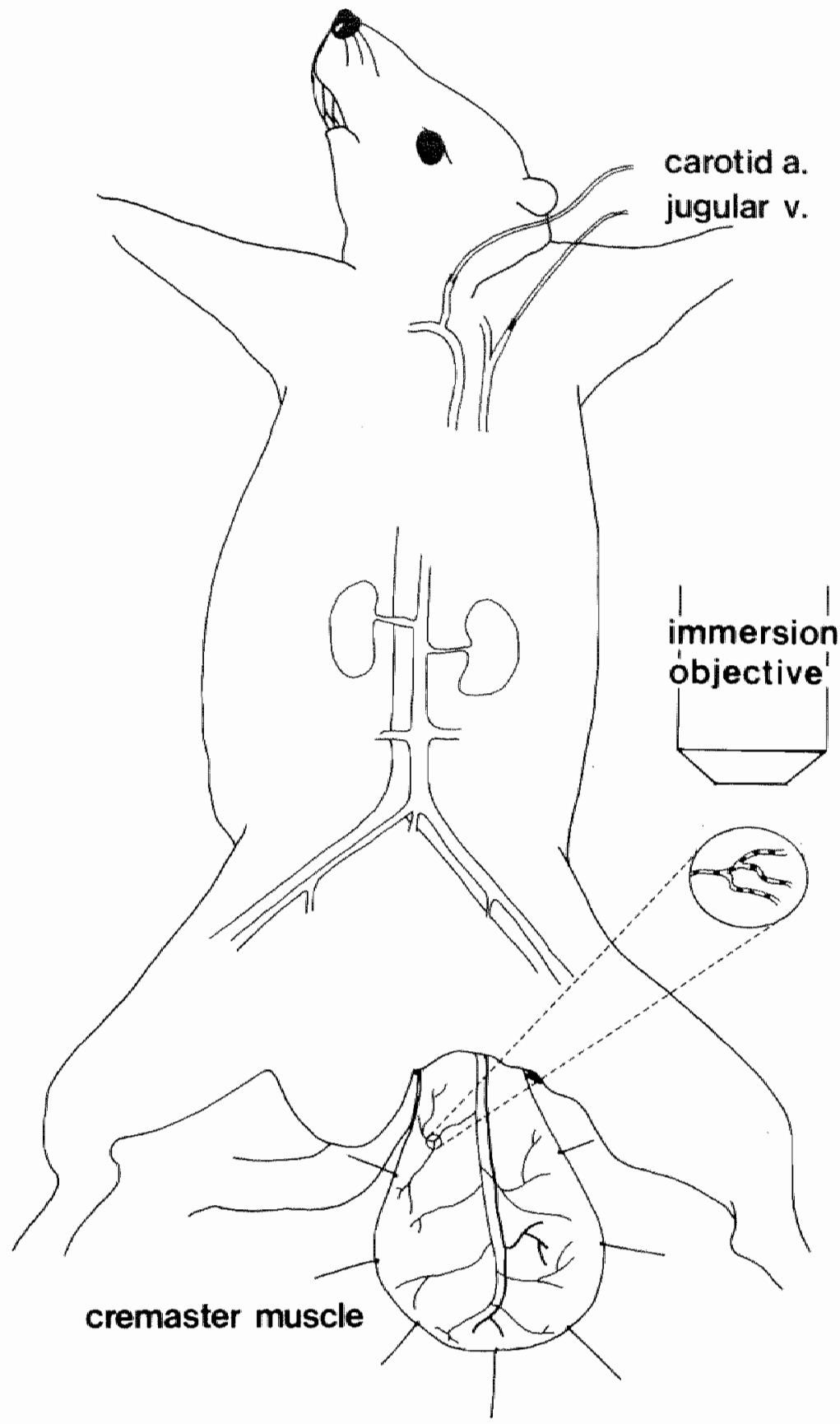

Fig. 3.1: General lay-out of the experimental set-up for the cremaster muscle. 
functional branching order.

\subsubsection{Mcrovascular terminology}

Mt. crovascular topology should classify the vessels according to their function in distributing the flow over the organ. At rest, a certaln distribution of flow occurs. When wasodilated a different partition of flow can be observed. Topology should be such that a geparation in different classes allows for maximal recognition of the different functions.

Terminology in this study was based on the identification of different wessel types by their location in the network relative to their branching order and function. This scheme was first applied to the cremaster muscle by Hutchins and Darne11 (1974). A representative version of a microcirculatory network with well defined characteristics is shown in fig. 3.2 .

In the cremaster muscle in the middle of the preparation there is only one straight running perfusing arteriole which was defined as first order arteriole (Al). All side-branches of the single Al vessel were defined as second order vessels (A2). Along the second order vessels, Y-shaped branchings with equal diameters or head-on interconnections with similar large arterioles were all classified as being A2. Lateral off-shoots of second order vessels with smaller diameters were classified as third order vessels (A3). All side-branches of A3 vessels with distinctly smaller diameters were classified as fourth order vessels (A4). Since fourth order arterioles were precapillary arterioles, no further downsteam classiffcation scheme was applied.

\subsubsection{Arterlolar diameters and recruitment}

The entire muscle was documented using a Leltz lx objective in combination with its Leitz condenser lens to study the gross angioarchitecture of the muscle in particular the Al and A2 vessels.

The experimental protocol was divided into 3 subgroups: (1) The entre Al vessel and a1l its side-branches (A2) close to their branching point were observed via a Leitz $4 \mathrm{x}$ objective and overlapping recordings were made for off-line measurements of vessel diameter and segment length between two side-branches; (2) In the arteromedial part 
of the muscle with high transparency (see section 2.7 .3 ), one A2 vessel was selected. Image recordings were made with a leitz $4 x$ object1ve. A hand-drawn map was made for quick orientation during the course of the experiment. All perfused side-branches were documented with a salt-water imersion objective (SH 25); (3) One arteriole among the A3 vessels which branch off from the A2 vessel was selected and meticulously studied for the occurrence of side-branches (A4) as evidenced by flowlng RBCs. Selection of the A3 wessel was solely based on clear distinction of the margins of the vessel wall over a distance of at least $1500 \mu \mathrm{m}$. Many arterioles close to the surface of the muscle allow for proper diameter analysis and detection of all their sidebranches (A4). Selection of an 43 close to the edge of the preparation was avolded because (total) milcrovascular blood flow tends to be higher in traumatized areas altered by dissection (Lindbon et $a 1$, 1982; Proctor and Busija, 1985).

After completion of this part of the protocol, adenosine was added in the superfusate to achieve a final concentration of $10^{-3} \mathrm{M}$ to cause maximal vasodilation. "The vasodilation was considered to be maximal since in pilat-experiments no additional increase in diameter was observed following addition of $0.2 \mathrm{mg} / \mathrm{ml}$ sodium nitroprusside to the adenosine superfusate. The entire protocol $(1-3)$ was repeated 15 min following superfusion with adenosine. In a small number of experiments recrutted $A 3$ vessels in WKY and SHR were documented for analysis and number of side-branches and segment lengths.

During the recordings one investigator vlewed directly through the microscope eye-pleces and counted the number of vessels. The second Investigator took care of proper video-documentation and of focussing at several tissue depths for optimal images on the monitor. Diameter analysis (section 2.10.1) was performed off-1ine. The dilating capacity of artertoles was assessed according to SchmidSchonbein et al (1987).

Vessel segment lengths beween side-branches and total vessel length measurements were made off-line from overlapping video-images. Total vessel length was always deternined in the vasodilated state. Length of first order arterioles was determined by measuring the length between the site of the first off-spring until its last side- 
branch. The last segment was deternined by its last side-branch which could be detected during vasodilation and contained flowing red blood cells. Length measurements were performed with a callbrated vernier calliper. The number of side-branches of each vessel category was normalized by calculating the mean interdistance. The number of sidebranches per unit of vessel length was converted into mean distance, 1.e. interdistance.

\subsubsection{Involvement of arteriolar arcades}

In addition in 5 experiments, a11 A3 vessels fed by one A2vessel were examined over their full length to determine whether they were part of an arcade, that is whether they formed at their end a second connection with the A2, during both control and vasodilation. This was also carefully examined for recruited arterioles which were directly fed by the Al vessel.

\subsubsection{Capillary diameter and recruitment}

During the thind part of the protocol (section 3.2.1), in the downstream area of A4 vessels capillaries in 6 WKY and 6 SHR were selected within a shallow depth of the tissue. Capillaries were observed and dacumented using an Sw50 objective in bright-field microscopy. Recordings for diameter analysis were made in the control state and fallowing adenosine. Diameters were measured with a vernier cal1 iper.

Capillary recruitment was studied using fluorescence microscopy (section 2.9). Capillaries were visualized after a slow intravenous injection of FITC-BSA Sigma (200 $\mathrm{mg} / \mathrm{kg})$. Alomg an A2 vessel, 10 areas were selected where capillary flow was supplied by the A2. Videorecordings were made for off-line analysis of the proper captllary bed and care was taken to select an area where no larger vessells could interfere with obscured an accurate measurement of caplliary lengths. For each recording site, the $\mathrm{XY}$-coordinates of the microscope stage were determined with a digital microposition sensor and documented (Heidenhain, GrubH, Traunheut, W-Germany). For accurate reference of the recording site, a second video casette recorder (VCR) was used to record the site of measurement and to search for the original area of 
measurement. When this part of the experiment was completed, the preparation was treated with vasodilators and the protocol was repeated.

In pllot-expertments it was found that topically applied adenoshe induced plasma leakage, as evidenced by the extravascular appearance of PITC-BSA, and consequently images were hardly sultable for analysis. Leakage of FIT, however, could effectively be reduced by a 20-15 min pretreatment with a beta-2 agonist terbutaline (Bricanyl ${ }^{R}$, Astra Chemicals Benelux, Rijswifk, The Wetherlands; $0.5 \mathrm{mg} / \mathrm{ml}$ ). Following pretreatment with terbutaline (final concentration in superfusate $250 \mu \mathrm{g} / 1$ ), the experiment was continued by superfusion with adenosine $\left(10^{-3} \mathrm{M}\right)$ and terbutaline. Both agents were dissolved in the Tyrode"s solution. Neither treatment or combination of terbutaline w th adenosine produced any measurable change in arterial pressure.

Al1 video-recordings of capillaries were made during a $1-2 \mathrm{~min}$ period. By slowly and carefully focussing at different tissue depths, al1 capillaries were included.

At the end of the experiment in 6 WKY and 6 SHR, tissue thickness of the anteromedial part of the muscle was measured by focussing on the upper surface of the muscle and then on the lower side using the fine adjustment micrometer scale, always using a salt-water imersion objective (SW25). By slowly replaying and stopping the video-tape capillaries of all tissue depths were analyzed. Total capillary length of each area $(200 \times 250$ uml was determined twice with a calibrated curvimeter and the mean value of each area was used for further data analysis. Of each anlmal, the mean value of 10 areas was determined.

Capillary density was expressed as the total captllary length (units) of surface area and per volume ratio.

\subsubsection{Statistical analysis}

All data are presented as means $\# S E M . N=$ number of animals. To test for differences in blood pressure, heart rate, age and body welght between the two groups, the Student's t-test was used. For comparison of vessel diameter and density between the hypertensive and normotenslye groups, the non-parametric Mann-Whitney U-test was used. Values of $p$ less than 0.05 were regarded as significant. 


\subsection{Results}

\subsection{General findings}

Experiments were successfully performed on 14 WKY and 14 SHR. The MAP, HR, age and body weight values of WKX's and SHR"s are listed in table 3.1. MAP in the hypertensive animals was only modestiy increased (on the average by $14 \mathrm{~mm} H g$ ) as compared to the normotensive control rats. Differences between these groups were statistically significant $(p<0.05)$. The hypertensive rats had a higher heart rate $(p<0.01)$. All rats used in this study were 5-6 weeks old and had body weights of approximately 105 grams. No statistically significant differences between the groups of hypertensive and normotensive rats were found, as far as the values of the two latter parameters are concerned.

Table 3.1: Group comparison between WKY and SHR.

WKY n $\quad$ SHR

$\begin{array}{lccccccc}\text { MAP (mun Hg) } & 89 & \pm 3.0 & 14 & 103 & \pm 3.9 & 14 & p<0.01 \\ \text { HR (bpm) } & 343 \pm \pm 12.0 & 14 & 380 & \pm 16.0 & 14 & p<0.05 \\ \text { age (days) } & 38.1 \pm 1.1 & 14 & 36.1+0.9 & 14 & \mathrm{n} . \mathrm{s} . \\ \text { body weight (grams) } & 106 \pm 3.4 & 14 & 105 \pm 5.9 & 14 & \mathrm{n} . \mathrm{s} .\end{array}$

\subsubsection{Microvascular geometry}

Arteriolar branching patterns were consistent. In the resting situation, each preparation was perfused by only one major arteriole (A1). The Al vessel branches usually into 6-10 straight running A2 vessels, which distribute blood over the muscle and are colled in the distal part of the preparation. The vascular branching pattern of the Al vessel can be compared with an asymetrically bifurcating tree.

Five to 8 A3 vessels branch off perpendicularly from the $A 2$ arterioles and supply a restricted area with blood. Three to 6 A4 


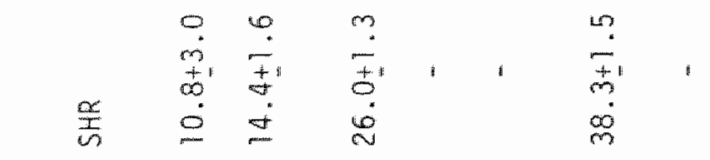

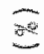

$\frac{a j}{0}$

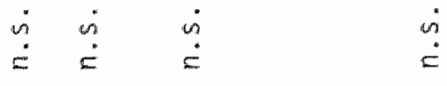

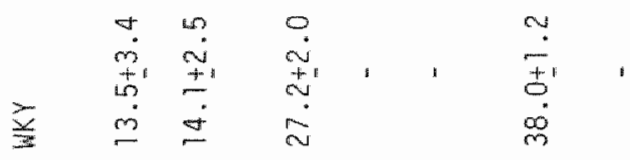

$\underset{\infty}{\infty}$

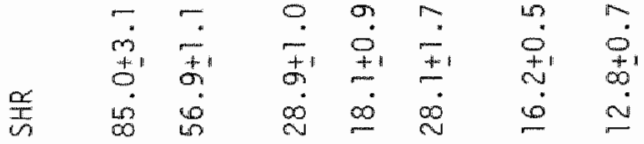

5
5
0
0
0
0
0
0
0
$=0$

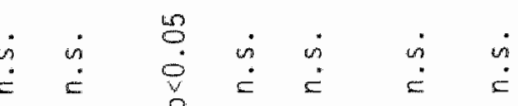

$+$

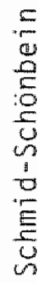

$+$

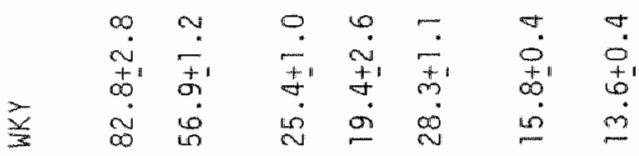

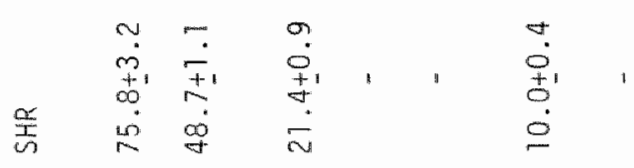

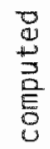

五

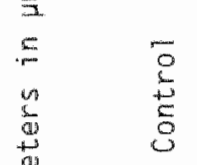

$\therefore \quad$ in

$\dot{m}$

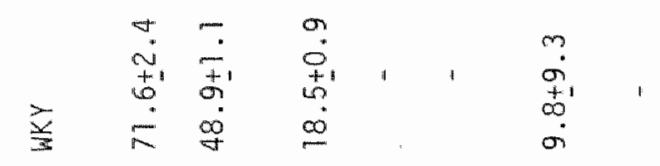

몸

튬

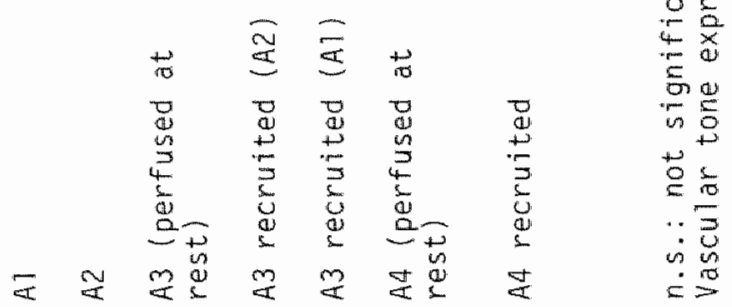


arterioles branch of perpendicularly or obliquely from A3 vessels. Finally these A4 vessels give off the capillaries which form a capillary network. Within a layer, capillaries can be nicely aligned or form a dense meshwork. Sometimes several layers can be distinguished.

\subsubsection{Arteriolar diameters}

In table 3.2 the diameters in the control state and following dilation of arterioles which were perfused in the control state are shown. A statistically significant difference was only found for third order vessels, the dianeter of which was even slightly larger in SHRs. Topical administration of adenosine caused all vessels in both groups to increase in diameter. Again except for the A3 arterioles no significant differences were observed between the diameter in the SHR and the WKY group. Vasodilation was relatively stronger in smaller arterioles.

The dilating capacity increased toward the capillary bed. Third and fourth order vessels exhibited the highest increase in dianeter.

At several levels within the microvascular bed recruitment of arterioles was observed in both WKYs and SHRs. Recruited A3 vessels had smaller diameters than comparable arterioles already perfused in the control state $(p<0.01)$ (see table 3.2). This was also found for the recruited A4 vessels $(p<0.01)$.

Following vasodilation the number of arterloles perfused by the first order arteriole increased as well. Based on their maximum diameter these vessels were classified as A3 vessels because no differences were noticed with "true" A3 vessels (table 3.2).

\subsubsection{Arteriolar recruitment}

Each preparation was fed by one Al vessel (table 3.3) both in the resting situation and following vasodilation. The number of perfused Al and A2 vessels did not differ between WKY and SHR (table 3.3). As a consequence the interdistance of $A 2$ vessels between SHR and WKY did not differ statistically in the resting state and following vasodilation. In the resting sltuation, the number of A3 vessels per A2 was smaller in SHR as compared to WKY. Consequently, the mean interdistance in SHR was longer ( $p<0.05)$ (table 3.3). 
Table 3.3: Nubber of arterioles and interdistance as its normalized length for each type of parent vessel.

n.s. = not significant

$\mathrm{n}=$ number of animals

WIX $\quad \mathrm{S} \quad \mathrm{SHR}$

Number of Al vessels

Control

Vasodtlated

Increase in perfused

Al vesgels

Number of $A 2$ vessels

Control.

Vasod llated

Increase in perfused

A2 vessels

Interdistance ( $\mathrm{m}$ )
Control
Vasodilated
Change in inter-
distance

Number of A 3 vessels

Control

Vasodilated

Increase in perfused

A3 vessels

Interdistance ( $(1 \mathrm{~m})$

Control

Vasodilated

Change in inter-

distance

Number of $\mathrm{A}_{4}$ vessels

Control

Vasodilated

Increase fin perfused

A4 vessels

Interdistance ( $\mu \mathrm{m})$

Control.

Vasodilated

Change in inter-

distance

$\begin{array}{rrrr}1.0+0 & 14 & 1.0 \pm 0 & 14 \\ 1.0 \pm 0 & 14 & 1.0 \pm 0 & 14 \\ 0 & 14 & 0 & 14\end{array}$

$7.5+0.7 \quad 12$

$8.8+0.5 \quad 14$

n.s.

$7.5 \mp 0.7 \quad \mathbb{1} 2$

$8.8 \pm 0.5 \quad 14$

n.s.

D 12

a

14

$2064+11.9 \quad 1$

$2064 \mp 119 \quad 12$

$1885+142 \quad 14$

$1885+1.42 \quad 14$

n.s.

n.s.

0

12

0

12

n.s.

$7.9+1.1 \quad 1.2$

13.0+1.4 12

$5.2+0.5$

$6.6 \mp 0.5$

14

14

$p<0.05$

$p<0.01$

$\begin{array}{lllll}5.1 \pm 0.9 & 12 & 1.4 \pm 0.3 & 14 & p<0.05\end{array}$

$1932+340 \quad 12$

$1.135 \mp 222 \quad 1.2$

$2800+268$

$2168+186$

14

$p<0.05$

$797+177 \quad 12$

$632+175$

14

$p<0.05$

$5.9+0.9 \quad 11$

$3.3+0.5 \quad 10$

$p<0.05$

9.1. $\mp 0.8 \quad 11$

$4.4 \pm 0.5 \quad 10 \quad p<0.01$

$3.2+0.1 \quad 1.1$

1. $1 .+0.2$

10

$p<0.05$

$488+72 \quad 11$

11

$880+145$

10

$p<0.05$

$304 \pm 44$

$616 \mp 100$

10

$p<0.05$

$184+39$

11

$264+73$

$10 \quad p<0.05$ 
Following vasodilation the number of A3 vessels perfused increased. This was seen in both SHR and WKY. The magnitude of the increase in the number of $A 3$ perfused was less in the sur $(p<0.05)$. The discrepancies between WKY and SHR in interdistance became more pronounced (table 3.3). Of the functionally avallable A3 vessels approximately $39 \%$ was not perfused in WKY and only $26 \%$ in SHR.

The same pattern was found for the $A 4$ vessels. In the control situation, the number of $A 4$ vessel was less and the mean interdistance was longer in SHR than in WKY (table 3.3). In the vasodilated state, a smaller number of $\mathrm{A}_{4}$ vessels was recruited in SHR as compared to WKY. of the functionally avallabe vessels at rest $35 \%$ of the A4 vessels was not perfused in the WKY and only $25 \%$ in the SHR.

The recruited arterioles (A3) with A2 as parent vessel were further examined. The interdistance of off-shoots off A2 vessels was: WKY: $299+39 \mu \mathrm{m}(\mathrm{n}=5)$ and SHR: $533+37 \mu \mathrm{m}(\mathrm{n}=12)$, respectively. Their microvascular characteristics (interdistance) did not differ from the contral group and can thus be regarded as identical.

The absolute number of recruited "A3 vessels" fed by an Al vessel was less in SHR as compared to WKY, but did not reach the level of significance (HKY: $2.2 \pm 0.2, n=26 ;$ SHR: $1.5+0.5, n=19$ ). The interdistances of these vessels in the SHR were comparable with their corresponding control group (A3 vessels perfused at rest).

\subsubsection{Arteriolar arcades}

The number of third-order arterioles interconnected to form an arcading system was sma11. In both SHR and WKY only one A3 vessel appeared to be part of an arcade in the control situation (number of $A 3$ analyzed: 20 and 25 ). In the SHR group it was noted only once that a recruited arteriole opened up to an arcading network. Arteriolar arcades were never observed at the level of fourth order arterloles.

\subsubsection{Capillary diameters and recruitment}

In the control situation the capillary diameters in WKY and SHR did not reveal any statistically significant differences (table 3.4). Adenosine did not increase diameters in both strains. 
Tabel 3.4: Capillary diameter (um), capillary length ( $\mathrm{mm} / \mathrm{mm}^{2}$ ) and cremaster muscle thickness ( $\mu$ m) in 6 wKY and 6 SHR in the resting situation and following foplcal treatment with adenosine ( $f$ inal concentration: $10^{-3} \mathrm{M}$ ).

WKY

SHR

\begin{tabular}{|c|c|c|c|}
\hline $\begin{array}{l}\text { Capillary diameter ( } \mu m) \\
\text { (control sltuation) }\end{array}$ & $3.9+0.4$ & $\mathrm{n} \cdot \mathrm{s}$. & 4.040 .5 \\
\hline $\begin{array}{l}\text { Caplilary dianeter (um) } \\
\text { (vasodilation) }\end{array}$ & $4.0+0.4$ & $\mathrm{n} . \mathrm{s}$. & $4.0+0.4$ \\
\hline $\begin{array}{l}\left.\text { Caplilary length ( } \mathrm{mm} / \mathrm{mm}^{2}\right) \\
\text { (control stuation) }\end{array}$ & $44.9+1.7$ & $p<0.01$ & $33 \cdot 1+1.2$ \\
\hline $\begin{array}{l}\left.\text { Capillary length ( } \mathrm{mm} / \mathrm{mm}^{2}\right) \\
\text { (wasodilation) }\end{array}$ & $45.8+1.7$ & $p<0.01$ & $34 \cdot 6 \pm 1 \cdot 4$ \\
\hline Muscle thickness ( $\mu \mathrm{m}$ ) & $259.3+5.7$ & $\mathrm{~m} \cdot \mathrm{s}$. & $251.7+11.2$ \\
\hline
\end{tabular}

In table 3.4 the capillary density (expressed as mo capillary length/ $\mathrm{mm}^{2}$ tissue surface area) in WKY and SHR are presented. Muscle thickness of WKY and SHR did not differ statistically (WKY: $259.3 \pm 5.7 \mathrm{\mu m}$ vs. SHR: $251.7 \pm 11.2 \mu \mathrm{m})$. In the control state in SHR the capillary density was approximately $26 \%$ less than in WKY. Since caplllary density did not change in the vasodilated state, no recrultment could be de termined.

\subsection{Discussion}

\subsubsection{General}

This study was designed to quantitate functional and structural differences in vasculature between WKX and SHR rats in the early phase of spontaneous hypertension by means of functional morphometry. In the control situation small but statistically significant differences between NKY and SHR were observed. In the control situation the SHR have a lower flow carrying capactry and exchange surface area. In the vasodilated state equivalent wh an increased demand of flow, SHR 
have less capacity to dilate and to recruit. Only at the capillary leve1, no changes were observed.

\subsubsection{Microvascular terminollogy}

The vessel classification used in this study reflects the functional determinants of the cremaster muscle. First and second order arterioles ( $A 1$ and $A 2$ ) have a transport function and have a relatively low dilating capacity with large diameters. Third and fourth order arterioles ( $A 3$ and $A 4$ ) have a regulatory function with a high dilating capacity and small diameters. In a number of $A 3$ and $A 4$ vessels a complete temporal closure of the vessel lumen occurs. These vessels can be recruited.

The functional significance of arteriolar arcades $\mathbb{1 n}$ regulation of flow seems to be limited because they are rarely observed for third order arterioles and are even absent for fourth order arterioles.

\subsubsection{Arteriolar diameter}

In the present study during the control state and following vasodilation, dianeters of arterioles of 5-6 week old SHR are not significantly different from those in WKY (see table 3.2)" The data presented by Bohlen et al (1977), Bohlen and Lobach (1978), Dusseau and futchins (1979), and Chen et al (1981) agree with our Findings. only a single report showed a higher vascular resistance corresponding with an increased dilating capacity (Roy and Mayrovitz, 1982), while Hutchins and Darme1l (1.974) reported even an Increased arteriolar diameter in young SHR. Our findings may be extrapolated to skeletal muscle preparations like the rat gracills (Prewit et al, 1982) and the spinotrapezivis muscle (zweifach et al, 1981) revealing no evidence For an increased vasodilating capacity at an early age.

Comparable vessel types of the age-matched rats in this study did not reveal changes in maximal diameter in the vasodilated state except for the A3 vessels, showing larger diameters. This is at variance with the hypothesis proposed by Folkow (1983) suggesting that spontaneous hypertension is characterized by an increased vessel wall and hypertrophy reduces the vessel llumen size following maximal vasodilation. Our evidence is, however, indirect because we did not meas - 
ure wall thicknesg.

\subsection{Arter lolar recrultment}

A low number of arterioles can have elther an anatomical or functional cause (2ueffach, 1983). Functional rarefaction is characterized by an increased number of arterioles which were temporarily non-perfused, and has been demonstrated for the cremaster (Chen et al, 1981) and gracilis muscle (Prewitt et al, 1984). Structural rarefaction is characterized by a diminished number of arterioles functionally avallable following maximal vasodilation.

Most studes focussing on functional and structural alterations of the microvasculature of the cremaster muscle used stereological techntques by counting the number of intersections (Chen et all, 1981) or analyzed microvascular networks from photomontages by measuring the length of each Individual vessel per unit surface area (Hutchins and Darne11, 1974; Fnge1son et al, 1986).

We have chosen for functional morphometry by measuring the distances between side-branches of the same vessel order level along the representative parts of the arterlolar tree and expressing the distances per unlt vessel length. Our method is preferable because it allows for discrimation between the number and the length of parallel conductance vessels because the branching pattern is known. Although in the cremaster muscle arteriolar arcades do not play a significant role in regulation of tissue perfusion these can in principle be distinguished as wel1.

From the absence of recruitment of $A 1$ and $A 2$ vessels together with their low dilating capacity, it can be concluded that Al and A2 vessels have a transport function. The lack of difference between SHR and WKY indicates a normal transport function in SHR.

The flow carrying capacity in the terminal portion of the vascular bed is lower in SHR as compared to WKY. The arteriolar reserve determtned when all arterioles were functionally avaliable appeared to be lowered in SHR. The regulation of perfusion is primarily restricted to the terminal part of the circulation, since arteriolar recruitment was only observed for $\mathrm{A} 3$ and $\mathrm{A} 4$ vessels.

The low number of $A 3$ and $A_{4}$ vessels in the SHR as compared to 
WKY may account for an additional increase in resistance and/or rise of arteriolar blood pressure.

Our study agrees with a study published by Hutchins et al (1.982) showing decreased arteriolar densities in the cremaster muscle of young rats. This is not unique for the cremaster muscle and has been reported for the gracilis muscle (Prewitt, 1982; Henrich and Hertel, 1982). Our study is partly at variance with studies of chen et a1 (1981) which demonstrated besides an anatomical also a functional rarefaction at the same age suggesting an increased dilating capacity*

\subsubsection{Capillary diameter and density}

The presented results are in agreement with previous studies performed on skeletal muscle preparations (Chen et a1, 1981; Prewitt et al, 1982) showing no difference between WKY and SHR in caplllary diameter.

In the control situation in SHR, the capillary exchange surface area was clearly diminished and capillary rarefaction was present. No capillary recruitment occurred. This means that all capillaries functionally avallable are perfused in the control state of the tissue and that arterioles do not temporarily shut off groups of capillarles. Capillaries apparently form one dense network with dense mutual interconnections. The capillary network has a multiple input system. Hence, no increased number of perfused cap 11 aries was observed.

Al though others (Chen et al, 1981) have shown that caplilary recruitrent does occur at this age in SHR, the differences may be easily attributed to methodological differences. In the present study, capl1laries were visualized by means of fluorescence mlcroscopy and a plasma marker and not by the presence of flowing RBCs as observed in bright-field microscopy. Furthermore, microvascular observations are in most cases restricted to a fairly shallow depth of tissue and capillaries situated in deeper layers of the tissue may be overlooked when using brigh-field microscopy.

Our results are in accordance with observations in the cremaster muscle of young 5 -week old hamsters where maximal vasodilatation failed to increase capillary density (Sarelfus et al, 1.981).

Capillary rarefaction was also observed in the gracilis muscle 
(Prewtet et al, 1984), but contrary to the findings in our study, no caplllary carefaction could be determined in the spinotrapezius muscle (Gray, 1982) in both young and mature SHR as compared to WKY. Whether this is a pecularity of the spinotrapeztus muscle has to be assessed. In conclusion, in the young hypertensive rat with a rapidly increasing blood pressure both the number of perfused arterloles at rest as well as the functional artertolar reserve was diminished. This was associated with an equally affected decreased capillary denstity. No evidence was obtained for an increased dilating capacity or smaller diameters in the passive state in spontaneous hypertenston. The primary defect underlying the increased resistance and thus the progressive rise in blood pressure is a structural alteration of the vascular architecture probably due to a diminished vascular growth.

\subsection{References}

Bohlen HG, Gore RW, Hutchins PM. Comparison of microvascular pressures in normal and spontaneously hypertensive rats. Microvasc Res 13, $125-130,1977$.

Bohlen $H G$, Lobach D. In vivo study of microvascular wall characteristics and resting control in young and mature spontaneously hypertensive rats. Blood Vesse1s 15, 322-330, 1978.

Bohlen HG. Intestinal microvascular adaptation during maturation of spontaneously hypertensive rats. Hypertension 5, 739-745, 1983.

Bohlen $H$. Localization of vascular resistance changes during hypertension. Hypertension 8, 181-183, 1986 .

Chen II, Prewitt RL, Dowe11 RF. Microvascular rarefaction in spontanesouly hypertensive rat cremaster muscle. Am J physiol 241, H306-11310, 1.981 .

Damon DH, Duling BR. Distribution of caplliary blood flow in the microctrculation of the hamster: an in vivo study using eplfluorescent microscopy. Microvasc Res $27,81-951984$.

Dusseau JW, Hutchins PM. Stimulation of arteriolar number by salbutanol. In spontaneously hypertensive rats. Am J Physiol 236, H134$1140,1979$.

Engelson ET, Skalak TC, Schmid-Schönbein GW. The microvasculature in skeletal muscle. I. Arteriolar network in rat spinotrapezius muscle. Microvasc Res 30, 29-44, 1985.

Engelison $\mathrm{R}$, Schid-Schonbeln GW, Zwe if fach BW. The microvasculature in skeletal muscle. II. Arteriolar network anatomy in normotensive and spontaneously hypertensive rats. Micravasc Res $31,356-374$, 1986.

Evenwel RT, Kasbergen CM, Struyker Boudier HAJ. Central and reglona1 hemodynamlcs and plasma volume distribution during the develop- 
ment of spontaneous hypertension in rats. Clin Exp Hypert A5, $1511-1536,1983$.

Folkow B. Structural factors: the vascular wall. Hypertension 5 (suppl 3), 58-62, 1983.

Gray SD. Muscle capillaries in hypertension. Nicrovase Res $27,39-49$, 1984.

Henrich H, Hertel RF, Microvascular hemodynamics in spontaneous hypertension. In: Microvascular aspects of spontaneous hypertension (ed: H. Henrich). Hans Huber Publishers, Bern, 1982, pp 21-39.

Hudlicka 0 , Zweifach BW, Tyler KR. Capillary recruitment and flow velocity in skeletal muscle after contraction. Microvasc Res 23, $201-203,1982$.

Hudlicka $O$, Tyler KR, Wright AJA, Ziada AMAR. Growth of caplliaries in skeletal muscle. Prog Appl Microcirc 5, 44-61, 1984.

Hutchins PM, Dernel1 AE. Observation of a decreased number of small arterioles in spontaneously hypertensive rats. Circ Res 34 (supp1 1), 161-165, 1974.

Hutchins PM. Dusseau JW, Marr MC, Greene AW. The role of arteriolar structural changes in hypertension. In: Microvascular aspects of spontaneous hypertension (ed: H Henrich). Hans Huber Publishers, Bern, 1982, pp 41-53.

Joshua IG, Weigman DL, Harris PD, Miller F. Progressive microvascular alterations with the developnent of renovascular hypertension. Hypertension 6, 61-67, 1984 .

Lee RMKW, Garfield RE, Daniel EE. Morphometric study of structural changes in the mesenteric blood vessels of spontaneously hypertensive rats. Blood Vessels $20,57-71,1983$.

Lindbon L, Tuma RF, Arfors KE. Blood Elow in the rabbit tenuissimus muscle. Influence of preparative procedures for lintravital microsopic observations. Acta Phystol Scand 114, 121-127, 1982.

Nishiyama $K$, Nishiyama $A$, Frohlich ED. Reglonal blood flow in normotensive and spontaneously hypertensive rats. Ath $J$ Physiol 230, $691-698,1976$.

Prewitt RL, Chen II, Dowell R. Development of microvascular rarefaction in the spontaneously hypertensive rat. Am J Physiol 243: H243-H251, 1982.

Prewitt RL, Chen II, Dowel1 RE. Microvascular alterations in the one-kidney, one-clip renal hypertensive rat. Am J Physlol 246, H728-14732, 1984 .

Proctor KG, Busija DW. Relatonship among arteriolar, regional, and whole organ blood flow in cremaster muscle. Am $\mathrm{J}$ physiol 249 , $1434-\mathrm{H} 41,1.985$.

Roy JW, Mayrovitz HN. Microvascular blood flow in the normotensive and spontaneously hypertensive rat. Hyperteasion 4, 264-271, 1982 .

Sarelius IH, Damon DN, Duling BR. Microvascular adaptations durling maturation of striated muscle. Am J Physiol 241, $1317-H 324$, 1981.

Schmid-Schonbein GW, Zweifach BW, DeLano FA, Chen PCY. Microvascular tone in a skeletal muscle of spontaneously hypertensive rats. Hypertension 9, $164-171,1987$.

Stith TL, Hutchins PM. Central hemodynamics in the developmental stage of spontaneous hypertension in the unanesthetized rat. Hypertension $1,508-517,1979$.

Vetterlein F, Schridt G. Functional caplllary density in skeletal 
muscle during vasodilation induced by isoprenaline and muscular exercise. Herovase Resi 20, 156-164, 1980.

Zweifach BW, Kowalcheck S, DeLano $E$, Chen P. Micropressure-fllow relationships in skeletal muscle of spontaneously hypertensive rats. Hypertension 3, 601-614, 1981.

Zweifach $B$ W. The wlcrocirculation in experimental hypertension. State of the art review. Hypertension 5 (suppl I), 10-16, 1983. 
4. CUTANEOUS MUSCLE MICROCIRCULATION IN ADULT CONSCIOUS WORMOTENSIVE AND SPONTANEOUSLY HYPERTENSIVE RATS

\subsection{Introduction}

Microvascular alterations of resistance vessels of nearly every organ system and in particular skelatal muscle may contribute to a considerable degree to the increased peripheral resistance in spontaneous hypertension (Bohlen, 1986). The information concerning the changes of the microvasculature of SHR as compared to WKY are malnly obtained by intravital microscopic observations of acute preparations requiring surgical manfpulations with general anesthetics (Hutchins and Darnel1, 1975; Henrich et al, 1978; Chen et al, 1981; Prewlt et a1, 1982; Bohlen, 1983). These interventions may disturb normal physiology and vascular smooth muscle reactivity.

A depressent effect of general anesthetics on vascular smooth muscle tone has been reported for both macro- and microcirculation (Smith and Hutchins, 1980; De Lano and Zweifach, 1981; Faber et al, 1982; Colantuani et al, 1984). Furthermore, in several microvascular studies using skeletal muscle preparations, different anesthetics or combinations of anesthetics are used complicating comparison of experimental data.

Microvascular data obtained from muscle preparations in conscious SHR and WKY are scarce. For the present study, we used the dorsal microctrculatory chamber as a technique for microscoplc observations of the cutaneous maximus muscle in consclous rats. Anatomical analysis of this muscle revealed predominantly fast-twitched red fibers (Type IIA) and therefore this muscle can be regarded as str1ated muscle (Smith et a1, 1985). Vascular resistance in skelletal muscle is increased during the established phase of hypertenston and is responsible for the bulk of the increased peripheral reststance (Evenwel et al, 1983; Iriuchi jima, 1983; Mueller, 1983). In chapter 3, it was shown that an enhanced arteriolar dilating capacity is not a primary step in the development of spontaneous bypertension. There is growing evidence that during the maintenance phase of spontaneous hypertension (larger) arterioles and/or arteries do exhibit smaller 
diameters (Bohlen, 1986; Schwid-Schonbein et al, 1987; Miller et al, 1987 ) and contribute to vascular resistance. Microvascular observathons of various skeletal muscles of anesthetized rats did not consistently demonstrate a reduced lumen of arterlolar resistance vessels in spontaneous hypertension.

Therefore, In this study, comparable types of vessels in adult consclous WKY and SHR were analyzed. In addition, we looked for the presence of vasomotion, a phenomenom which can be regarded as normal In the Intact tissue (Funk et al, 1983; Colantwoni et al, 1984; Mulvany, 1983) and may play a role in the regulation of tissue perfusion (Tangelder et al, 1984) and in determining vascular resistance (Funk et al, 1983). A decreased amplitude of vasomotion and an increased calculated vascular resistance of arterioles were demonstrated for the spinotrapezius muscle in SHR (Borders and Zweifach, 1979; Borders, 1980).

\subsection{Experimental protocol}

Rats (SHR and WKY) were provided with the dorsal microcirculatory chamber as described in detail in section 2.8.1. Approximately one week was allowed for full recovery. At the experimental day, rats (age 10-12 weeks) were placed in the rodent restrainer for in-vivo microscopy. Detalls about the microscope, which was rotated $90^{\circ}$, and recording system can be found in section 2.9 .1 . Rats were loosely restralned. The restrainer minintzed motion but did not impede respiration. The deslgn of the restrainer allowed adaptation to rats of differing sizes (Stith et al, 1985). The chamber was fixed to the restrainer and the window cleared with distilled water using a cotton wool stick. The restrainer was mounted on the vertical stage of the microscope with the rat in a ventral side down position. Video recordings wh low magnication served to document the entire tilcrowasculature and its ang foarchitecture. In areas with optimal optical clarity, arteriolar and venular trees were selected. During a 3-minute period, recordings were made of consecutive segments of the vascular tree for aff-line diameter measurements. The types of vessels were 
grouped to the functional branching order and classifed alphanumerically. The primary perfusing arterioles of the muscle were designated as the first orders (Al) with their branches designated second orders (A2). Branches from the second and third order were third and fourth order (A.3 and A4), respectively. The same vessel chassification was used for the venous side $(W 1-\sqrt{4})$. For arterioles with vasomotion (spontaneous rhythmic cycles of constriction and dilation) graphic recordings of arteriolar diameter were analyzed for maximal and minimal diameter, mean vessel diameter (maximal plus minimal/2), vasomotion amplitude (maximal minus minimal diameter/2), relative amplitude (ratio af vasomotion amplitude and mean vascular dlameter) and frequency of vasomotion. The total observation period of each rat lasted 90 min. Central hemodynamic parameters (MAP, HR) were measured as explained in detail in chapter 2 .

Al1 data are presented as mean + SEM. Data of SHR and WKY were compared, using Student's t-test for unpared observations. Differences were considered statistically significant if p 0.05 .

\subsection{Results}

A11 surgical procedures were successfully performed in 5 SHR and 7 WKY rats and fulfilled our criteria for physiological conditions. Results of central hemodynamic parameters are presented in table 4.1 . The adult SHR showed markedly higher blood pressure, with an average increase of $31 \mathrm{~mm} \mathrm{Hg}$. At this age (10-12 weeks), no differences in HR were found beween SHR and WKY at statistically slgnificant levels.

The general network andomy in both SHR and WKY were almilait. Most arterioles formed non-symetric bifurcating trees. Artertolar arcades with multiple feeding arterioles (AI) were observed in 2 SHR and 3 WKY. Arcades at the arteriolar side were oberved for the A2 and A3 vessels with sonetimes pendiculating flow patterns. Simllar vascular arrangements were noticed at the venular side.

In fig. 4.1, mean arteriolar diameters for successive branching orders are presented. The magnitude of the differences between vessels in SHR and WKY varies with particular branching orders. A decreased 

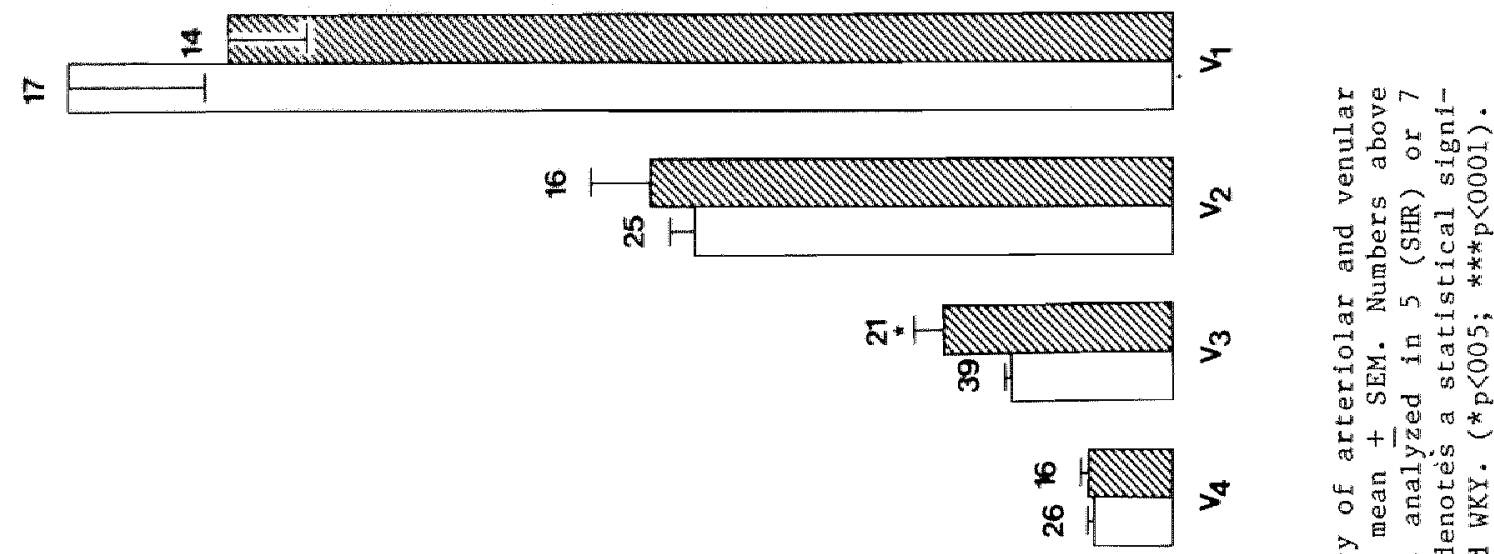

$\infty$
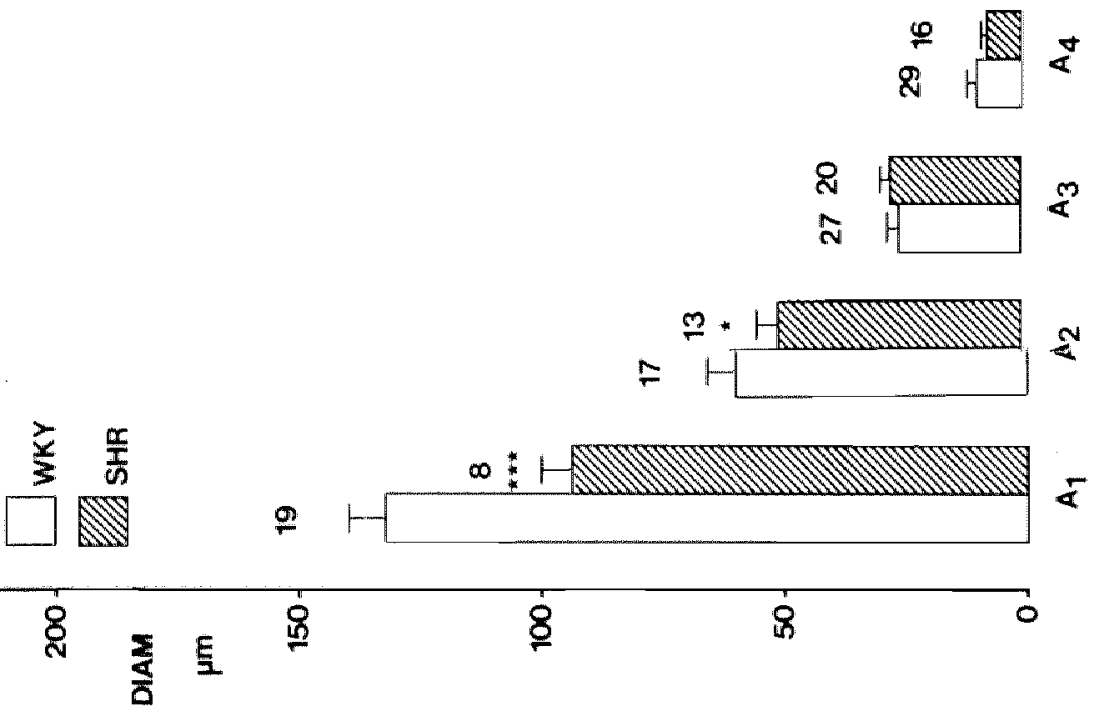

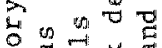

$000 \frac{5}{0}$

a to $x$

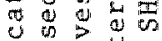

5

会。

苗

0.010

点悬䓌。

औ 5 क

ये 4 क क

需

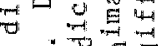

a o

品

if 05 or 0

$30 \frac{5}{3}$

$\stackrel{+*}{\because}$

ind 
Table 4.1: Central hemodynamic parameters (24-hour averages). Mean arterial pressure (MAP) and heart rate (HR). Data are presented as mean \pm SEM.

WKY $\mathbb{n}$ SHR

$\begin{array}{llllll}\mathrm{MAP}(\mathrm{Hg}) \mathrm{Hg}) & 110+2 & 7 & 141+2 & 5 & \mathrm{p}<0.001 \\ \mathrm{HR}(\mathrm{b} \text { pm) } & 304 \pm 4 & 7 & 312+14 & 5 & \mathrm{n} . \mathrm{s} .\end{array}$

lumen was found for first and second order arterioles in sHR. The thost pronounced decrease $(28 \% ; \mathrm{p}<0.001)$ was determlned for the first order arterioles (SHR: $94.6 \pm 6.9 \mu \mathrm{m}$; WKY: $130.5 \pm 7.8 \mu \mathrm{m}$ ) while second order arterioles had diameters smaller than $21 \%$ as compared to WKY (SHR: $50.6+5.3 \mu \mathrm{m} ;$ WKY: $64.7 \pm 5.7 \mu \mathrm{m})$. Third and fourth order arterioles had equal diameters. In SHR, vessel diameters of postcapillary venules were marginally increased and only statistically different from control for the V3 vessels (V3 SHR: $47.9+6.7 \mu \mathrm{m}$; V3 WKY: $33.1 \pm 1.9 \mu \mathrm{m}$; p $<0.05)$ as can be seen in fig. 4.1 as well. It should be noted that the largest venulles (VI) in SHR had diameters slightly smaller than in WKY.

Restricted parts at the arteriolar side of the microvascular bed exhibited vasomotion. If vasomotion was present, it could only be observed in third and fourth order arterioles (table 4.2). Vasonotion was present in $30 \%$ of all SHR A3 vessels analyzed and in $41 \%$ of the $A 3$ vessels in WKY. In SHR, $63 \%$ and in WKY $45 \%$ of a.1 A4 vessels analyzed exhiblted vasomotion. In most A4 vessels vasomotion showed an on-off behavior with periodic complete arteriolar closure and cessation of flow. Distally stuated capillaries from these A4 wessels showed intermittent flow. A striking difference between SHR and WKY Is an increased amplitude of vasomotion of $A 3$ vessels in SHR. While nean calculated diameters were similar for this vessel category, the amplitude of vasomotion increased by $30 \%$ in SHR as compared to WKY (table 4.2).

Although A4 vessels in SHR had only slightly larger diametera (SHR: $6.9+0.7$ vs. WKY: $5.4+0.3 \mu \mathrm{m}$ ), it appeared to be statistically 
different $(p<0.05)$.

No differences in vasomotion frequencles were found between third and fourth order arterioles nor statistically significant difFerences between SHR and WKY. Only one A4 vessel in SHR did not exhiblt a complete closure (relative amplitude $16.2 \%$ ) while all A4 vessells in WKY showed the on-off phenomenon. The average vasomotion Erequency varled between $6.0-6.8$ cyches/min.

Table 4.2: Vasomotion parameters of thild and fourth order arterioles.

WKY $n$ SHR

Third order artertoles

$\begin{array}{lccccc}\begin{array}{l}\text { Mean dlaneter } \\ (\mu \mathrm{m})\end{array} & 22.4+2.8 & 11 & 20.3+1.2 & 6 & \mathrm{n} . \mathrm{s} . \\ \begin{array}{l}\text { Rrequency } \\ (c y c l e s / \text { min) }\end{array} & 6.1+0.5 & 11 & 6.7+0.5 & 6 & \mathrm{n} . \mathrm{s} . \\ \begin{array}{l}\text { Amplitude } \\ (\mu \mathrm{m})\end{array} & 6.4+0.7 & 11 & 10.7+2.2 & 6 & \mathrm{p}<0.05 \\ \begin{array}{l}\text { Relative amplitude } \\ (\% \text { of mean) }\end{array} & 30.6+3.2 & 11 & 60.3+11.7 & 6 & \mathrm{p}<0.05\end{array}$

Fourth order arterioles

\begin{tabular}{|c|c|c|c|c|c|}
\hline $\begin{array}{l}\text { Mean diameter } \\
\text { (jim) }\end{array}$ & $5.4+0.3$ & 13 & 6.940 .7 & 10 & $p<0.05$ \\
\hline $\begin{array}{l}\text { Trequency } \\
\text { (cycles/min) }\end{array}$ & $6.0+0.4$ & 13 & $6.8+0.5$ & 10 & $\mathrm{n} . \mathrm{s}$. \\
\hline $\begin{array}{l}\text { Amplitcude } \\
(\alpha \mathrm{ma})\end{array}$ & $5.4+0.3$ & 13 & $6.1+0.8$ & 10 & $\mathrm{n} . \mathrm{s}$. \\
\hline $\begin{array}{l}\text { Relative } \\
\text { amplitude } \\
\text { (\% of mean) }\end{array}$ & $100+0$ & 13 & $91.6+8.0$ & 10 & $\mathrm{n} \cdot \mathrm{s}$. \\
\hline
\end{tabular}




\section{4 Discussion}

\subsubsection{Animal preparation}

The preparation we used consisted of preformed tissue and has been preserved intact through careful surgical procedures. It appeared to be very important to use sterile surgical techniques and systemic antibiotic therapy. If surgery was properly performed rats showed a quick post-operative recovery, minimal weight loss and no signs of infections. During handling, all rats used in these experiments seemed to be comfortable and not limited in their normal behavior by the implanted chamber. The healing periad of the chamber lasted for approximately $5-7$ days and consisted of edema reabsorption. After a maximal healing period of 1 week, vasomotion in small arterlales was usually present. Trama during surgery to the wall of blood vessels and microbleedings should be meticulausly avoided because they prolong healing time. In addition, the presence of extravascular red blood cells and serum within the preparation can elicit angiogenesis (Hudlicka, 1984), thereby disturbing normal angioarchitecture of the muscle. It is hard to compare the muscle with the pre-operative state but the chamber was constructed to preserve the normal environmental conditions such as ion concentrations, gas tensions and temperature (Suith et al, 1985).

Furthermore, vasomotion was present in our preparation and this can also be observed in tissues like the nail fold, the bat wing or dorsal skin fold of the hamster (Fagrell et al, 1980; Funk et al, 1983; Colantuoni et a1, 1984). Deterioration of the preparation used in this study was usually manifest after 5-6 weeks. Deterioration can be observed as a development of granulation tissue. In that case, Intravital microscopic observations are then also difficult becase optical clarity is hampered and vasomotion is absent. However, in this study observations were done 2-3 weeks following implantation of the chamber. "No signs of deterioration had occurred by that time.

\subsubsection{Angloarchitecture}

The arteriolar network of the cutaneous maximus muscle showed a large variety in topology. Arteriolar arcades were present for the A2 
and $A 3$ vessels. This indicates that the Al and A2 vessels are responstble for local blood supply and distribution but that the regulation of blood flow and caplilary perfusion is predominantly restricted to A3 vessels and transwerse arterloles (A4 vessels). Experiments studying arterlolar recrultment following topical application of vasodilators are therefore necessary.

\section{4.3 Dlameter analys 18}

"The fncreased resistance during the established phase of hypertension has been attributed to arteriolar constriction or structural factors related to an increased wall to lumen ratio due to encroachment on the Iumen of a thickened vessel media (Folkow, 1983; Mulvany, 1978). The key finding of the comparison between microvascular diameters in skeletal muscle of conscious SHR and WKY in the present study is a decreased lumen for first and second order arterioles entering the muscle.

Several investigators studied microvascular diameters of skeletal muscle in adult rats. From these studies it seems that genetic hypertenston is not assoclated with a general vasoconstriction of resistance vessels, sometimes even a dilatation was observed (Bohlen and Lobach, 1978; Zweifach et a1, 1981; Henrich and Herte1, 1982). Only in one study, arteriolar constriction was observed in mature SHR (Prewitt et al, 1982). Definite conclusions cannot be drawn from these studies because they all used anesthetized animals. The importance of small arteries and arterioles in general to the increased peripheral reslstance was recently discussed by Bohlen (1986). Small arterles are probably responsible for the bulk of the increased resistance and a stiall reduction in diameter accounts for a steep increase in resistance (Mayrovitz and Roy, 1983). This was demonstrated by micropressure measurements revealing a considerable and steep pressure drop of 40-60\% already in primary arteriales entering the cremaster preparation (Bohlen et al, 1977). Apparently, a major fraction of vascular resistance lies proximal to the microvasculature in the feed vessels (Segal and Duling, 1986). A second method is the power dissipation measure which demonstrated the highest resistance to flow for larger arterioles (Borders and Granger, 1986). The reason of a greater con- 
striction of larger arterioles may be a more dense innervation by the sympathetic nervous system (Marsha11, 1982), an increased neurogenic tone in SHR (Judy et al, 1976) or alterations of the rheological properties of the arteriolar wall.

Resting lumen diameters of third and fourth order arterioles were not different from those found in WKY. Situllar results were also obtained for anesthetized animals from the cremaster, gracilis and spinotrapezius muscle. This means that there is no increase in vascular resistance due to vasoconstriction of the terminal portion of the arteriolar bed. In SHR, the peripheral resistance is increased by approximately 50\% (Bohlen, 1986) and small arterioles are responsible for $15 \%$ of the increased vascular resistance.

Thus, mechanisms other than reduced vascular lunen should be responsible. A reduced number of perfused arterloles has been proposed (Hutchins and Darnel1, 1974; Chen et al, 1981; see also chapter 3). A second mechanism has been described recently. In the spinotrapezius muscle, the length ratio of arcading arterioles per volume tissue was increased without any evidence for anatomical rarefaction (Engelson et a1, 1986). In our preparation, arteriolar arcades were observed. The present experiments were not designed to further study these possib11ities.

The smaller vessel size of first and second order arterioles includes important consequences for the efflcacy and phystological approach of pharmacological treatment of spontaneous hypertension (Zusman, 1986). A variety of vasodilators, nowadays frequently used in combination with diuretics or beta-blockers for long-term treatment of: hypertension should primarily affect larger arterloles or small arteries.

Postcap11lary wenules in SHR (V2-V4) were dilated as compared to WKY. It is possible that postcapillary dilatation prevents an increased capillary filtration by changtng the pre- to postcapillary resistance ratio. The basal mechanism(s) remain(s) to be explained. Dilameters of larger venules (VI) were slightly less in sur. Since the Vl vessels belong to the capacitance vessels a decreased diameter in SHR fits well with earlier observations revealing a decreased reglonal blood volume in spontaneous hypertension in rats (Evenwel et al, 
1983).

\subsubsection{Vasionotion}

Onily arterloles exhibited vasomotion and if present, in third and fourth order arterloles. Rhythmic diameter changes were not observed in first and second arder vessels.

Few authors report about vasomotion in skeletal muscle arterioles in hypertension. Borders and Zweifach (1979) found a decrease in vasomotion amplitude and a concomitant fucrease in vascular resistance $1 n$ rat splnotrapezius muscle. These rats were $7-9$ weeks old and at this age, hypertenstion is characterized by overperfusion of the skeletal muscle vascular bed. Rats we used were in the early established phase with a still nomal regional distribution of cardiac output but an already increased organ resistance (Smith et a1, 1979; Evenwel et al, 1983; Irtuchijima, 1983). The increased wasomotion amplitude of A3 vessels in SHR in our study indicates local reduction of vascular resistance. The cause of changes in vasomotion parameters in SHR remains unclear. In mature SHR, the same arterial inflow has to be distributed over the muscle by a lowered number of arterioles (Hutchins and Darne11, 1974; Chen et al, 1981; Prewitt et al, 1983). The increased amplitude of vasomotion may serve as a mechanism to restore local tissue blood flow and supply the capillaries.

In summary, the results support the hypothesis as advanced by Folkow (1983) that an increased peripheral resistance in SHR can be the result of a smaller arteriolar lumen of resistance vessels. In consclous rats, skelletal muscle arterioles, responsible for the bulk of the Increased peripheral resistance were markedly narrowed in hypertension. More longltudinal studies in conscious animals are needed to elucidate the mechantsin of microvascular network changes in SHR. The dorsa1 microcirculatory chamber technique used in this study provides an outstanding model to accomplish this goal. 
Bohlen, HG, Gore RW, Hutchins PM. Comparison of microvascular pressures in normal and spontaneouslly hypertensive rats Microvasc Res 13, 125-130, 1977.

Bohlen HG, Lobach D. In wivo study of microvascular wall characteristics and resting control in young and mature spontaneously hypertensive rats. Blood Vessels $15,322-330,1978$.

Bohlen $\mathrm{H}$. Localization of vascular resistance changes during hypertension. Hypertension $8,181-183,1986$.

Borders J, Zwelfach BW. Vasomotion patterns of skeletal muscle circulation in normal and hypertensive rats. Microvase Res 17,361 , 1979.

Borders JL. Vasomotion patterns in skeletal muscle in normal and hypertensive rats. PhD-thesis, University of California, San Diego, 1.980.

Borders JL, Granger HJ. Power dissipation as a measure of peripheral resistance in vascular networks. Hypertension 8, 184-191, 1986 .

Chen II, Prewitt RL, Dowell RF. Microvascular rarefaction in spontaneously hypertensive rat cremaster muscle. Am J Physial 24l, H306-H310, 1981 .

Colantuoni A, Bertoglia S, Intaglietta M. Quantitation of rhythmic diameter changes in arterial microcirculation. Am $\mathbb{J}$ Pliysiol 246, H508-H517, 1984 .

Delano FA, Zwelfach BH. Anesthesia and microvascular dynamics in SHR. An J Physiol 241, H821-H828, 1981.

Dusseau JW, Hutchins PM. Stimulation of arteriolar number by salbutamol in spontaneausly hypertensive rats. Am I Physiol 236, H134H140, 1979.

Engelson ET, Schmid-Schönbein GW, Zweifach BW. The microvasculature in skeletal muscle II Arteriolar network anatony in normotensive and spontaneously hypertensive rats. Microvasc Res $31,356-374$, 1986.

Evenwe1 RT, Kasbergen CM, Struyker Boudier HAJ. Central and regional. hemodynamics and plasma wolume distribution during the development of spontaneous hypertension in rats. Clin Exp Hypert $A 5$, $1511-1536,1983$.

Faber JE, Harris PD, wiegman DL. Anesthetic depression of microcirculation, central hemodynamics and respiration in decerebrated rats. Am J Physiol 243, H837-4843, 1982 .

Folkow B. Structural factors, the vascular wall. Hypertension 5 (suppl. III), $58-62,1.983$.

Funk W, Endrich B, Messmer K, Intaglietta M. Spontaneous arteriolar vasomotion as a determinant of peripheral vascular resistance. Int J Microcirc: Clin Exp 2, $11-25,1983$.

Funk W, Intaglietta M. Spontaneous arteriolar vasomotion. Progr App1 Microcirc 3, 66-82, 1983.

Henrich $H$, Hertel $R$, Assmann $R$. Structural differences in the mesentery microcirculation between normotensive and spontaneously hypertensive rats. Pfiligers Arch 375, 153-1.59, 1978.

Henrich HRF, Hertel R. Microwascular hemodynamics in spontaneous 
hypertenson. In: Microwascular agpect of spontaneous hypertenston (ed: Herrent), Hans huber Publishers, 1982, pp 21-39.

Mullicka 0. Developent of microcleculation: Capllary growh and adaptation. In: Handbook of physiology - The cardiovascular syster (secion 2), chapter IV, pp 165-216, 1984.

Hutchine PM, Darnel1 Ag. observation of a decreased number of small arterloles in spontaneously hypertensive rats. Cire Res 34,85 (suppl I) 161-165, 1974.

Hutching PM. Arteriolar rarefaction in hypertension. Bibl Anat 18, $160-168,1979$.

Irluchifra $J_{*}$ Reglonal blood how in conscious spontaneousiy hypertensive rats. Ipn J Physiol 33, 41-50, 1983.

Judy WV, Hatanabe AM, Henry DP, Besch MR, Wurphy WR, Hockel GM. Sympathetic nerve activity. Role in regulation of blood pressure in the spontaneously hypertensive rat. Circ Res 38 (suppl II), $21-29,1976$.

Marsha11 M. The fafluence of the sympathetic nervous system on ind $v$ idual vessels of the microcirculation of sheletal muscle of the rat. J Physto $132,169-136,1982$.

Mayrovitz HN, Roy J. Microvascular blood flow: evidence indicating a cublc dependence on arteriolar diameter. Am 3 Physiol 245 , 11031-11038, 1983.

Miller BG, Conwors BA, Bohlen MG, Evan AP. Cell and wall morphology of integtinal arterioles from $4-506$ - and 17- to 19- week-old Wistar-Kyoto and spontaneausly hypertensive rats. Hypertension $9,59-68,1987$.

Muller SM. Longltudinal study of the hindquater vasculature duting development in spontaneously hypertensive and Dahl salt sensitive rats. Hypertension 5, 489-497, 1983.

Mulvany M, Hansen $\mathrm{PK}$, Aalksjaer C. Direct evidence that the greater contractilty of resistance vessels in spontaneously hypertensive rats is associated with a narrowed lumen, a thickened media, and an increased number of snooth muscle cell layers. CInc Res $43,854-864,1978$.

Mulvany M. Functional characteristics of vascular smooth muscle. Prog Appl Microcire 3, 4-18, 1983.

Prewlt $R L_{,}$, Chen IT, Dowel1 R. Development of microvascular rarefaction in the spontaneously hypertensive rat. Am J Physiol 243, $243-251,1982$.

Schmid Schönbein GW, Zweifach $B W$, Delano FA, Chen PCY. Microvascular tone in a skeletal muscle of spontameously hypertensive rats. Hypertension $9,164-171,1987$.

Segal SS, Duling BR. Communtcation between feed arteries and microvessels in hamster strlated muscle: segmental vascular responses are functionally coordinated. Circ Res 59, 283-290, 1986.

Smdth TL, Hutchins PH. Central hemodynamics in the developmental stage of spontaneous hypertension in the unanesthetized rat. Hypertension 1, 508-517, 1979.

Smith TL, Hutchins PH. Anesthetic effects on hemodynamics of spontaneously hypertensive and Wistar-Kyoto rats. Am J Physiol 238, H539-4544, 1980.

Smith TL, Osborne SW, Hutchins PH. Long-term micro- and macrocirculatory measurements in conscious rats. Microvasc Res 29, 360-370, 1985. 
Tangelder GJ, Slaaf Dh, Reneman RS. Skeletal muscle microcirculation and changes in transmural and perfusion pressure. Prog Appl Microcirc 5, 93-108, 1984.

Zusman RM. Alternatives to traditional antibypertensive therapy. Hypertension $8,837-842,1986$. 
5. ADRENERGTC STIMULATION OF THE RAT MESENIERIC VASCULAR BED: A COKBINED MACRO- AND MTCROCIRCULATORY STUDY

\subsection{Introduction}

The basic abnormality in chronic essential hypertension is an increased peripheral resistance. One of the primary factors controlling vascular resistance is the sympathetic nervous system. A large number of observations in various animal models of hypertenston supports the concept that an increased sympathetic tone 1 s a key event in the development of hypertension.

vascular smooth muscle contraction by symathetic stimulation is mediated primarily by the alpha ${ }_{1}$-adrenoceptor subtype, whereas post-

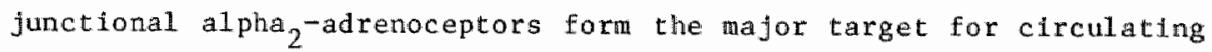
catecholamines (Timnermans and Van Zwieten, 1982; Alabastar and Davey, 1984). Exogenous application of adrenoceptor agonists is an often used method to mimick the effects of enhanced sympathetic activity. Thus, long-term elevation of circulating levels of noradrenaline by chronic intravenous noradrenaline infusion causes a sustalned Increase in vascular resistance and arterial pressure (Kleinjans et al, 1984). However, It has not yet been established whether activation of sympathetic nerves leads to similar effects on vascular resistance as the exogenous application of adrenoceptor agonists. In fact, both in vitro and in vivo data suggest that vasoconstrictors or neurogenic stimuli may produce similar increases in total resistance with strongly different effects on consecutive vascular segments (N1Isson, 1984; Grega and Adamiki, 1987).

The purpose of the present study was to compare the effects of sympathetic nerve stimulation with those of exogenous application of adrenergic agents on microvascular dymanics. The mesenteric preparation was chosen as the object of study for several reasons: (1) the relatively easy access for intravital microscopic studies; (2) the dense sympathetic innervation of this tissue as judged by the marked reflex responses of the splanchnic bed to somatic and viscerall stimult (Gootman et al, 1983; Nijhof et al, 1983); (3) the splanchnic vascular resistance is among the first to rise in the spontaneous form of 
hypettension in rats (SHR; Evenwel et al, 1983). The influence of endogenously released noradrenaline by sympathetic nerves was investigated by electrical stimulation of the posterior hypothalamus. Pharmacologtcal stimulation was performed by using the natural neurotransmitter noradrenaline. Phenylephrine was chosen for 1 ts selective alpha ${ }_{1}$-adrenoceptor agonist activity. A third vasopressor substance anglotensine II - was chosen for its actions independent of alphaadrenoceptor stimulation. Vasopressor substances were given via extravascular and different intravascular routes in order to study their bastc actions with minimal interference of systemic reflex mechanisras.

\subsection{Experimental protacol}

Only WKY rats between 275-340 grams were used in this study. Figure 5.1 depicts the general lay-out of the experimental set-up. The different sets of expertments are summarlzed in table 5.1. It provides the route of drug admitistration, the different vasopressor substances used, the number of animals per group, and which techniques or methods were used in the different experiments. For an extensive description of all preparative techniques used the reader is referred to chapter 2. In general, experiments started 30-45 min after completion of all surgical procedures and equilibration of the preparation. In all sets of experiments, MAP and HR were measured throughout the experiment.

In the first set of experiments, vasopressor substances were given intravenously and each injection was preceded by a 3-minute perlod to obtain baseline values. When intravital microscopy of the mesentery was performed red blood cell velocity (section 2.10.2) and arteriolar diameter (section 2.10.1) were measured and flow through the superior mesenteric artery was measured using Doppler flowmetry (section 2.5.1). In the same animal, dose-response curves were made for NA, PE and AII, starting with the lowest dosages. Following injection, all hemodynamic variables were measured and recorded until the Intial values were reached again. Between each injection, $10 \mathrm{~min}$ were allowed for recovery. In the second set of experiments, the same drug administration protocol was used, but now drugs were administered i.a. 


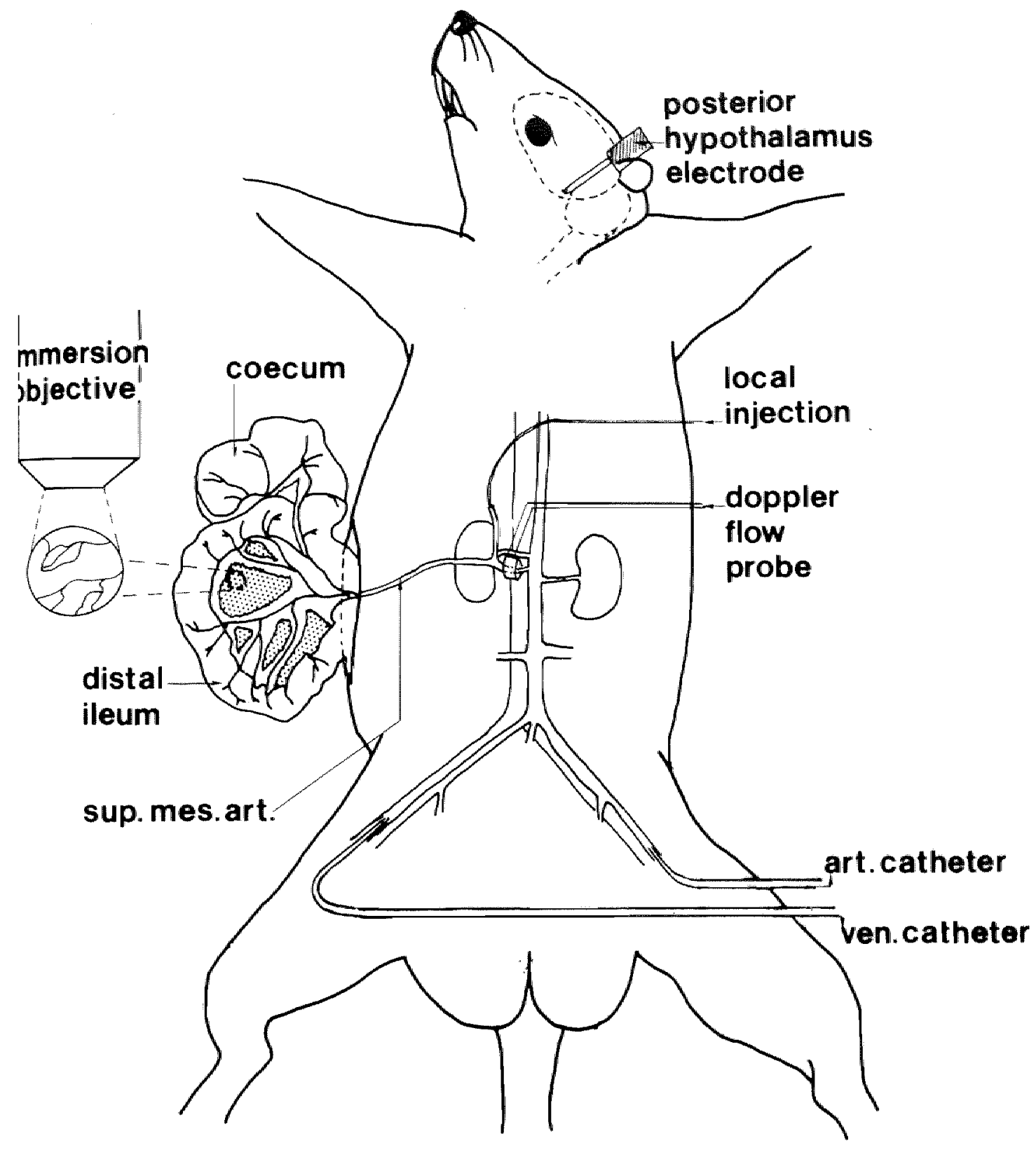


Table 5.1: Different subsets of experiments in the present study.

\begin{tabular}{|c|c|c|c|c|}
\hline Route of drug ad- & Drugs used & & Me thods & \\
\hline stimulation & & $\begin{array}{l}\text { Intravital } \\
\text { microscopy } \\
\text { combined } \\
\text { with Dopple } \\
\text { El owmetry }\end{array}$ & $\begin{array}{l}\text { Intra-vital } \\
\text { microscopy }\end{array}$ & $\begin{array}{l}\text { Doppler } \\
\text { flowinet }\end{array}$ \\
\hline Intravenous & $\mathbb{N A}, \operatorname{PE}, \operatorname{AII}$ & $\begin{array}{l}n=4 \\
v=4\end{array}$ & $\begin{array}{l}n=6 \\
v=6\end{array}$ & $\begin{array}{c}n=8 \\
-\end{array}$ \\
\hline Intra-arterial & NA & $\begin{array}{l}n=4 \\
v=4\end{array}$ & $\begin{array}{l}n=3 \\
v=3\end{array}$ & - \\
\hline Topical & NA & - & $\begin{array}{l}n=8 \\
v=10\end{array}$ & - \\
\hline $\begin{array}{l}\text { Posterlor } \\
\text { hypothalamus }\end{array}$ & & - & $\begin{array}{l}\mathrm{n}=5 \\
\mathrm{v}=7\end{array}$ & - \\
\hline
\end{tabular}

$\mathrm{n}=$ number of animals, $\mathrm{v}=$ number of vessels, NA: noradrenaline, PE: phenylephrine, AII: anglatensin II.

Instead of $1 . v$. Drugs were administered locally to achieve higher concentrations at the receptor site of the vessels under study. Furthermore the Involvement of systemic reflex effects can be minimized. In the third set of expertments, noradrenaline was directly superfused on the mesentery. During these experiments, inner arteriolar diameter was measured. When the maximum effect was reached the preparation was superfused with a fresh Tyrode's solution. Between each superfusion, 10 min were allowed for recovery. In the last set of experiments, only intravital microscopy was used and the microvascular effects upon hypothalamic stimulation were studied.

\section{2 .1 Drugs used}

Three vasopressor substances were used: noradrenaline, phenylephrine and angiotensin II. Noradrenaline, the most important neuro- 
transmitter, released upon sympathetic stimulation, stimulates postsynaptic alpha-adrenoceptors. Phenylephrine is a synthetlcally dertved pressor agent and is more selective in stimulating the alpha -adreno- $^{-}$ ceptor subtype. Angiotensin II exerts its effect by a direct action on the vessel wall independent of alpha-adrenoceptor activation.

Noradrenaline ( (-)arterenol bitartrate salt; NA), phenylephrine $((-)$ phenylephrine-hydrochloride; PE) and anglotensin II (Hypertensin; AII) were dissolved in saline (0.9\% NaC1). Pressor agents were given as bolus injections elther intravenously or intra-arterially ( $1 * \psi_{*}$ or i.a., respectively) wia the femoral vein or the supertor mesenteric artery in a volume of $50 \mathrm{\mu l}$. The following dosages were used in increasing concentration: noradrenaline $0.1-0.3-1.0-3.0 \mu g / \mathrm{kg} ;$ phenylephrine $1.0-3.0-10 \mu \mathrm{g} / \mathrm{kg}$ and anglotensin II $3-30-300 \mathrm{ng} / \mathrm{kg}$.

In some experiments, noradrenaline was superfused on the mesentery (section 2.4.3). To this end, noradrenaline was dissolved in increments of a factor of 3 in a Tyrode solution in concentrations varying between $0.3-300 \mu \mathrm{g} / 1\left(10^{-9}-10^{-6} \mathrm{M}\right)$. For each step, a maxima1 volume of $40-50 \mathrm{~m} 1 / \mathrm{min}$ of the noradrenaline solution was applied toplcally by a Harvard infusion pump, within 3-5 min. The regular superfusion rate was $7-10 \mathrm{ml}$ Tyrode's solution. Al1 solutions were freshly prepared on the experimental day. Noradrenaline was protected from light by aluminum.

All parameters were recorded on a multichannel physiological recorder (Schwarzer).

The data are expressed as nean \pm SEM. Changes in hemodynamic parameters are presented as percentage of control. The maximal effect on the parameters was used for further analysis.

\subsection{Results}

Base-1ine values of the different groups of experimental animals are sumarized in table 5.2 . 
Thable 5.2: Control values of mean arterlal pressure (MAP), heart rate (HR), vessel diameter (Q) and red blood cell (RBC) velocity in the diffent groups of animals used in this study (mean + SE).

$\operatorname{MAP}(\mathrm{mmiHg}) \quad \mathrm{HR}(\mathrm{bpm}) \quad$ (jm)

RBC velocity $(\mathrm{mm} / \mathrm{s})$

\section{Intravenous}

injections

$\begin{array}{lllll}\begin{array}{l}\text { Combined } \\ \text { Doppler and } \\ \text { intravital } \\ \text { microscopy) }\end{array} & \begin{array}{l}116+4 \\ (n=\overline{4})\end{array} & \begin{array}{l}262+11 \\ (n=\overline{4})\end{array} & \begin{array}{l}20.5+2.9 \\ (n=4)\end{array} & \begin{array}{l}2.6+1.5 \\ (n=\overline{4})\end{array} \\ \begin{array}{l}\text { Intravital } \\ \text { microscopy }\end{array} & \begin{array}{l}112+2 \\ (n=\overline{6})\end{array} & \begin{array}{l}287+17 \\ (n=\overline{6})\end{array} & \begin{array}{l}18.2+0.7 \\ (n=6)\end{array} & \begin{array}{l}2.2+0.4 \\ (n=\overline{6})\end{array} \\ \begin{array}{l}\text { Doppler flow- } \\ \text { metry }\end{array} & \begin{array}{l}98+4 \\ (n=8)\end{array} & \begin{array}{l}292+5 \\ (n=\overline{8})\end{array} & - & --\end{array}$

Intra-arterial

injections

\begin{tabular}{|c|c|c|c|c|}
\hline $\begin{array}{l}\text { Combined } \\
\text { (Doppler and } \\
\text { intravital } \\
\text { microscopy) }\end{array}$ & $\begin{array}{l}122+6 \\
(n=4)\end{array}$ & $\begin{array}{l}310+15 \\
(n=\overline{4})\end{array}$ & $\begin{array}{l}23 \cdot 0+3 \cdot 9 \\
(n=4)\end{array}$ & $\begin{array}{l}3 \cdot 2+0 \cdot 3 \\
\left(n=\frac{4}{4}\right)\end{array}$ \\
\hline $\begin{array}{l}\text { Intravital } \\
\text { microscopy }\end{array}$ & $\begin{array}{l}105+8 \\
(n=\overline{3})\end{array}$ & $\begin{array}{l}258+31 \\
(n=\overline{3})\end{array}$ & $\begin{array}{l}20.2+2.7 \\
(m=3)\end{array}$ & $\begin{array}{l}3 \cdot 7+1 \cdot 5 \\
(n=\overline{3})\end{array}$ \\
\hline $\begin{array}{l}\text { pical } \\
\text { pplication }\end{array}$ & $\begin{array}{l}122+3 \\
(n=8)\end{array}$ & $\begin{array}{l}302+11 \\
(n=8)\end{array}$ & $\begin{array}{l}22 \cdot 3+2 \cdot 3 \\
(n=1 \overline{0})\end{array}$ & -- \\
\hline $\begin{array}{l}\text { entral neural } \\
\text { timulation }\end{array}$ & $\begin{array}{l}125+5 \\
(n=5)\end{array}$ & $\begin{array}{l}311+12 \\
(n=5)\end{array}$ & $\begin{array}{l}21.9+1.9 \\
(n=7)\end{array}$ & $\begin{array}{l}3 \cdot 0+0 \cdot 3 \\
(n=7)\end{array}$ \\
\hline
\end{tabular}

\section{3 .1 I.V. bolus Injections}

Fig. 5.2 presents a typical recording following the $i \cdot v$. administration of $1.0 \mu \mathrm{g} / \mathrm{kg}$ noradrenaline. Blood pressure increased while blood flow through the superior mesenteric artery decreased. Maximal changes in these variables were usually observed within 5-10 s following infection. 
Intrawenous

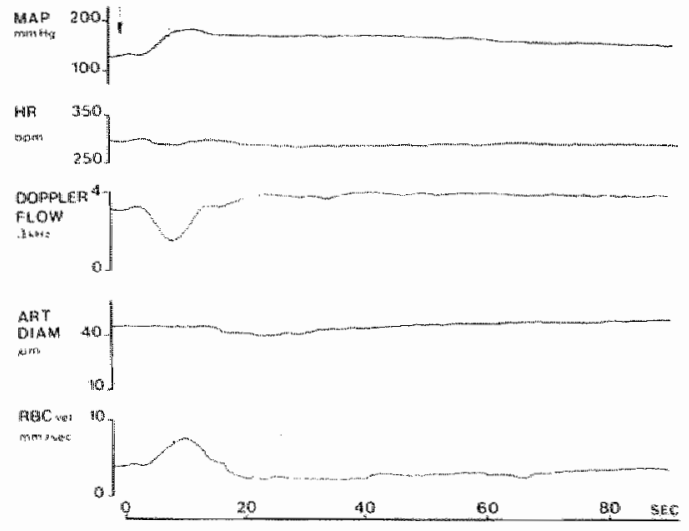

Fig. 5.2: Effects of an intravenous bolus of $1.0 \mu \mathrm{g} / \mathrm{kg}$ noradrenaline on mean arterial pressure (MAP), heart rate (HR), blood flow through the superior mesenteric artery, mesenteric arteriolar diameter and red blood cell velocity (RBC vel). The injection was given at $t=0$. The dotted line marks the moment: of maximum change in organ blood flow.

Intra arterial

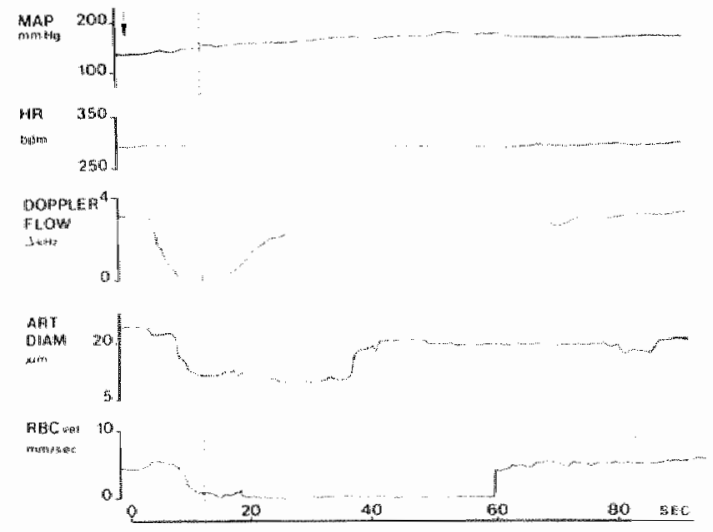

Fig. 5.4: Effects of an intra-arterial bolus of $1.0 \mu \mathrm{g} / \mathrm{kg}$ noradrenaline. Mean arterlal blood pressure (MAP), heart rate (HR), regional blood flow (superior mesenteric artery; Doppler flow), mesenteric arterlolar diameter (art dlam) and red blood cell velocity (RBCvel). The injection was given at $t=0$. The dotted line marks the moment of maximum change $1 \mathrm{n}$ organ blood flow. 
The mesentertc arterioles showed the following response. At the moment that MAP Increased, red blood cell velocity tended to increase, reached its maximum at $10-15$ s and then gradually declined. Wascular constriction could only be observed between 8-15 seconds after the maximal increase in blood pressure. This was consistently found in all experiments. Simllar resilts were obtained after $1 . v$. administration of phenylephrine and anglotensin II. Bolus injections of only saline did not cause any effect.

The maxinum increase in blood pressure was $64.7+5.7 \%, 48+3.9 \%$ and $45.7+2.8 \%$ for the highest dosages for respectively NA, $P$ and AII. Higher dosages were not used because of severe side-effects like arrhythmias. Fig. 5.3 sumarizes all data with the exception of HR, since this variable did not change significantly in any of the experimental groups.

\subsubsection{I.a. bolus Injections}

A series of experiments were performed to study local vascular reactivity while minimizing systemic effects by injecting vasopressor substances directly into the superior mesenteric artery. Fig. 5.4 presents a typlcal recording after $1 . \mathrm{a}$. injection of $1.0 \mu \mathrm{Hg} / \mathrm{kg}$ noradrena1ine. Mesenteric artery blood flow decreased sharply and was followed by a decrease in arteriolar diameter and arteriolar red blood cell velocity. The decrease of regional blood fllow ran parallel to changes in arteriolar diameter. Administration of the vehicle solution did not have any effect. Table 5.3 compares the maximum changes in hemodynamic vartables obtained with different doses of $i . a$. versus $1 . v$. noradrenaline obtalned in the anImals in which combined Doppler and intravital mlcroscople measurements were made. The data show that, in contrast to 1.v. administration, 1.a. infection of noradrenaline always leads to a reduction of $\mathrm{RBC}$ vel, even at the low doses of 0.01 and $0.03 \mu \mathrm{g} / \mathrm{kg}$ which do not affect MAP. Furthermore, the data show a much stronger effect of 1.a. noradrenaline on arteriolar diameters. At the two highest doses there is almost complete arteriolar closure and stasis of the RBCs. 

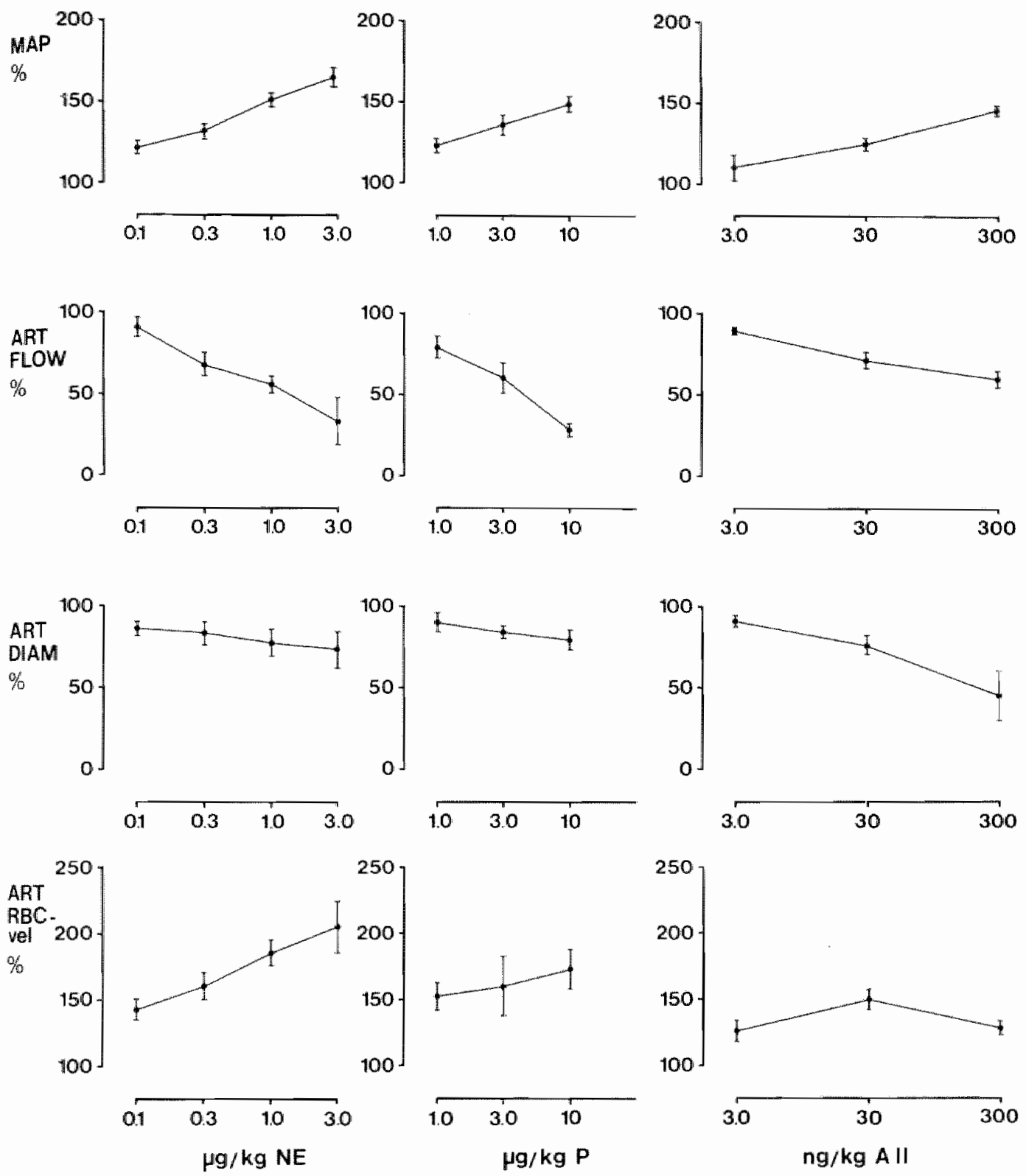

Fig. 5.3: Effects of different intravenous doses of noradrenaline (NE), phenylephrine (P) and angiotensin II (AII) on mean arterial pressure (MAP), superior mesenteric artery blood fllow, mesenteric arteriolar diameter and red blood celd. velocity (RBC vel). 
Table 5.3: Changes in mean arterlal pressure (MAP), Doppler blood flow, arteriolar diamter (D) and red blood cell velocity (RBC vel) during intravenous or intra-arterial administration of different doses of noradrenaline in the rat (mean $\pm S E ; n=4$ )
MAP (\%)
flow $(\%)$
$\phi(\%)$
RBC vel $(\%)$

\begin{tabular}{|c|c|c|c|c|c|c|c|c|}
\hline $\begin{array}{l}\text { Dose } \\
(\mu \mathrm{g} / \mathrm{kg})\end{array}$ & i.v. & i.a. & $1 \cdot v$ & $\mathbb{1}$. $a$. & $1 \cdot v \cdot$ & i. a * & $1 . \mathrm{w}$. & $1 . a$. \\
\hline 0.01 & & $+1+1$ & & $-12+4$ & & $-18+5$ & & $-3 I+11$ \\
\hline 0.03 & & $+4+1$ & & $-23 \pm 6$ & & $-22+6$ & & $-50+18$ \\
\hline 0.1 & $+27+5$ & $+11+3$ & $-18+4$ & $-46+8$ & $-12+5$ & $-40+7$ & $+44+12$ & $-70+15$ \\
\hline 0.3 & $+43+5$ & $+20+5$ & $-41 \pm 12$ & $-70+8$ & $-15+4$ & $-72 \pm 9$ & $+62+11$ & stasis \\
\hline 1 & $+79+21$ & $+41 \pm 7$ & $-49+9$ & $-91+10$ & $-24+10$ & $-95+7$ & $+85+14$ & stasis \\
\hline 3 & $+78+7$ & & $-69+6$ & & $-30+13$ & & $+77+20$ & \\
\hline
\end{tabular}

\subsubsection{Toplcal adminlstration of noradrenaline}

Toplical administration of noradrenaline consistently caused an arteriolar constriction. The maximum effect on arteriolar diameter was noticed when $10^{-6} \mathrm{M}$ noradrenaline was applied. Solutions with a higher concentration provoked irreversible effects like stasis which did not disappear after superfusion with fresh Tyrode's. Although arteriolar red blood cell velocity was not measured consistently in these experiments, an increase in RBC velocity was never observed. The results are summarlzed in fig. 5.5.

\subsection{Central neural stimulation}

St Imulation of the posterior hypothalamus was successfully performed in 5 animals. A total number of $7 \mathrm{~A}_{2}$ vessels were studied. Fig. 5.6 shows an original recording with stimulation of $64 \mathrm{~Hz}$. Blood pressure $(+42+3 \% ; n=5)$ and $H R(+19+6 \% ; n=5)$ increased as a result of the symathetic stimulation. A considerable delay (10-30 s) between the effects on blood pressure and arterlolar constriction was observed as was also found after the $1 . v$. bolus injections. The maximum decrease in dianeter amounted to $40+13 \%$. Red blood cell velocity in- 


\section{topical application of $\mathrm{NE}$}

\section{Art
diam}

\section{0}

Arteriolar diameter

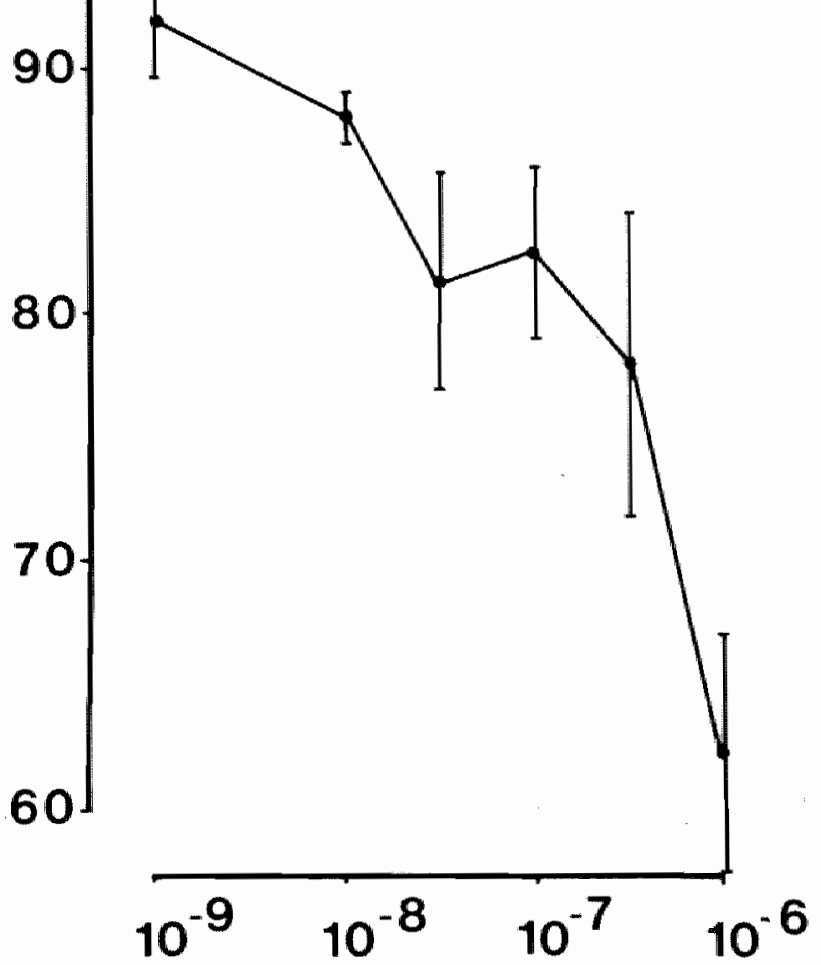

M NE 


\section{POSTERIOR HYPOTHALAMUS STIMULATION}
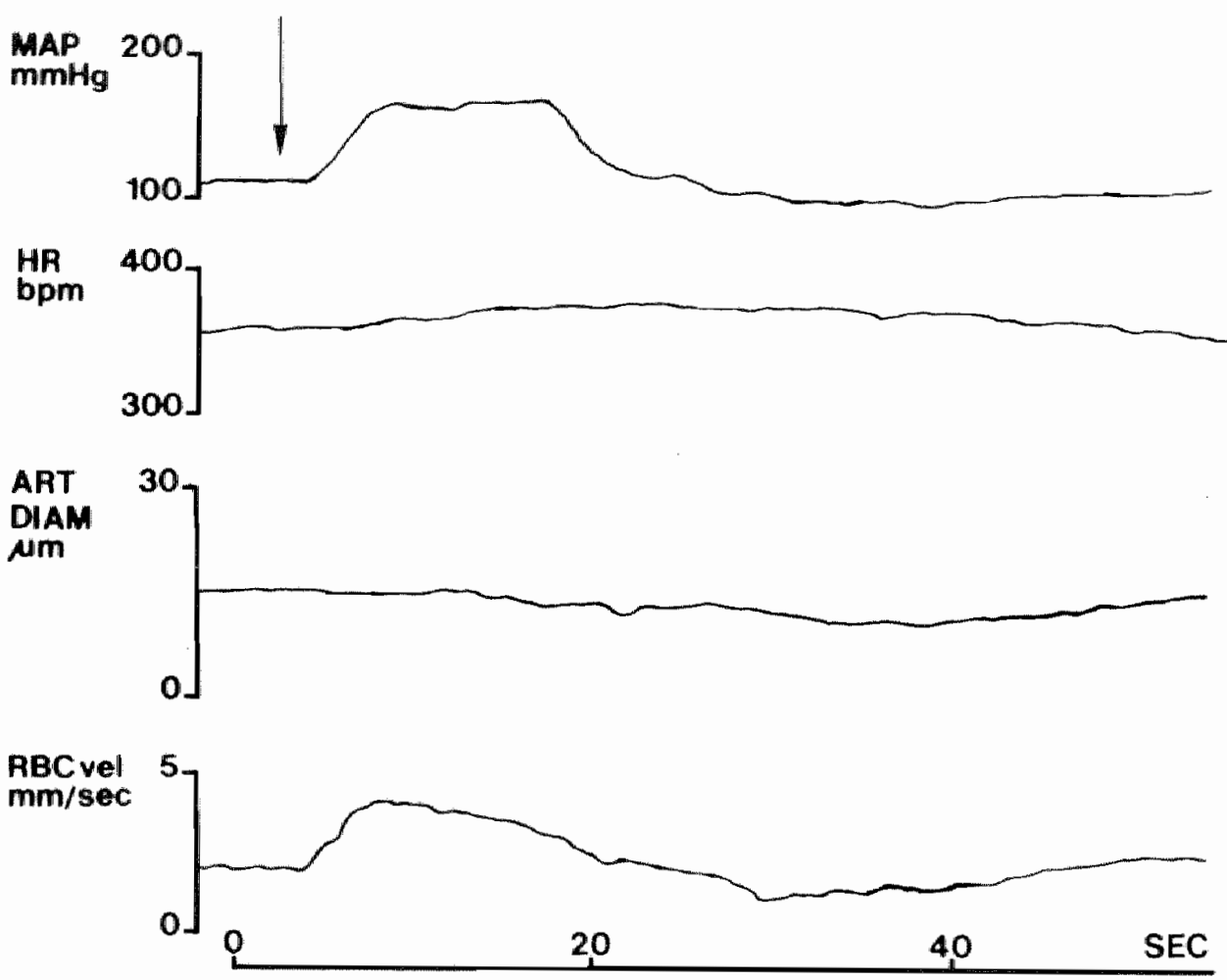

Fig. 5.6: Effects of electrical stimulation of the posterior hypothat lamus on mean arterlal blood pressure (MAP), heart rate (HR), arteriolar diameter (art dian) and red blood cell velocity (RBCvel). Stimulation was started at the point of the arrow and was continued for $15 \mathrm{~s}$ * 
creased $(+37+8 \%)$ in parallel to blood pressure increase.

\subsection{Discussion}

In this study, we demonstrated that exogenous application of (adrenergic) vasoconstrictors or neurogenic stimuli may produce an overall increase in total resistance to blood flow, with strongly different effects on consecutive segments within one vascular bed. Evidence for such divergent effects was thus far obtained in in-vitro, isolated ring preparations of arteries of different sizes (Nilsson, 1984) or in in-vivo, isolated perfused organ preparations (Grega and Adamski, 1987). In this study we have introduced a new in-vivo approach for combined macro- and microcirculatory studies in the intact rat. It combines the use of miniaturized Doppler flow probes for the continuous measurement of arterial blood flow with the intravital microscopy approach to study microcirculatory dynamics. The method is sti11 based upon the use of anesthetized animals. In a previous study (Le Noble et al, 1984) we showed that for the study of the splanchnic vascular bed, pentobarbital is the anesthetic of choice, since it does not affect vascular sensitivity to pressor stimuli in this vascular bed significantly. Our intra-arterial and toplcal noradrenaline administration data confirm a good sensitivity of our preparation to a pressor stimulus. Noradrenaline produces a local wasoconstrtction in doses well below those causing systemic effects.

A major result of our study was the difference 1 in effects obtalned with local (e.g. intra-arterial, topical) noradrenaline adninistration on the one hand and intravenous administration of this and other pressor agents as well posterior hypothalamic stimulation on the other hand. One could argue that these differences are related to divergent local drug concentrations with different routes of administration. It is technically hard, if not imposstble, to measure the actual local drug concentrations in our experimental set-up. However, we can estimate possible differences in local concentrations on the basls of previously published phamacoklnetic models of local versus systemic 
drug administration (Chen and Gross, 1979; Damen et al, 1986). According to these models, the following relationships can be used:

$$
\frac{\mathrm{C}_{\mathrm{Tra}}}{\mathrm{C}_{\mathrm{Tiv}}}=1+\frac{\mathrm{C} \mathrm{s}_{\mathrm{S}}}{\mathrm{Q}_{\mathrm{T}}}
$$

In which $C_{\text {pla }}$ and $C_{\text {nIf }}$ are the drug concentration in the arterial blood in the target organ upon respectively intra-arterial and intravenous drug administration; $\mathrm{Cl}_{\mathrm{S}}$ is the systemic drug clearance and $\mathrm{Q}_{\mathrm{T}}$ is the organ blood flow. On the basis of published data on noradrenaline clearance (approximately $50 \mathrm{ml} / \mathrm{min}$; Benedict et al, 1978; Esler et al, 1979) and rat splanchnic blood flow (approximately $10 \mathrm{~m} 1 / \mathrm{min}$; Evenwel et al, 1983), the quotient $\mathrm{C}_{\text {Tia }} / \mathrm{C}_{\text {Tiv }}$ can be estimated to be in the range of $5-10$.

In our experiment we have used a range of different concentra-

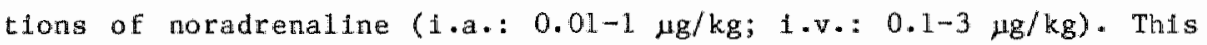
implies that we covered potential differences in local concentrations of a range exceeding the factor 5-10 calculated above. Even with this large range of obtained local concentrations we found both qualitative and quantitative differences with the two routes of administration. Intraarterial noradrenalime caused a decrease in arteriolar diameter, $R B C$ velocity and Doppler flow, both at concentrations that did not influence MAP and that increased MAP. This implies a local vasoconstrlction also at the level of the microcirculation. Intravenous noradrenaline, on the other hand, caused a decrease in Doppler flow, hardly affected aterlolar diameter and increased RBC velocity.

The increase in $\mathrm{RBC}$ velocity during intravenous noradrenaline administration may be caused by a redistribution or shunting of blood. The effect was consistently found for all three vasopressor substances, indicating a response independent of alpha-adrenoceptor stimulation, but rather linked to hemodymamic changes at a more central level, e.g. the increase in blood pressure. Banks et al (1985) have recently show that splanchnic vasoconstriction is disproportionally reflected in the mucosa and submucosa. The muscularis seems to 
be least reactive with regard to sympathetic stimulation. The bulk of blood flow through the superior mesenteric artery goes to the intestines and the mucosa and submucosa receive approximately $70 \%$ of this flow during resting conditions. The physiological function of resistance changes in the mucosa and submucasa may be a contribution to constant pressure and flow conditions essential for mucosal oxygen supply and intestinal absorption processes (Gore and Bohlen, 1977; Banks et al, 1985). The mesentery receives about $1 \%$ of total splanchnic flow (Richardson and Johnson, 1970) and can therefore play only a limited hemodynamic role. Furthermore, it belongs to the low priority vascular beds. Its possible role could be shunting of blood during acute changes in blood pressure in concordance with the muscularis layer and in this way it could contribute to the integrity of the vital parts of the intestinal tract. This study does not allow any conclusions as to the nature of the factors determining the redistribution of flow. However, the local reactivity data clearly show that the microvascular effects are not the result of a direct local action of the sympathetic stimuli via alpha-adrenoceptor stimulation.

central nervous system stimulation is a generally accepted method to increase peripheral sympathetic tone to precapillary vessels (Minomilya et al, 1970; Baez et al, 1977; Stoddard-Apter et all, 1983). Furthermore, chronic electrical stimulation of the posterior hypothalamus has been used to simulate the development of essential hypertension (Folkow and Rubinstein, 1966; Takeda and Binag, 1978). Rat mesenterlc arterioles show an intense autofluorescence after pretreatment with formaldehyde, indicating a dense sympathetic innervation (Hertel and Henrich, 1981). In our study, electrical stimulation of the postierior hypothalamus increased blood pressure considerably. This area is particularly sensitive since no blood pressure increase was observed in animals with electrodes implanted just outside this area.

The hemodynamic pattern following hypothalamic stimulation was an increase in MAP with a constrictor response of mesenteric microvessels. The microvascular response did not run in parallel with the blood pressure increase. Basically, similar results were obtained following $\mathbb{i} \cdot \mathrm{v}$. bolus injections of noradrenaline, suggesting a redistribution of flow, rather than a direct vasoconstriction. Baez et al 
(1977) obserwed a microvasulat constriction following stimulation of different stres in the forebrain and wdbrain. However, it is difficult to compare their results with ours, since they stimulated different stes in the central nervous system, did not measure red blood cell velocity and did not report on the exact time course between changes in MAP and microcirculatory varlables.

In conclusion, our results indicate that exogenous application of adrenergic and other vasoconstrlctors or neurogenic stimuli may produce an overall increase in tatal resistance to blood flow in the splanchnic bed of intact rats, with different effects on the consecutive segments in this bed. The herodynamic effects depend upon the way of stimulation or the route of drug administration. Interpretation of experimental results on the vascular reactivity of mesentertc microvessels should take into account the experimental design.

\subsection{References:}

Alabaster V, Davey M. Precapillary vessels: effects of sympathetic nervous system and of catecholamines. J Cardiovasc Pharmacol 6 (suppl), 365-376, 1984 .

Baez S, Feldman SM, Gootman PM. Central neural influence on precapillary microvessels and sphincter. Am J Physiol 233, 141-147, 1977.

Banks RO, Gallavan RH, Zinner MJ, Bulkley GB, Harper SL, Granger DN, $J a c o b s o n$ ED. Vasoactive agents in control of the mesentertc microctrculation. Fed Proc 44, 2743-2749, 1985.

Benedict $C R$, Fllenz $M$, Stanfford $C$. Changes in plasma noradrenaline concentration as a measure of release rate. Br J Pharmacol 64, $305-309,1978$.

Chen HSG, Gross JF. Physiologicaliy based pharnmacakinetic models for anticancer drugs. Cancer Chemother Pharmacol 2, 85-94, 1979.

Daemen MJAP, THijssen HHW, Van Essen H, Snits JEM, Struyker-Boudier HAJ. Comparative pharmacokinetic evaluatiog of intra-arterial versus systemic delivery of $\mathrm{Cr}{ }^{5} \mathrm{EDA}$ and 125 iodohippurate into the left and right kidney of the rat. J Pharm Sci 75, 1137-1141, 1986.

Esller MD, Hasking GJ, Willett IR, Leonard PW, Jennings GL. Noradrena1 the release and sympathetic nervous system activity. J Hypert $3,117,1985$.

Evenwe1 RT, Kasbergen CM, Struyker-Boudier HAJ. Central and regional hemodynamics and plasma volume distribution during the development of spontaneous hypertension $\mathbb{H}$ rats. C1in Exp Hypert A5, 
$1511-1536,1983$.

Folkow B, Rubinstein E. Cardiovascular effects of acute and chronic stimulation of the hypothalamic defence area in the rat. Acta Physiol Scand 68, 48-57, 1966.

Gootman MP, Gootman N, Buckley BJ. Maturation of central autonomic control of the circulation. Fed Proc 42, Mo. 6, 1983.

Gore RRW, Bohlen HG. Microvascular pressures in rat intestunal muscle and mucosal villi. Am J Physiol 233, H685-H693, 1977.

Grega GJ, Adamski SW. Patterns of constriction induced by vasoactive agents. Fed Proc 46, 270-275, 1987.

Haywood JR, Shaefer RA, Fastenow C, FInk GD, Brody MJ. Regional blood flow measurement with pulsed Doppler flowmeter in conscious rat. A⿴l J Physiol 241, H273-H278, 1981 .

Hertel $\mathrm{R}$, Henrich $H$. Spontaneous hypertension as consequence of postnatal catecholame disorder in microvessel walls. Bibl Anat 18, $180-183,1980$.

Intaglietta M, Tompins WR. Microvascular measurement by videa image splitting. Microvase Res 5, 309-312, 1979.

Kleinjans JCS, Smits JFM, Van Essen H, Kasbergen CM, Struyker Boudier HAJ. Hemodynamic characterization of hypertension Induced by chronic intrarenal or intravenous infusion of norepinephrine in conscious rats. Hypertension 6, 689-699, 1984.

König JFR, Klippel RA. The rat brain. Williams and wikens, Baltimore MD, USA, 1963.

Le Noble LML, Smits JFM, Slaaf DW, Tangelder GI, Struyker-Boudier HAT. Effects of anesthesia on regional and microcirculatory hemodynamic effects of vasopressor substances in the rat. Int $J$ Microcirc Clin Exp 3, 314, 1984.

Nilsson $H$. Different nerve responses in consecutive sections of the arterial system. Acta Physiol Scand $121,353-361,1984$.

Ninomiya I, Judy $W$, Wilson M. Hypothalanic stimulus effects on sympathetic nerve activity. Am J Physial 218, 453-462, 1970.

Nyhof RA, Laine GA, Meiniger GA, Granger HJ. Splanchnic circulation in hypertension. Fed Proc 42, 1690-1693, 1983.

Reneman RS, SIaaf DW, Lindbom L, Tangelder GJ, Arfors KE. Muscle blood flow disturbances produced by simultaneously elevatd venous asnd total muscle tissue pressure. Microvasc Res 20,307-318, 1980.

Richardson DR, Johnson PC. Changes in mesenteric caplilary flow during norepinephrine infusion. Am $J$ Physiol 219, 1317-1323, 1970.

Slaaf $D$, Alewijnse $R$, Wayland $H$. Use of telescopic Imaging in intravital microscopy: a simple solution for conventional microscopes. Int J Microcirc $1,121-134,1982$.

Slaaf DW, Arts $T$, Jeurens TM, Tangelder GJ, Reneman RS. Filectronic measurement of red blood cell velocity and volume low in microvessels. In: Investigative microtechniques in medicine and biology (eds: Chayen J, Bitensky L). Dekker, New York, 1984, PP $327-364$.

Smits JFM, Kasbergen CM, Van Essen H, Klefnjans JCS, Struyker-Boudier HAJ. Chronic local infusion into the renal artery of unrestratned rats. Am J Physiol 244, 304-307, 1983.

Snits JFM, Struyker Boudier HAJ. Systemic and regional hemodynamics following acute inhibition of angiotensin I-converting enzyme in the conscious spontaneously hypertensive rat. Prog pharmacol 5 , 40-49, 1984 . 
Stoddard-Apter SL, Stegel A, Leven BE. Plasma catecholamine and cardilovascular responses following hypothalamic stimulation in the awake cat. I Autonom Nerv Syst $8,343-360,1983$.

Takeda $K$, Bunag R. Sympathetic hyperactivity during hypothalamic stimulation in spontaneously hypertensive rats. I Clin Invest $62,642-648,1978$.

Timmermans PBMW and Van Zwleten P. Alpha -adrenoceptors: classification, localization, mechanisms, and targets for drugs. J Med Chem 25, 1389-1401, 1982. 
6. DIFFERENTIAL EFFECTS OF GENERAL ANESTHETICS ON REGIONAL VASOCONSTRICTOR RESPONSES IN THE RAT

\subsection{Introduction}

Although there is a tendency towards the use of unanesthetized animals most microvascular studies require general anesthetics to externalize tissues for microscopic abservations. It is well established that anesthetics interfere with cardiovascular reflexes like baroreflexes (Cox and Bagshaw, 1979) and chemoreflexes (Zimpfer et al, 1981). It has also been shown that anesthesia may affect the vasculature directly, thus influencing constriction or dilatation (Altura et al, 1980). In fact, urethane has been shown to interfere with alpha $2^{-}$ adrenoceptor mediated vasoconstriction (Armstrong et a1, 1982; Moore et al, 1984). These effects seem to depend upon interference of anesthetics with transmembrane calcium fluxes or mobilization of intracellular calcium (Altura et al, 1979; Altura et al, 1980; Magg. et al, 1984).

Effects on calciun metabolism may result in differential effects on vasoconstriction, depending upon the nature of the vasoconstrictor drug's cellular action as wel1 as possible regional differences in the body in the way vasoconstriction may be achieved. Therefore, in the present study the effects of an alpha ${ }_{1}$-adrenoceptor agonist (phenylephrine), a mixed alpha 1 - and alpha ${ }_{2}$-agonist (noradrenaline) and the non-adrenergilc vasoconstrictor agent anglotensin II on regional hemodynamics in conscious rats and in rats anesthetized with pentobarbital or an alpha-chloralose/urethane mixture were compared. These anesthetics or combination of anesthetics were chosen based on their frequent use in microvascular studies. The reglonal responses were studed since they reflect arteriolar alterations.

\subsection{Experimental protacol}

Rats, weighing 275-300 $\mathrm{g}$, were divided into 3 groups. Doppler 
Flow probes and catheters were implanted as described in chapter 2 .

In group I (7 animals), surgery was performed under pentobarbital (PB) anesthesla $(60 \mathrm{mg} / \mathrm{kg}$ 1.p.). Followlng surgery, animals were allowed 3-4 days to recover and they were used in the conscious state. In groups II and III, surgery was performed immediately prior to the experiments. In group II ( 8 animals), amesthesia was induced by slow infection of $30 \mathrm{mg} / \mathrm{kg}$ pencobarbital through a tail vein. In group III (10 andmals), alpha-chloralose and urethane (C-U; 1-13.3\%) were given in a dose of $3-4 \mathrm{ml} / \mathrm{kg}$ intraperitoneally. Prior to surgery, comparable anesthetic depth was evaluated by tail pinch. If necessary, additional anesthetic was given.

In groups II and III, the trachea of all animals was intubated to facilitate spontaneous breathing. Furthermore, a continuous infusilon of $0.9 \% \mathrm{NaCl}$ was given through the arterial catheter at a rate of $3 \mathrm{~m} 1 /$ hr to prevent dehydration (Maddox et al, 1977).

\subsubsection{Drugs}

No radrenaline-mitartrate, phenylephrine hydrochloride, angiotensin II, and alpha-chloralose were purchased from Sigma (St. Louis, Mo). All substances were dissolved in $0.9 \% \mathrm{NaCl}$ and solutions were freshly prepared imediately prior to the experiments.

Dose-response curves for noradrenaline $(0.1-3 \mu \mathrm{g} / \mathrm{kg})$, phenylephrine $(1-10 \mu \mathrm{g} / \mathrm{kg})$, and anglotensin II $(3-300 \mathrm{ng} / \mathrm{kg})$ were obtained In all animals. The order in which drugs were given as well as the doses were randomized.

After stabilization of hemodynanics, base-line values for mean arterial pressure (MAP), heart rate (HR) and flows were obtained as the means of 5 consecutive readings at 1 min intervals just before injections. Then, $i$. injections of vasopressor substances were given In a 50 , 1 volume. Between injections, $10-15$ min were allowed for recovery of hemodymamics.

Blood flows were obtained as KHz Doppler shift. Effects are presented as percentage changes from control values. Resistance changes In the vascular beds were calculated from changes in MAP and changes in respective Doppler shifts and are expressed as percentage changes. A maxinal tacrease of $500 \%$ for resistance was assumed if blood flow 
approached zero.

All data are presented as mean + SEM, unless indicated otherwise. Base-line values for MAP and $\mathrm{HR}$ in the 3 groups were compared with a one-way analysis of variance and a modified t-test (section 2.11). Dose-response curves were compared with one-way analysis of variance as described by Zerbe (section 2.11). Significance was defined at the $5 \%$ level.

\subsection{Results}

Base-line values for MAP and HR in the 3 experimental groups are sumarized in table 6.1. As compared to consclous rats, pentobarbital anesthetized rats had a reduced HR, whereas MAP was not significantly different from that in consclous rats. In contrast, in chloralose/urethane anesthetized rats, MAP was reduced, but HR was similar to that in conscious rats.

Table 6.1: Baseline values for mean arterial pressure and heart rate (** $\mathrm{p}<0.01 ; * * p<0.001)$.

$\begin{array}{lcll} & N & M A P & H R \\ \text { Conscious } & 7 & 101+4 & 358+15 \\ \text { G-U anesthetized } & 10 & 83 \pm 4 * * & 349+6 \\ \text { PB anesthetized } & 8 & 98+4 & 292+5 * * *\end{array}$

6.3.1 Effects of noradrenaline (NA) in consclous and anesthetized rats In all 3 groups of rats, NA Increased MAP dose-dependently (cf. $\mathrm{fig}$. 6. LA). The pressor response in $\mathrm{PB}$-anesthetized anfmals was greater than that in conscious animals $(p<0.01)$. C-U anesthesla did not significantly alter the pressor response. The reduction in HR that was observed following NA in conscious rats was significantly suppressed 


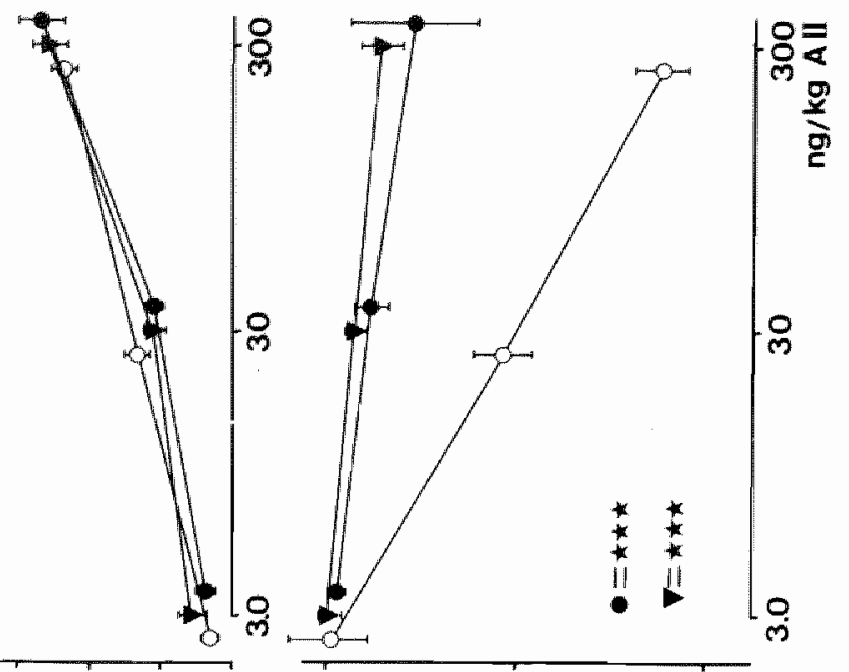

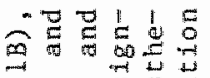
से 25

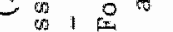
ge 至물 $=1 \overrightarrow{8}$ a $0=0$

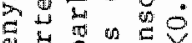

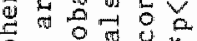

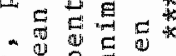

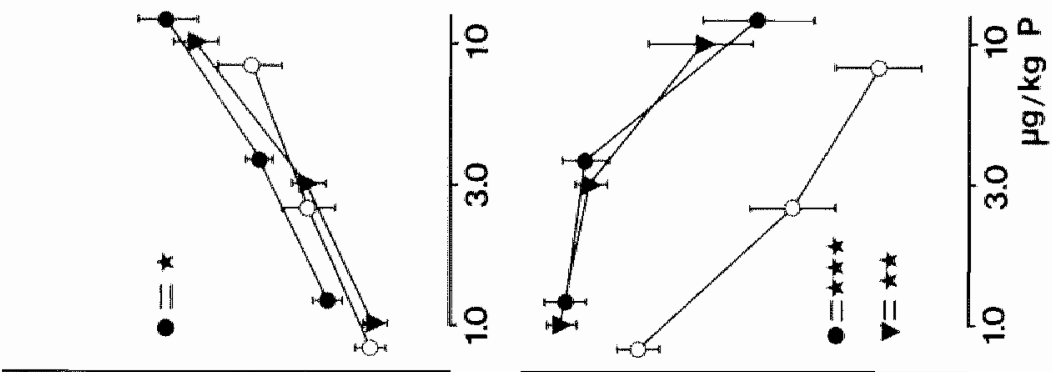

$0^{\frac{0}{9}}$ 更然。
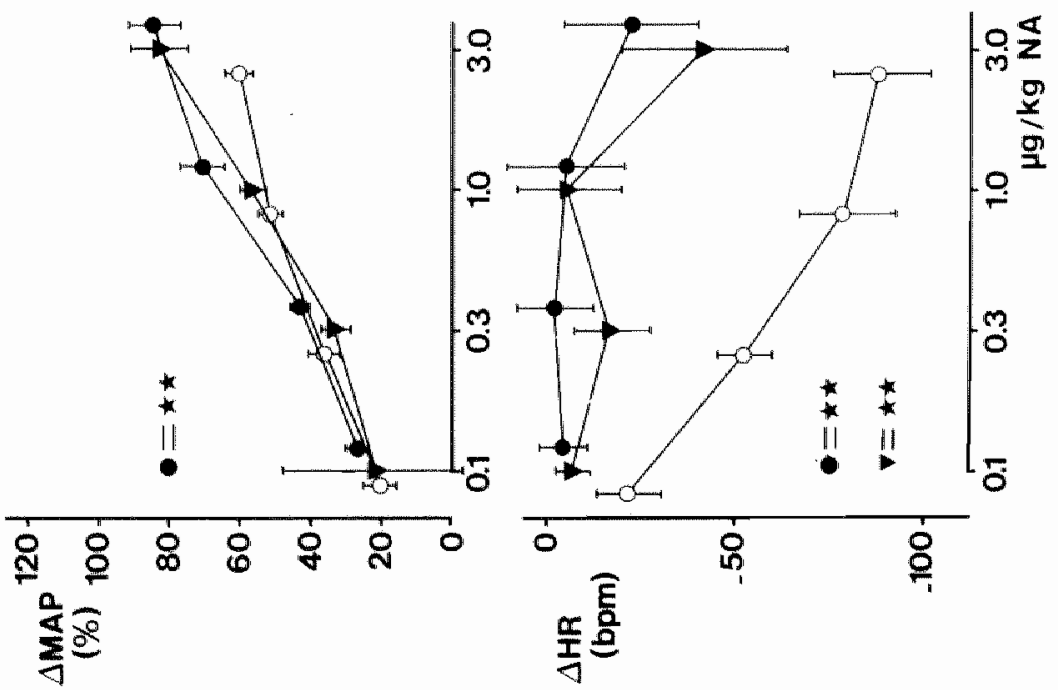
等区

ㄷํ워ํㅇ

स० 11 क

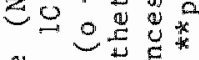
9 क क क

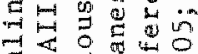
$\pi(-1)$ 可员包它

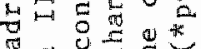

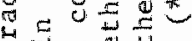
$30=0$ 足点出出 แ山 0 어

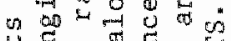

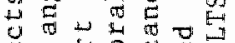
w a $\because$ $\dot{0}$ io 

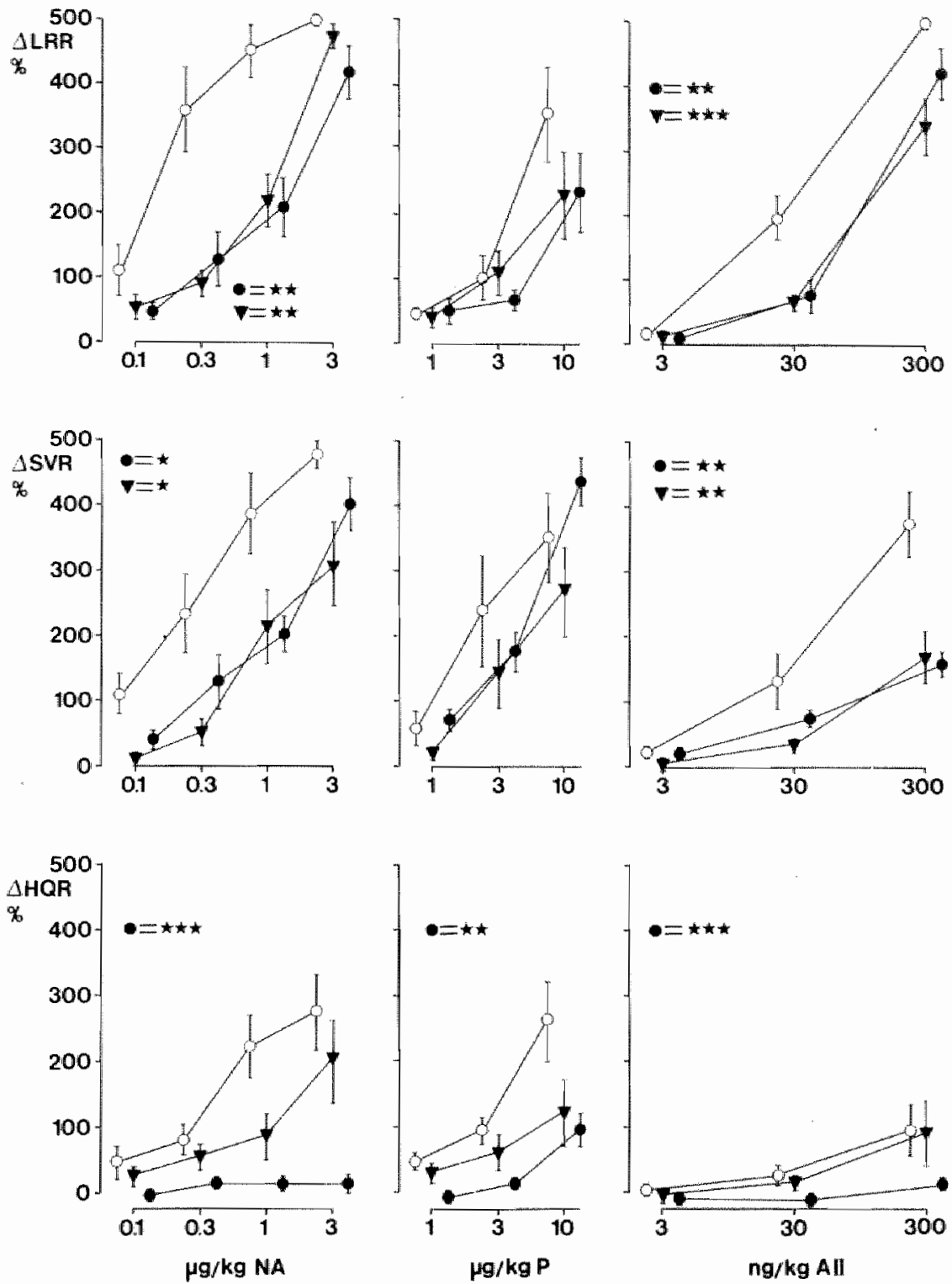

Fig. 6.2 Effects of noradrenaline (NA; $1 A$ ), phenylephrine (P; $1 B$ ), and angiotensin II (AII; LC) on left renal resistance (LRR), splanchnic vascular resistance (SVR) and hindquarter resistance (HQR) in conscious $(a-0)$, pentobarbital $(\bullet-\bullet)$, and chloralose-urethane anesthetized animals $(-)$. For significances of the differences between conscious and anesthetized anirdals (*p<0.05;**p<0.01; ***p<0.001), cf. section RESULTS. 
In both Ps-anesthetized $(p<0.01)$ and $c-0$ anesthetized animals ( $p<$ $0.01)$.

Effects of anesthetics on MA-induced changes in regional vascular resistanceg are sumarized in fig. $6.2 \mathrm{~A}$. In all 3 vascular beds, NA Increased vascular resistance dose-dependently. In the hindquarters, this effect was smaller than in the kidney and splanchnic vascuLar bed (cf * $\mathrm{f} 1 \mathrm{~g} \cdot 6.2 \mathrm{~A}$ ).

Pentobarbital caused a general reduction of the vascular responses. In all 3 groups, vasoconstriction was inhibited. In the hindquaters, this resulted in complete abolition of vasoconstriction.

C-U had a differential effect on Wh-induced vasoconstriction. Signiflcant depression of the dose-response curve was noted in the renal $(p<0.01)$ and splanchnic vascular beds $(p<0.05)$, whereas vasocomstriction in the hindquarters was affected insignificantly. Differences between $P B$ and $C-U$ anesthetized animals were significant ( $p<$ 0.05) only in the hindquarters.

6.3.2 Effects of phenylephrine (P) in conscious and anesthetized rats $P$ caused a dose-dependent increase in MAP in all 3 groups ( $f i g$. 6.1 B). The effect in $P B$-anesthetized animals was greater $(p<0.05)$ than that in conscious rats. HR was reduced in all groups, but anesthesia Inhibited this effect significantly (PB anesthesia: $p<0.001$; C-U anesthesia: $p(0.01)$.

Reglonal resistances increased dose-dependently in all 3 groups of animals (Cf. $\mathrm{Ag}$. 6.2B). Neither $P B$ nor $C-U$ significantly affected these vasoconstrictions, although there was a tendency towards a general depression.

6.3.3 Effects of anglotensin II (AII) in consclous and anesthetized rats

AII increased MAP dose-dependently and to a similar degree in al1 3 groups ot animals. As with the other vasopressor substances, HR decreased, but the bradycardla was significantly less in both $\mathrm{C}-\mathrm{U}-$ anesthetized $(p<0.001)$ and $P B$-anesthetized $(p<0.001)$ animals than in conscious animals (cf. fig. 6. $1 \mathrm{C}$ ).

In conscious animals, AII caused general vasoconstriction (cf. 
fig. 6.2C). The effect was least pronounced in the hindquarter vascular bed. PB anesthesia inhibited wasoconstriction in all 3 beds ( $p$ $0.01)$. In contrast, $C-U$ did not alter hindquarter vascular responsiveness, but did diminish the effects on renal ( $p<0.001$ ) and splanchnic $(\mathrm{p}<0.01)$ vascular resistances.

\subsection{Discussion}

In the present study, we compared the effects of 3 different vasoconstrictor substances on regional hemodynamics in conscious, $\mathrm{PB}$-anesthetized rats and $\mathrm{C}-\mathrm{U}$-anesthetized rats. Our cholce of vasoconstrictor agents was related to their different modes of cellular action. Thus, phenylephrine has predominantly alpha -adrenoceptor $^{-}$ action. Norepinephrine stimulates both alpha ${ }_{1}^{-}$and alpha, -adrenocepcors, whereas anglotensin II predominantly acts through stimulation of specific angiotensin receptors. The choice of anesthetics was based upon their frequent use in cardiovascular research. The particular ratio of alpha-chloralose and urethane in the mixture was chosen on the basis of a study in rats (Delano and Zweifach, 1981), comparing microvascular responsiveness under different anesthetic conditions. The ratio of $1: 13.3$ was proven there to cause least depression of the responsiveness.

Reports on the effects of pentobarbital and chloralose-urethane combinations on resting MAP and HR are conflictimg. Thus, PB has been reported to lower MAP (Smith and Hutchins, 1980; Linas et al, 1980; Walker et al, 1983; Kawaue and Iriuchijima, 1984) or not to change MAP (Lee et a1, 1985). Also chloralose-urethane combinations reduced (Smith and Hutchins, 1980) or did not affect MAP (DeLano and Zweifach, 1981). Effects on HR were similarly varlable. Differences seem to depend upon doses of anesthetics, strain differences and, in the case of $\mathrm{C}-\mathrm{U}$, the ratio of the anesthetics within the mixture. In the present study, we observed a lowering of MAP but not AR by $C-11$, and reduced HR and unchanged MAP following PB. The doses were chosen on the basis of comparable depth of anesthesia.

All 3 vasoconstrictor agents caused dose-dependent increases in 
MAP In conscious and anesthetized rats. PB tended to potentiate this response following noreplaephrine and phenylephrine. Possibly this results from depression of baroreflexes that tend to correct blood pressure increases. Such depression by general anesthetics has been described (Cox and Bagshaw, 1979) and is evidenced in the present study by diminution of reflex bradycardia. However, if this were the only mechanism inwolved in the potentiation of responses on MAP, it should be expected that effects of ald 3 vasoconstrictors were potentiated similarly by both anesthetics, because in all cases, there is comparable inhlbition of reflex bradycardia. The reason for the differences between the different agents is not understood, but may depiend upon venous actions.

Several studies have indicated that anesthetics influence vascular responsivenss to constrictor agents. In isolated rat aortae and portal veins, Altura and Weinberger (1979) found a decreased response to both adrenaline and angiotensin II following addition of urethane. In a study of isolated rabbit ear arteries, others also noted a reduction of noradrenaline-induced contractions by urethane (Maggi et al, 1984). Also, in microcirculatory studies of the cremaster muscle in rats, noradrenaline effects were inhibited by urethane (Miller and Wiegman, 1977). None of these studies did, however, address the possibility of regional differences in the effects. In one other study, vascular responses to hemorrhage during different types of anesthesia were studfed (Seyde et al, 1985). These authors noted that especially the increases in muscle vascular resistence rexe inhibited by the wse of elther $\mathrm{PB}$ or urethane as compared to conscious animals. Of course, a major difference between their study and ours is the fact that in our preparation we did not primarily reduce cardiac ontput and effects did not depend upon reflexes.

In the present study, vasoconstriction occurred in al1 3 vascular beds studied, following administration of noradrenaline, pheny1ephritue and anglotensin II $\mathbb{1 n}$ conscious rats. The magnitude of these responses dininished from renal > splanchnic > hindquarter. Thus, it would seem that the hindquarter vascular bed is a relatively passive bed, reacting to changes in MAP, which may be regared as autoregulatory responses. 
Responses to the vasoconstrictor agents were influenced differentially both with regard to the anesthetic and to the vascular bed. Responses to phenylephrine in all 3 beds were not altered significantly. Effects to NA as well as AII were significantly diminished in all 3 vascular beds by $P B$ anesthesia. And although $C-U$ had similar inhibitory effects in the kidney and splanchnic vascular bed, C-U did not significantly alter responses to noradrenaline and angiotensin II in the hindquarter vascular bed.

General anesthetics have been show to interfere with cellular calcium metabolism (review: Altura et al, 1980). Although both pentobarbital and urethane interfere with intra- as well as extracellular calcium related effects, the relative importance of the effects on the two mechanisms is unclear.

The cellular mechanlsus resulting in vasoconstriction following alpha $_{1}$-adrenoceptor, alpha ${ }_{2}$-adrenoceptor and anglotensin II receptor stimulation differ. Thus, the constrictor response to alpha ${ }_{1}$ stimulation predominantly depends upon a mobilization of intracellular calcium, whereas postsynaptic alpha 2 -adrenoceptor stimulation results in an influx of calcium into the cell (Van Meel et al, 1981). Angiotensin II-induced vasoconstriction depends upon facilitation of calcium influx and mobllization of intracellular calcium (Deth and van Breemen, 1977). On this basis, phenylephrine, being an alpha -adrenoceptor agonist, should be expected to behave differently from the mixed alpha ${ }_{1}$ and alpha ${ }_{2}$-agonist noradrenaline as well as angtotensin II. The latter two should behave similarly.

From the present study, where we found that the effects of alpha, ${ }^{-a d r e n o c e p t o r ~ s t i m u l a t i o n ~ a r e ~ n o t ~ a f f e c t e d ~ b y ~ a n e s t h e s i a, ~} 1$ would seem that, in general, effects on intracellular calcium mobllization are much less than on influx of extracellular calcium at the doses of anesthetics that we used. The two anesthetics had comparable effects on constrictor responses in all 3 beds with the exception of the hindquarters which predominantly reflects skeletal muscle blood flow. Although chloralose/urethane did not affect vasocongtriction in this region, pentobarbital completely abolished responses ta anglotensin II and noradrenaline. In a recent study, we have observed hindquarter vasodilatation as the only vasodilatory response to calclum- 
entry blockers in consclous nomotensive and hypertensive rats (Mievelstein et al, 1985). This suggests that, with regard to responses to calclun Influx, the auscular vacular bed behawes differently from the others. The reason for the difference between $P B$ and $C-U$ observed in the present study is not clear but may depend upon relative importance of the effects of pentobarbital and chloralose/urethane on the two calclun mechanisms. Possibly, pentobarbital has more pronounced effects on calcium-influx dependent vasoconstriction than chloraloseurethane.

In conclusion, the present study indicates that anesthetic doses of boch pentobarbital and chloralose/urethane differentially inhibit vasoconstrictor responses with regard to the nature of the constrictor agent. Furthermore, especially responses in the skeletal muscle vascular bed may depend upon the anesthetic used. This warrants further care in the interpretation of results from cardiovascular phamacological experiments in which anesthetics are used.

\subsection{List of references}

Altura BM, Weinberg J. Urethane and contraction of vascular smooth muscle. Br J Pharmacol 67, 255-263, 1979.

Altura BM, Altura BT, Carella A, Turlapaty PDMV, Weinberg J. Vascular smooth muscle and general anesthetics. Fed Proc 39, 1584-1591, 1980 .

Armstrong JM, Lefevre-Borg $F$, Scatton B, Cavero $I$. Urethane inhibits cardlowascular responses mediated by the stimulation of alpha-2 adrenoceptors in the rat. J Pharmacol Exp ther 223, 524-535, 1982 .

Cox RH, Bagshaw RJ. Influence of anesthesia on the response to carotid hypotension in dogs. An J Physiol 237, H424-H432, 1979.

Delano FA, Zweffach BW. Anesthesia and microvascular dynamics in spontaneously hypertensive rats. Am J Physiol 241, H821-H828, 1981 .

Deth R, Van Breemen C. Agonist-induced release of intracellular CA ${ }^{2+}$ In the rabbit aorta. I Membrane Blo1 30, 363-380, 1977 .

Kawaue $Y$, Irluchijtma $J$. Changes in cardiac output and peripheral rlows on pentobarbital anesthesia in the rat. Jpn J Physiol 34, $283-294,1984$.

Lee SS, Glrod C, Valla D, Geoffroy P, Lebrec D. Effects of pentobarbital sodium anesthesia on splanchnic hemodynamics of normal and porta1-hypertensive rats. Am J Physiol 249, G528- G532, 1985. 
Linas SL, Berl T, Aisenbrey GA, Better OS, Anderson RJ. The effect of anesthesia on hemodynamics and renal function in the rat. Pflagers Arch $384,135-141,1980$.

Maddox DA, Price DC, Rector FC. Effects of surgery on plasma wolume and salt and water excretion in rats. Am J Physiol 233, F600F606, 1977.

Maggi CA, Manzini S, Parlani M, Meli A. Analysis of the effects of urethane on cardiovascular responsiyenss to catecholaminesin terms of its interference with Catr mobilization from both intra- and extracellular pools. Experientia 40, 52-59, 1984.

Miller FN, Wiegman DL. Anesthesia-induced alteration of small vessel responses to norepinephrine. Eur J Pharmacol 44, 331-337, 1977 .

Moore ND, Chadelaud $M$, Huchet $A M$ et al. Urethane interferes al th the alpha, -agonist guanfacine. J Cardiovasc Pharmacol 6, 973-974, 1984.

Mievelstein HMNW, Wan Essen H, Tyssen CM, Smit JFM, Struyker Boudier HAJ. Systemic and regional hemodynamic actions of calctum entry blockers in conscious spontaneously hypertensive rats. Eur J Pharmacol. 113, 187-198, 1985.

Seyde WC, McGowan L, Lund $N$, Duling $B$, Longnecker DE. Effects of anesthetics on regional hemodynamics in normovolenlc and hemorrhaged rats. Am J Physiol 249, H164-H173, 1985.

Smith TL, Hutchins PM. Anesthetic effects on hemodynamics of spontam neously hypertensive and Wistar-kyoto rats. An J Physiol. 238, H539- $1544,1980$.

Smits JFM, Struyker Boudier HAJ. Systemic and regional hemodynamies following acute inhibition of angiotensin I converting enzyme in the conscious spontaneously hypertensive rat. Prog Pharmacol 5, $39-49, \mathbb{1} 984$.

Van Meel JCA, De Jonge A, Kalkmann HO, WLlffert B, Timmermans PBMWM, Vanzwieten PA. Organic and Inorganic calctum antagonists reduce vasoconstriction in vivo medlated by postsynaptic alpha2-adrenoceptors. Naunyn Schniedeberg's Arch Pharmacol 316, 288- 293, 1981.

Walker LA, Buscemi-Bergin M, Gellai M. Renal hemodynamics in conscious rats: effects of anesthesia, surgery, and recovery. Am J Physiol $245, F 67-F 74,1983$.

Wallenstein S, zucker CL, Fleiss JL. Some statistical methods useful in circulation research. Circ Res 47: 1-9, 1980.

zerbe Go. Randonization andysis of the completely randonlzed destgn extended to growth and response curves. I Am Statist Assoc 74, $215-222,1979$.

Zimpfer MS, Sit SP, Vatner SF. Effects of anesthesia on the canine carotid chemoreceptor reflex. Circ Res 48, 400-406, 1981 . 
7. IN-VIVO EFFECTS OF SYNTHETIC ATRIOPEPTIN II (APTI) ON MESENTERTC MICROVESSELS OF SHR

\section{1 Introduction}

Atrial natriuretic factors (ANE) are a group of small peptides that derive from the heart and which have pronounced natriuretic properties (DeBold et al, 1981; Maack et al, 1984; Needleman et a1, 1985; Balleman et al, 1986). Besides their renal effects, natural as well as synthetic ANF have also been shown to relax pre-contracted vascular smooth muscle from a variety of arteries in vitro (Atlas et al, 1984; Garcia et al, 1984; Misono et al, 1984; Winquist et al, 1984). In a previous study in spontaneously hypertensive rats (SHR), it was noted that infusions of the synthetic ANF atriopeptin II (APII) did not cause arterial vasodilation, but rather increased regional vascular resistances (Lappe et al, 1985). At the same time, cardiac output fell as a result of reduced cardiac fllling pressures. Since this reduction of filling pressures persisted after bilateral nephrectomy, a (weno)dilator action on capacitance vessels for APII in vivo was proposed (Smits et al, 1985).

Therefore, in the present study, we investigated vascular effects of APII in SHR by comparing effects of systemically and intraarterially applied APII both on the intestinal microvessels of the distal fleum and on mesenteric microvessels in vivo.

\subsection{Experimental protocol}

Rats (SHR), weighing between $330-370 \mathrm{~g}$, were prepared for intravital microscopy of the mesentery or intestinal microcirculation as described in section 2.7. Fig. 7.1 deplcts the general lay-out of the experiments. Catheters were tmplanted for measurement of mean arterial pressure (MAP) and heart rate (HR) and furthermore for systemic infusion of pentobarbital or atriopeptin II (APII). Surgical procedures were performed as described in detall in chapter 2 . A small catheter was implanted in a small side branch of the superior mesenteric artery 


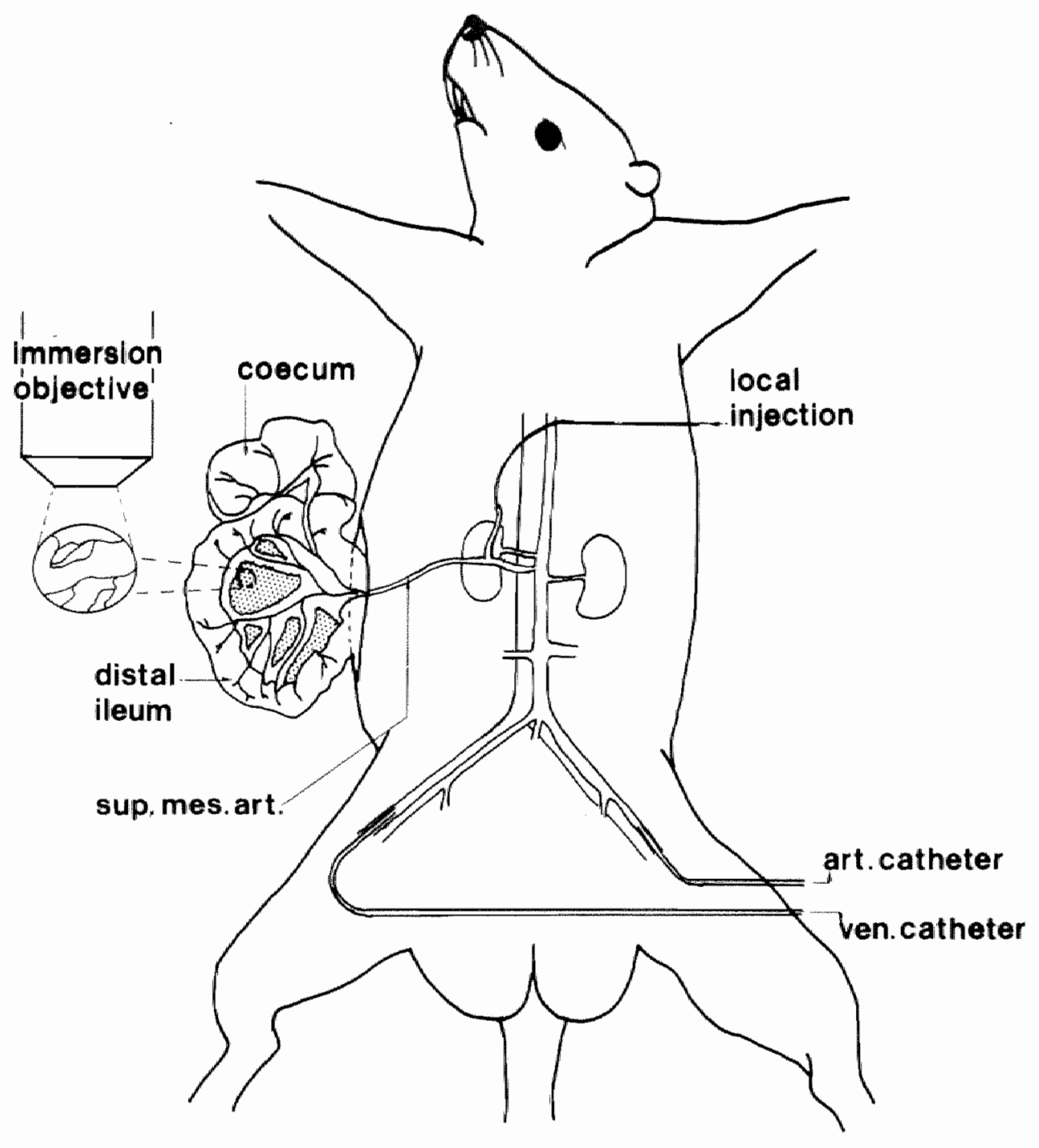

Fig. 7.1: General lay-out of the experimental set-up for the mesentery preparation. 
In a subset of experiments (section 2.4). The preparation was inspected at low magniflcation with a Leite long working distance objective (Leitz $4 \mathrm{x}$ ). Side-branches which directly branched off from the mean feeding and draining vessels of the llew were classlfied as second order vessels (A2 and V2, respectively). Second order vessels were video-documented with saltwater immersion objectives (SW 25 or SW 50).

Since the main vessels are surrounded by fat tissue which avoids proper (video) analysis of its side-branches, measurements were performed in the "empty" loops as clase as possible to their branching points.

Vessels of the intestinal microcirculation were video-documented with a Leitz $4 \mathrm{x}$ objective. Diameter and red blood cell velocity measurements ( $\mathrm{V}_{\mathrm{rbc}}$ ) were performed as explained in chapter 2.10 .1 and 2.10.2.

Blood pressure and heart rate were measured via the left femoral artery (see section 2.3) and systemic drug infusions were applied via a femoral vein (see section 2.4). Atriopeptin II (APII) was infused i. . while monitoring second-order microvessels in 8 animals. A control group of 6 rats was infused with saline.

Effects of intra-arterial (i.a.) infusions on second-order vessels were studied in 7 animals infused with APII and in 6 antmals Infused with sallne. In all these experiments, only one $A 2$ and one $V 2$ vessel were studied.

Al and VI vessel responses of the intestinal microcirculation were studied during 1 . I. Infusions of APII In 5 animals $614 \mathrm{Al}$ and 14 VI vessels), whereas effects of saline were studied in 4 andmals (9 Al and $9 \mathrm{vl}$ vessels).

For infusions a ramp-type protocol was used, similar to the one we used before (Lappe et al, 1985; Snits et al, 1985). Thus, after an equilibration period of 30-45 min, base-line measurements for all parameters were made. Infusions were started at the lowest infusion rate $(0.06 \mu g$ APII $/ \mathrm{kg} \cdot \mathrm{min}$ for $1 . \mathrm{al}$. infuslons or $0.25 \mu \mathrm{g}$ APII $/ \mathrm{kg} \cdot \mathrm{min}$ for i.v. infusions). Salime was infused in control andmals at an identical volume flow rate $(0.08 \mu 1 / \mathrm{min}$ respectively $0.2 \mu 1 / \mathrm{min})$. MAP and HR were recorded throughout the course of the experiment. After 15 
min, diameter and velocity measurements were made and the infusion rate was doubled. This procedure was repeated after $15 \mathrm{~min}$.

Al 1 data are expressed as mean \pm SE. Croups were compared using a oneway analysis of variance for unpaired observations (see chapter 2.11). Efects were considered statistically sigmificant if $p<0.05$.

\subsection{Rest1tes}

Base-line values for mean arterial pressure (MAP), heart rate (HR), vascular diameters and red blood cell velocities $\left(V_{r b c}\right)$ are summarized in table 7.1. MAP and HR did not differ significanty. Also, comparting the same order vessels, diameters and $\mathrm{V}_{\mathrm{rbc}} \mathrm{s}$ were similar in the groups.

\subsubsection{Effects of systemically infused APII}

Effects of saline and APII during $\mathbb{1} \cdot v$. Infusions are shown in fig. 7.2. Saline did not substantially affect MAP and HR. Vascular dianeters were also not affected. Effects on arteriolar $v_{r b c}$ were variable, resulting in a $16+16 \%$ increase during infusion of $0.8 \mathrm{pl} /$ $\mathrm{min}$.

ApTr caused a dose-dependent fall in MAP $(-41+5 \mathrm{~mm} \mathrm{Hg}$ during infusion of $1 \mu \mathrm{g} / \mathrm{kg} \cdot \mathrm{min})$. HR did not change statistically significantly. v rbc decreased both in A2 $(-3 \underline{3+1.0 \%)}$ and V2 vessels $(-34+8 \%)$. These decreaseg were significant as compared to the effects of saline $(p<$ $0.05)$. W2 diameter was not signiflcantly affected by APII. A2 dianteter decreased significantly ( $-12+5 \%$ during $1 \mu \mathrm{g} / \mathrm{kg}$. min; $\mathrm{p}<0.05)$.

\subsubsection{Effects of intra-arterially infused APII}

Effects of 1 .a. Infused saline and APII on MAP, HR and second-order vessels are sumarized in fig. 7.3. Again, saline did not have any gystenatic effects. APII reduced MAP only at the highest dose $(-32+9$ mom $\mathrm{Hg} ; \mathrm{p}(0.05)$, which corresponds to the lowest dose infused $1 . v$. The effects of this dose were not significantly different for the two routes. When given i.a., APII did not affect vascular diameters. However, as before both arteriolar and venular $V_{r b c}$ decreased $(-35+11 \%$ 


\section{$\triangle \operatorname{MAP}(\mathrm{mm} \mathrm{Hg})$}
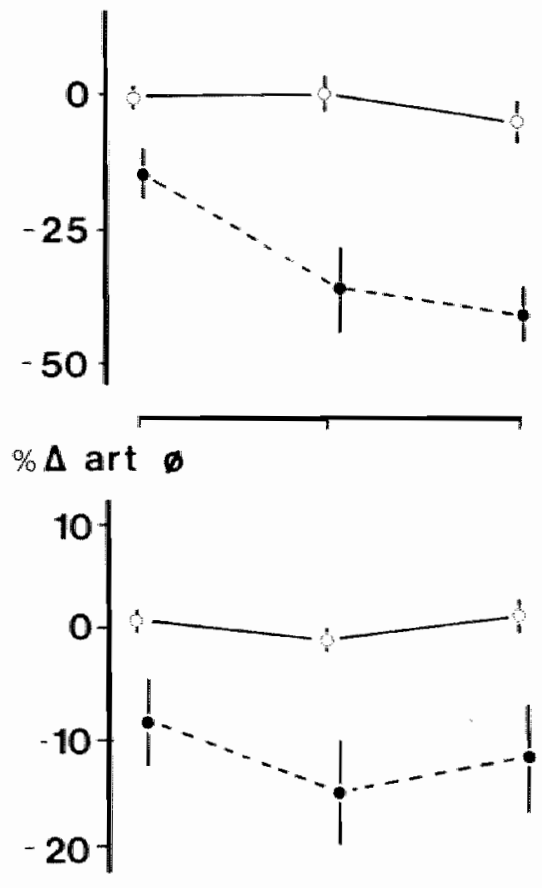

$\% \Delta \mathrm{V}_{\text {rbc }}$ art

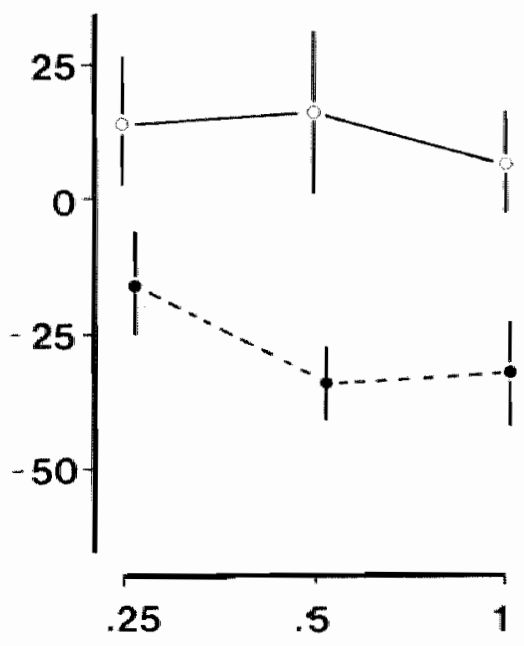

$\triangle H R(b p m)$

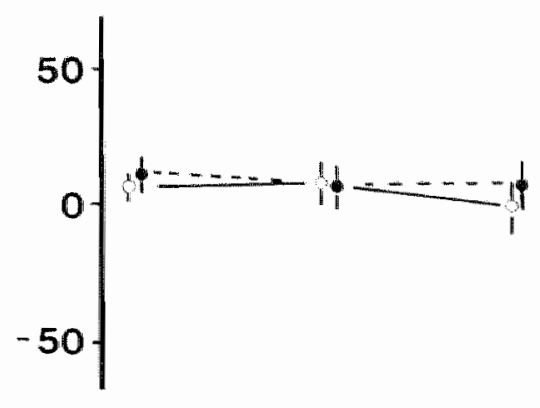

$\% \Delta$ ven $\emptyset$

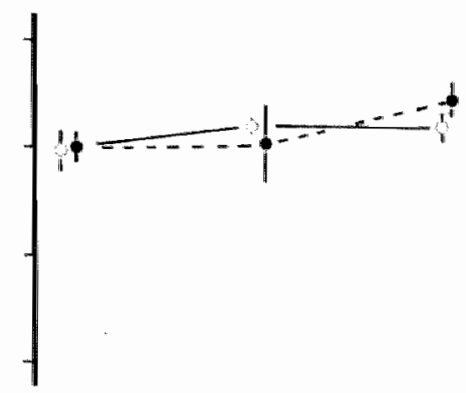

$\% \Delta v_{\text {rbc }}$ ven

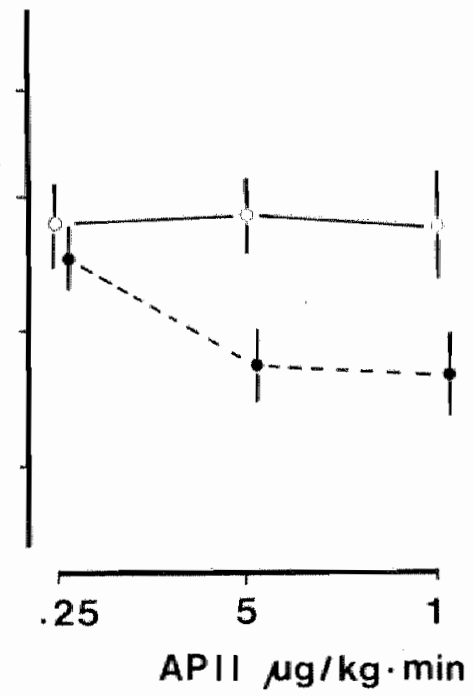

Fig. 7.2: Effects of saline (open symbols) and APII (closed syrabols) on MAP, HR, A2 diameter, W2 diameter, and red blood cell velocities in $A 2$ and $V 2$ vessels during intravenous infusions. Significance in the difference between sallne and APII infusions: * $p<0.05$. 

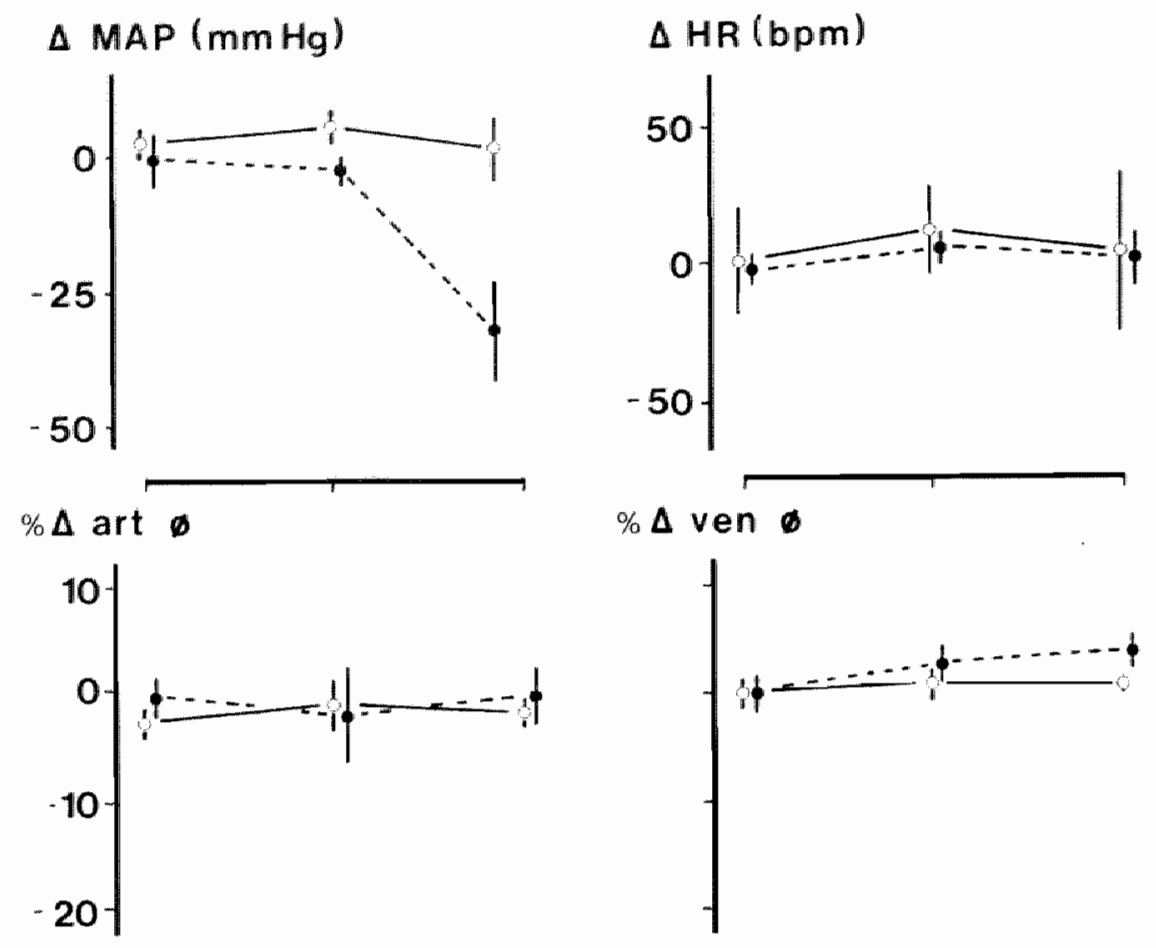

$\% \Delta \mathrm{V}_{\mathrm{rbc}}$ art
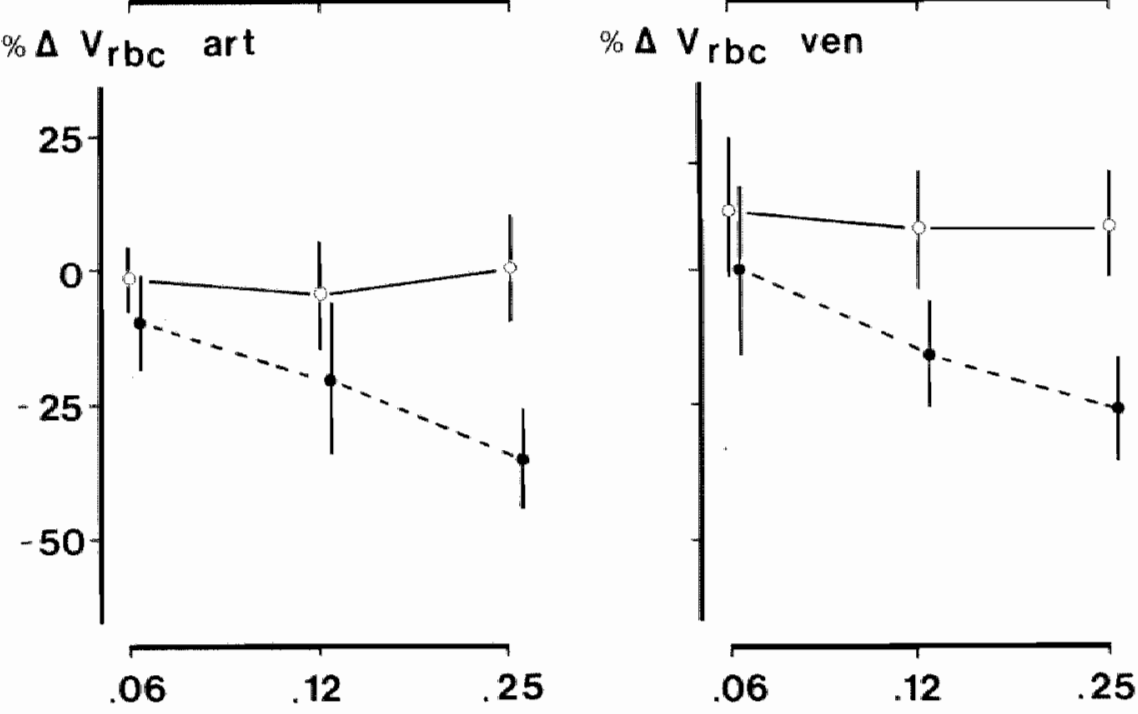

APII $\mu \mathrm{g} / \mathrm{kg} \cdot \min$

Fig. 7.3: Effects of saline (open symbols) and APII (cllosed symbols) on MAP, HR, A2 diameter, $\mathrm{V} 2$ diameter, and red blood cell veloctities in $A 2$ and $V 2$ vessels during intra-arterial infusions. Significance in the difference between saline and APIT infusions: * $p<0.05$. 

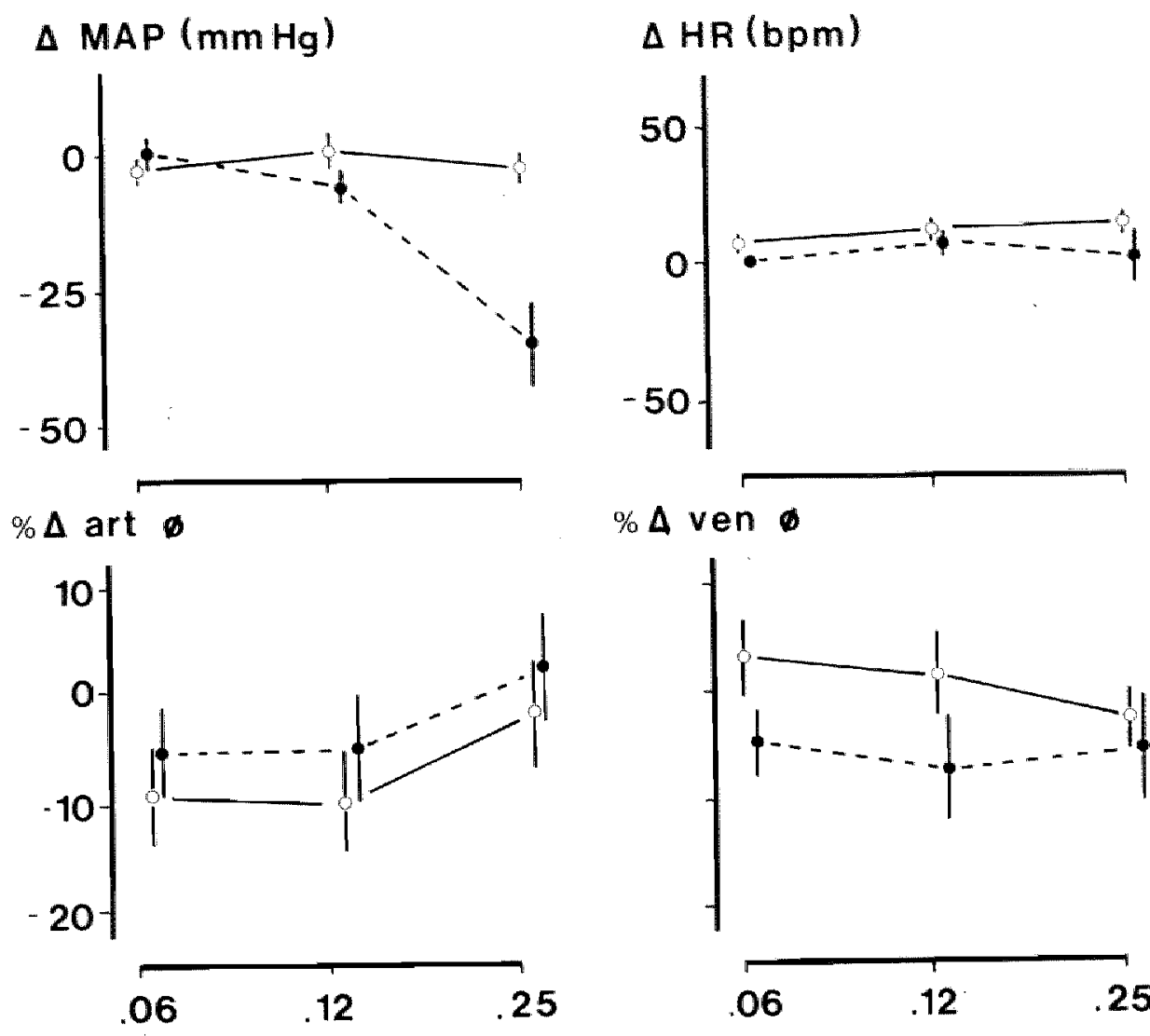

$\% \Delta$ ven 0

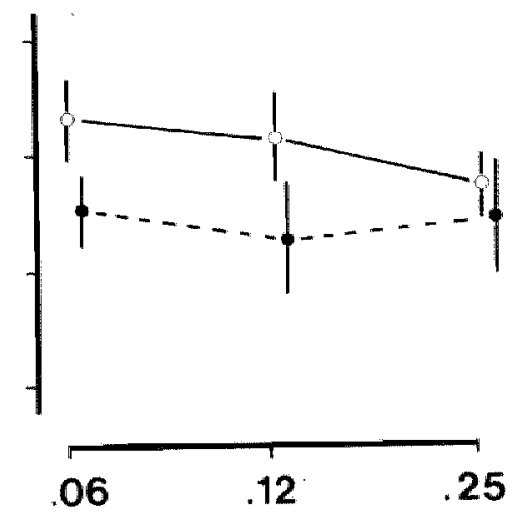

AP II $\mu \mathrm{g} / \mathrm{kg} \cdot \mathrm{min}$

Fig. 7.4: Effects of saline (open symbols) and APIL (closed symbols) on MAP, HR, Al diameter, and VI diameter during intra-arterial infusions. Significance in the difference between saline and APII infusions: * $\mathrm{p}<0.05$. 
and $-26+10 \%$, respectively, durlng $0.25 \mu \mathrm{g} / \mathrm{kg} \cdot \mathrm{min} ; \mathrm{p}<0.05$ as compared to saline). Effects on $V_{\text {rbe }}$ were again not significantly different at this dose, with regard to the route of administration.

Effects of $1 . a$. Infused APII and saline on MAP, HR and diameters of first-order arterioles and venules in the ilem of a separate group of antmals are summarized in fig. 7.4. Also in this group, APII decreased MAP only at the highest infused dose $(-34+8 \mathrm{~mm} \mathrm{Hg})$. Neither Al and VI. dlameters were significantly affected by $i \cdot a$. Infusions of APII.

Table 7.1. Start walues for the groups (mean + SEM).

\begin{tabular}{|c|c|c|c|c|c|c|}
\hline Group & $\begin{array}{l}\text { MAP } \\
(\mathrm{mm} \mathrm{Hg})\end{array}$ & $\begin{array}{l}\text { HRR } \\
\text { (bpm) }\end{array}$ & $\begin{array}{l}\text { art.diam. } \\
\text { (um) } \\
\text { A2 vessels }\end{array}$ & $\begin{array}{l}\text { ven.diam. } \\
\text { (yim) } \\
\text { v2 vessels }\end{array}$ & 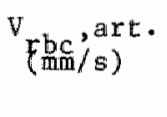 & $v_{(\mathrm{rbc} / \mathrm{b})}$, ven. \\
\hline $\begin{array}{l}\text { i. w. } \\
\text { saline }\end{array}$ & $1.77+2$ & $325+13$ & $26.7+3.5$ & $56.6+7.2$ & $8.7+1.9$ & $2.0+0.4$ \\
\hline $\begin{array}{l}\text { A. W* } \\
\text { APII }\end{array}$ & $165+6$ & $316+8$ & $21.8+3.4$ & $41.6+8.0$ & $8.5+2.7$ & $2.4+0.8$ \\
\hline $\begin{array}{l}\text { i.a. } \\
\text { saline }\end{array}$ & $161+6$ & $305+15$ & $19.7+2.9$ & $38.3+5.9$ & $7.6+1.6$ & $2.2+0.4$ \\
\hline $\begin{array}{l}\text { i.a. } \\
\text { APII }\end{array}$ & $152+7$ & $290+11$ & $28.7+1.5$ & $38.4+2.9$ & $8.2+1.7$ & $2.2+0.2$ \\
\hline
\end{tabular}
Al vessels VI vessels

1.a.

saline $\quad 168+7 \quad 310+7 \quad 69+2 \quad 138+7$

1.a.

APII

$160+5 \quad 290+11 \quad 68+4 \quad 132+9$ 


\subsection{Discusstion}

Although several investigatars have noted a vasodilator action of ANF in isollated, precontracted blood vessels (Atlas et all, 1984: Garcia et al, 1984; Mi sono et al, 1984; Winquist et al, 1984), we did not abserve vasodilation in intact, consclous SHR during infusions of the synthetic ANF APII, but rather vasoconstriction (Lappe et al, 1985). Reductions of cardiac filling pressures did, however, suggest a venodilator effect (Lappe et al, 1985; Smits et a1, 1985). The present study was designed to further characterize the effects of APII on the vasculature in vivo. We therefore studied the effects of both systemically and locally administered APII on the mesenterlc microcirculation of SHR.

During $\mathbb{1} \cdot v$. infusions of API, blood pressure fell. This effect was associated with a reduction of A2 diameter which parallelled the

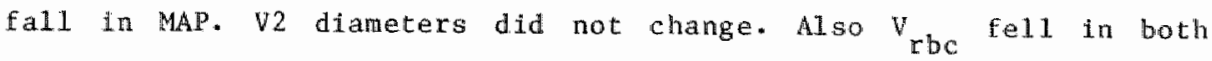
arterioles and venules, which ils in accordance with the previously found reduced splanchnic blood flow (Lappe et al, 1985).

In order to discriminate between direct and Indirect effects of APII, low-dose infusions were given directly into the supplying artery of the vessel beds under study $\mathbb{1 n}$ a second group of SHR. Here, we noted no effects on arteriolar ( $A 1$ and $A 2$ ) and venular (VI and V2) diameters. Vrbc was reduced only at the highest infusion rate, at which also blood pressure was reduced. These results suggest that the reduction of arteciolar diameter during infuston of APLI in the flrst part of the study does not result from a direct effect on the mesenteric vasculature. This is in accordance with a previous report, showing a lack of effect of ANF on isolated mesenteric microvesgels in vitro (Aalkjaer et al, 1985). Arterioles in that study were 5-10 times larger in dlameter $(200 \mu m)$ than the ones we studied here.

Most likely arteriolar constriction during 1 . W. Infusion of API I results from reflex effects. In a prevlous study, Lappe and co-workers (1985) showed that in consciaus SHR chemical sympathectomy prevents the vasoconstrictor responses to APII in the mesenteric circulation. Possibiy, the sympathetic nervous system also medlated vasoconstriction in our study, although primary cardiovascular reflexes like the 
sinoartfic baroreflex should be expected to be damped in our anesthetized preparation (Cox and Bagshat, 1979). We did not further pursue this.

At the higheat local infuston rate, corresponding to the lowest glven intravenously, we did not observe vasoconstriction, although MAP and $r$ bc were reduced signiflcantly. In fact, blood pressure was reduced by $35 \mathrm{~mm} \mathrm{Hg}$. During $1 . \mathrm{W}$. Infusions, similar reductions in MAP were assoclated with $10-15 \%$ reductions of A2 diameter. This suggests that the high APII Levels achleved locally in the mesenteric circulation were capable of antagonizing the expected reflex vasoconstriction in a way comparable to the effect of ANF noted on precontracted vessels (Atlas et al, 1984; Garcla et al, 1984; Misono et a1, 1984; Wirquist et al, 1984 ).

We have previously shown that the blood pressure reduction during infusion of APIL in SHR depends upon a fall in cardlac output which 1s, in turn, associated with reduced central venous and left atrial pressures (luappe et al, 1985). Since this latter effect perslsted after bilateral nephrectomy, we suggested a venodilator action of APII in SHR (Smits et al, 1985). In the present study, we did not observe an actual dilation of venules. This may suggest that dilation occurs only in larger capacitance vessels, or in beds other than the splanchnic circulation. Alternatively, the reduction of cardiac filling pressures may depend upon a reduction of blood volume through a route that does not depend upon diuresis. In this regard, it has recently been suggested that ANF may cause a shift of water from the intravascular space to the extravascular space through increased capl11ary flltration (Trippodo et al, 1986). Data in the present study do, however, not corroborate this suggestion. The $10-15 \%$ reduction of arteriolar diameter results in a 40-60\% increase of (precapillary) arteriolar resistance, assuming a cubic dependence of resistance on microvascular diameter (Mayrovitz and Roy, 1983). The lack of wenular diameter change would suggest a decrease in capillary pressure during i.v. infusion of API, espectally since flow fell at the same time.

Thus, although the present data do not allow a definite conclusion on the effect of ANF on capillary filtration, they do suggest that the hydraulic situation is in favor of a decrease, rather than an 
increase of capillary filtration. Possibly, however, ANF may increase vascular permeability. In the next chapter the effect of ANF on microvascular permeablitity will be investigated.

In conclusion, the present study indicates that API has no direct effect on ileum and mesenteric microvascular diameters in SHR in vivo. He did not obtain direct evidence for venous dilatation. The results suggest that the hydraulic conditions in the vascular bed between $A 2$ and $V 2$ vessels are not in favor of increased capillary filtration *

\section{5 References}

Aalkjaer C, Mulvany MJ, Nyborg MCB. Atrial natriuretic factor causes specific relaxation of rat renal arcuate arteries. Br J Pharmacol $86,447-453,1985$.

Atlas SA, Kleinert HD, Camargo MJ, Januszewicz $A$, Sealey JE, Laragh JH, Schilling JW, Lewicki JA, Johnson LK, Maack T. Purffication, sequencing and synthesis of natriuretic and vasoactive rat atrial peptide. Nature (Lond.) $309,717-719,1984$.

Ballerman BJ, Brenner BM. Role of atrial peptides in body fluid homeostasis. Circ Res 58, 619-630, 1986.

Bohlen $H G$. Intestinal microvascular adaption during maturation of spontaneously hypertensive rats. Hypertension $5,739-745,1983$.

Cox RM, Bagshaw R.J. Influence of anesthesia on the response to carotid hypotension in dogs. Am J Physiol 237, H424-H432, 1979.

DeBold AJ, Borenstein MB, Veress AT, Sonnenberg H. A rapid and potent natriuretic response to intravenous injection of atrial myocardial extracts in rats. Life Sc1 $28,89-94,1981$.

Garcia $R$, Thibault $G$, Lantin $M$, Genest J. Effect of purffled atrial natriuretic factor on rat and rabbt vascular strips and vascular beds. Am $J$ Physiol 247, R34-R39, 1984.

Henrich $H$, Hertel $R$, Assmann $\mathbb{R}$. Structural differences in the mesentery microcirculation between normotensive and spontaneously hypertensive rats. Pfligers Arch. 375, 153-1.59, 1978.

Lappe RW, Smits JFM, Todt JA, Debets JJM and Wendt RL. Fallure of atriopeptin II to cause arterlal vasodilation in the conscious rat. Circ Res 56, 606-612, 1985.

Lappe RW, Todt JA, and Wendt RL. Mechanlsm of action of vasoconstrictor responses to atriopeptin II in conscious SHR. Am J Physiol $249, \quad R 781-R 786,1985$.

Maack T, Marion DN, Camargo MJF, Klelnert HD, Laragh JH, Vaughan $\mathbb{E D}$ and Atlas SA. Effects of auriculin (atrial natriuretic factor) on blood pressure, renal function, and the renin-aldosterone system in dogs. A J Med 77, 1069-1075, 1984.

Mayrovitz HN and Roy J. Microvascular blood flow: Evidence indicating 
a cubic dependence on arteriolar diameter. Am $J$ Physiol 245, H103L-11038, 1983.

Milsono KS, Fukumi $M$, Gramer RT and Inagami $T$. Rat atrial natriuretic factor: complete amino acid sequence and disulfide linkage essential for biological activity. Biochem Biophys Res Comm 119 , $524-536,1984$.

Needleman P, Adams SP, Cole BR, Currie MG, Geller DM, Milchwener ML, Saper CB, Schwartz D, and Standaert DG. Atrlopeptins as cardiaC hormones. Hypertension 7, 469-482, 1985.

Smits JFM, Debets JJM, van Essen $H$, and Lappe $\mathbb{R} W$. Acute reduction of cardiac filling pressures by atriopeptin II in conscious SHR. Naunym Schniedeberg's Arch Pharmacol 329 (supp1), 253, 1985.

Trippodo NC, Chien AT, Pegram BL, Colle FE, MacPhee AA, and Kardon DS. Atrial natriuretic peptide decreases blood volume in intact and anephric rats. Fed Proc 45, 754, 1986.

Winquist RJ, Faison EP, and Nutt RF. Vasodilator profille of synthetic atrial natriuretic factor. Eur J Pharmacol 102, 169-173, 1984. 
8. EVALUATION OF MACROMOLEGULAR LEAKAGE AS A POSS IBLE MECHANISM FOR THE BLOOD PRESSURE LOWERING EFFECT OF ATRIAL NATRIURETIC PEPTTDE $(102-126 \mathrm{hANF})$

\subsection{Introduction}

The physiological role and mechanism of atrial natriuretic peptides (ANF) in cardiovascular homeostasis are poorly understood. Most studies agree on the blood pressure lowering effect being partly explained by its potent diuretic and natriuretic activity.

The (extrarenal) vascular effects are controversial. A decrease in total peripheral resistance occurs as a consequence of arteriolar dilation. The hypotensive effect of ANF, which has been observed in a variety of hypertensive models, has been assumed to be related to a vasorelaxant effect in vitro (Atlas et al, 1984; Garcia et al, 1984; Needleman et al, 1985; Thompson and Webb, 1986). However, based on in-wivo studies (Lappe et all, 1985; Volpe et al, 1986; Pegram et al, 1986) as well as on the data presented in the previous chapter obtained from microvascular studies, it seems unlikely that arteriolar dilation occurs. The arterioles are not the primary site of action of ANF. Rather the hypotensive effect is associated with an enhanced arteriolar constriction and an increase in total peripheral resistance (Lappe et a1, 1985, 1986; Criscione et al, 1987). Blood pressure is reduced through reduced cardiac filling pressures and, consequently reduced cardiac output. The fall in venous pressure durling continuous infusions of ANF could not be explained by a venous dilation (chapter 7). Both mesenteric as well as Intestinal wenules showed constant diameters, while cardiac filling pressures and thus cardiac output decreased.

- Alternatively, decreased filling pressures may result from a dem creased circulating blood volume as a consequence of an enhanced sodium and fluid excretion by the kidneys or by fluid shift toward the interstitium. Even in bilaterally nephrectomized rats ANF decreases cardiac filling pressures and blood pressure (smits et al, 1985) which indicates that the renal action is not a prerequisite for the blood 
pressure decrease.

From human and animal experiments, it has been suggested that Infugions of very low doses of ANE increase the hematocrit (DeBold et a1, 1981; Biollaz et a1, 1986; Flticklger et a1, 1986), although others could not confirm this (Lappe et al, 1985). An increase in hematocrit In humans was noticed before the onset of urinary losses of fluid and electrolytes (Blollaz et al, 1986). The hypotension was attributed to an increased capillary permeability with fluid shifts. This was also suggested by others in the renovascular hypertensive model. (Flückiger et al, 1986). Possible other sites of action of $A N F$ besides renal have to be included. Experimental evidence suggests that ANF may regulate water and lon transport in tissues such as the intestines, clliary bodtes and choroid plexus (rewiew, see Cantin and Genest, 1985).

The present study focusses on the role of ANF on local fluid transport and homeostasis within the rat mesentery microcirculation. AMF was continuously infused to assess whether the blood pressure decrease was associated with a simultaneous extravascular appearance of fluorescent macromolecules as an indicator of increased microvascular permeability. In addition, microvascular diameters and red blood cell velocity were measured to determine vascular responses.

\subsection{Experimental protocol}

\subsubsection{Antmals}

Wistar rats, welghing between $300-375 \mathrm{~g}$, were anesthetized with sodfum pentobarbital and catheters inserted to measure mean arterial bllood pressure (MAP) and heart rate (HR) (see section 2.2 and 2.3, respectively).

The left femoral vein was used for a continuous infusion of sodifum pentobarbital (see section 2.2). Depending on the experimental protacol, ANF was either applied systemically via the right femoral veln (section 2.4.1) or locally via a small side-branch of the superior mesenteric artery (see section 2.4.2). 


\subsection{Intravital microscopy}

Rats were prepared for intavital microscopic observation of the mesentery microcirculation (section 2.7.1). Vessels were classifled according to their hierarchical branching patterns. The centripetal mode of classification allowed for a functional description of the microvasculature. The arteriole which branches off perpendicular to the feeding vessel of the intestine was classified as second order (A2). Third and fourth order side-branches were classiffed as A3 and A4 vessel respectively. The same nomenclature was used on the venous side of the circulation. Venules were classified as V2, V3 and V4, respectively. Arterioles and venules were studied using transillunination (see section 2.9.1 and 2.10.1) and observed with a SW50 objective.

Velocity measurements were only performed in $\mathrm{A} 2$ and $V 2$ vessels (see section 2.10 .2 ). It was found that in a typical preparation these vessels suppply and drain one vascular bed and velocity measurements thus reflect total microvascular blood flow.

In a separate series of experiments , microvascular permeability was studied using fluorescence microscopy (see section 2.9.1).

FTTC-BSA (F1uorescein isothiocyanate, bovine serum albumin, Sigma, St. Louis, MO, USA) was infused intravenously (i.v.) within 3-5 min at a dose of $200 \mathrm{mg} / \mathrm{kg}$. FITC-BSA was dissolved in $0.5 \mathrm{ml}$ physiological saline $(0.9 \% \mathrm{NaCl})$. The 1 uninescent vessels were observed with a Le1tz $4 \mathrm{x}$ objective and video-documented as explained in section 2.9.1. Within one fleld of view on the video monttor, large areas of the vascular bed could be montored (arterloles, captliarles and venules). Only areas were selected with no sign of spontaneous leakage. In case 1 ymph vessels were present within the mesentery microctrculation these were video-documented as we11. The microvascular permeability could be assessed by counting the number of leaky spots following drug infusion. The experimental protocol was al ways ended by superfusion with histame (1.0 $\mu \mathrm{g} / \mathrm{ml})$ to determine the ability of the preparation for protein leakage (De Clerck et al, 1985). Microvascular leakage of macromolecules was studied following systemically administered 102-126 hANF while in the control group saline was infused. 


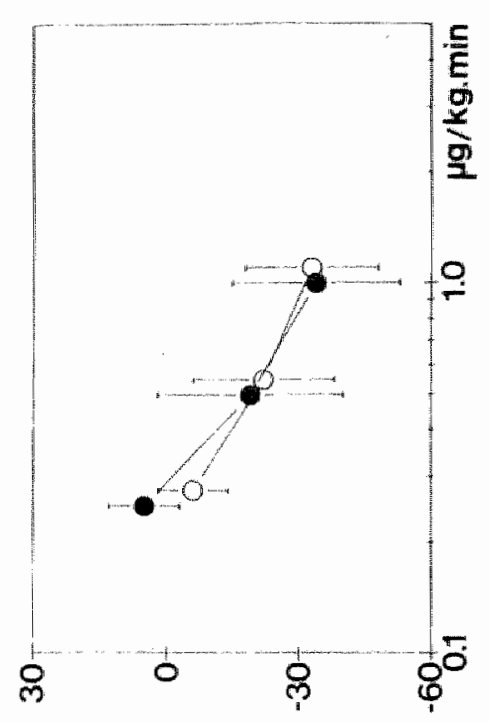

(wdq) $\mathbf{U H}^{\mathrm{F}}$

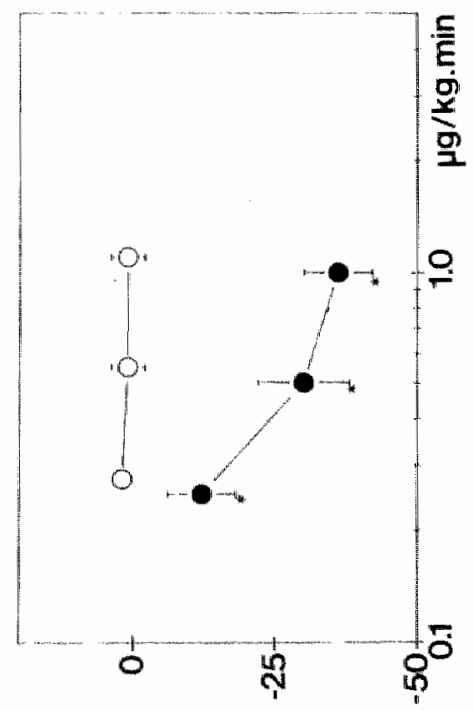

(6Hum) d $d W^{5}$
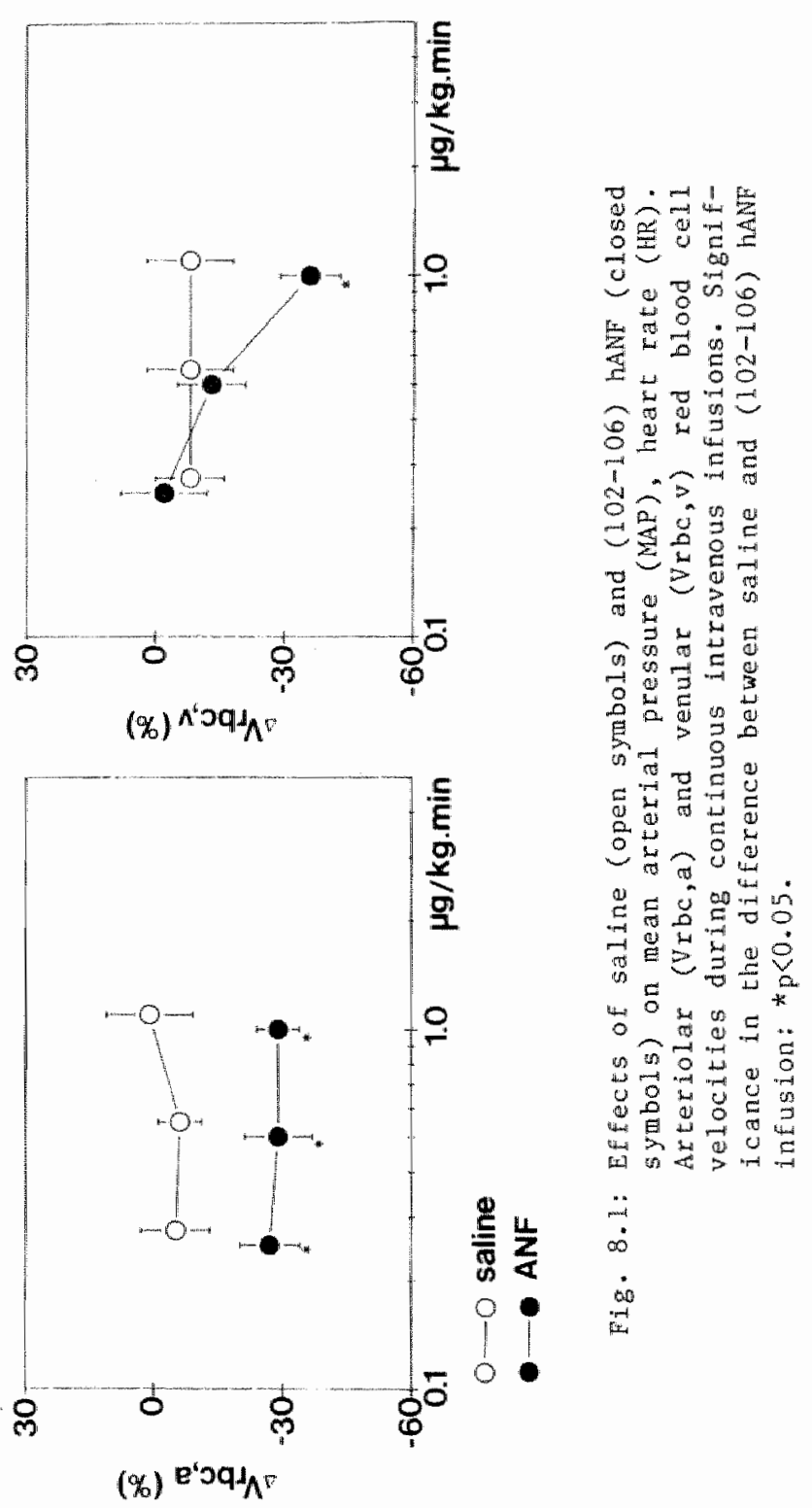

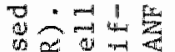
$0 \pm 2 E$ $\checkmark$ o in 0 \& 8

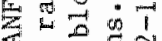
द. 50 $\pm 0 \rightarrow$ $6 \pi 0$ D出 $\mathrm{C} \mathrm{a}^{\mathrm{s}}$ की 0 is

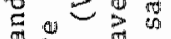

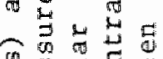
(i) 욜

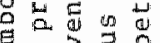
$\rightarrow \rightarrow 0$ in $\rightarrow$ แ Q D $ᄃ$ U

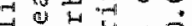
$\pi_{0} \cong$ 4 5 * 0 - $\quad 5 \ldots$ का को क्षे a 0 ०

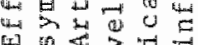




\subsubsection{Drug dosage}

ANF (102-106 hANF; WY 47.663) was infused $1 . v$. In 7 rats in a doge of $0.25-0.5-1.0 \mu \mathrm{g} / \mathrm{kg} / \mathrm{min}$. In 8 rats only the vehicle solution (saline) was infused $\mathbf{i} . y$. as control. Local intra-arterial infusion of ANF was performed in 7 rats and an equal number of rats received saline as control "For local drug delivery, a lower dosage was used $(0.0625-0.125-0.25 \mu \mathrm{g} / \mathrm{kg} / \mathrm{min})$.

gor infusions, a ramp-type protocol was used (Lappe et al, 1985). Baseline micro- (diameter, $V_{r b c}$ ) and macro hemodynamic parameters (MAP, HR) were determined during a 5 -min period.

Increasing doses of ANF or vehicle solution (saline) were infused. The doses were increased at 15-min intervals. Changes in the hemodynamic parameters were recorded at each dose 1 evel after a steady-state condition was achieved (15-20 min). Measurements were completed within 5 min.

Protein extravasation during infusion of ANF was studied in 8 rats and only the lowest and highest $i . v$. dosages were used. In 6 rats saline was infused systemically. These animals served as a reference group.

Al1 data are expressed as mean \pm SEM. Statistical analysis of the data was carried out, using one-way analysis of variance with repeated measures.

\subsection{Results}

Baseline values for mean arterial pressure (MAP), heart rate (HR), and vascular diameters and red blood cell velocity ( $\mathrm{rbc}_{\mathrm{rb}}$ ) are summarized for each subset of experfments in table 8.1 .

\subsubsection{Effects of systemically infused ANF}

Effects of saline and ANF during $i \cdot v$. Infusion are presented in figure 8.1 and 8.2 . Sallne infusion did not affect vascular diameters or $V_{r b c}$. During the course of the experiment, MAP remained constant while HR decreased slightly. ANF caused a dose-dependent fall in MAP. $\mathrm{V}_{\mathrm{rbc}}$ decreased both $\mathrm{ith} A 2$ and $\mathrm{V} 2$ vessels. 
Table 8.1: Base-1ine values for mean arterial pressure (MP), heart rate (HR), and vascular diameters and red blood cell velocity $\left(\mathrm{rbc}_{\mathrm{rb}}\right)$.

$\begin{array}{llll}\begin{array}{l}\text { 1.v. } \\ \text { saline }\end{array} & \text { i.v. } & \text { i.a. } & \text { i.a. } \\ \text { saline } & \text { ANF } \\ \text { start } & N \text { start } & \text { N start } \\ \text { value } & \text { value } & \text { value } & \text { start } \\ \text { value }\end{array}$

\begin{tabular}{|c|c|c|c|c|c|c|c|c|}
\hline $\mathrm{MP}(\mathrm{mm} \mathrm{Hg})$ & 8 & $119+5$ & 7 & $123+7$ & 7 & $112 \pm 7$ & 7 & $129+9$ \\
\hline $\mathrm{HR}$ (bpm) & 8 & $305+13$ & 7 & $298+14$ & 7 & $303+12$ & 7 & $323+20$ \\
\hline$V_{r b c, a}(\mathrm{~mm} / \mathrm{s})$ & 7 & $3.8+0.5$ & 6 & $4 \cdot 6+1.0$ & 7 & $8.3+2.1$ & 7 & $6.6+2.5$ \\
\hline$v_{\mathrm{rbc}, \mathrm{v}}(\mathrm{mm} / \mathrm{s})$ & 7 & $1.7 \pm 0.3$ & 6 & $3.3+0.9$ & 7 & $3.0+0.7$ & 7 & $2.2+0.8$ \\
\hline$\phi \mathrm{A} 2$ ( & 8 & $25.2+2.9$ & 6 & $24.4 \pm 3.4$ & 7 & $27.0+3.3$ & 7 & $30.4+4.5$ \\
\hline$\phi A 3$ ( & 9 & $13.8+1.3$ & 6 & $12.2+3.7$ & 10 & $14.0+0.9$ & 8 & $13.0+1.6$ \\
\hline$\emptyset \mathrm{A} 4$ (um) & 9 & $9.4+0.8$ & 5 & $8.2+0.6$ & 7 & $9.6 \pm 0.7$ & 5 & $9.3+1.6$ \\
\hline$\emptyset \vee 2 \quad(\mu \mathrm{m})$ & 9 & $46.0 \pm 8.1$ & 6 & $46.1+5.6$ & 7 & $45.3+6.6$ & 6 & $46.6 \pm 7.5$ \\
\hline$\emptyset$ v 3 (gum) & 9 & $18.7+3.5$ & 5 & $20 \cdot 5+4 \cdot 1$ & 9 & $19.9+3.3$ & 8 & $24.0+3.9$ \\
\hline $6 V_{4}(\mu \mathrm{m})$ & 8 & $10.8+1.8$ & 5 & $11.8+1.9$ & 7 & $12.3+1.9$ & 6 & $16.0+3.2$ \\
\hline
\end{tabular}

Systemic infusion of ANF did not affect HR. During 1.V. infusion of ANF arteriolar diameters decreased. The most profound decrease was seen in the larger arterloles (A2 and A3). Differences were statistically signiflcant for both arteriolarorder categorles only for the highest dosages. Venular diameters remalned constant durlng i.v. ANF infuston. This was observed for all vessel arder levels.

\subsubsection{Effects of intra-arterially infused ANF}

Effects of $1 . a$. Infused ANE and vehicle solution on MAP, HR and arterioles and venules are presented in figure 8.3. and 8.4. Although ANF was infused at lower dosages, MAP decreased in a dose-dependent manner. HR was not affected. Local infusion of ANF resulted in a maximal decrease of approximately $50 \%$ of arteriolar and venular $v_{\mathrm{rbc}}$ at 


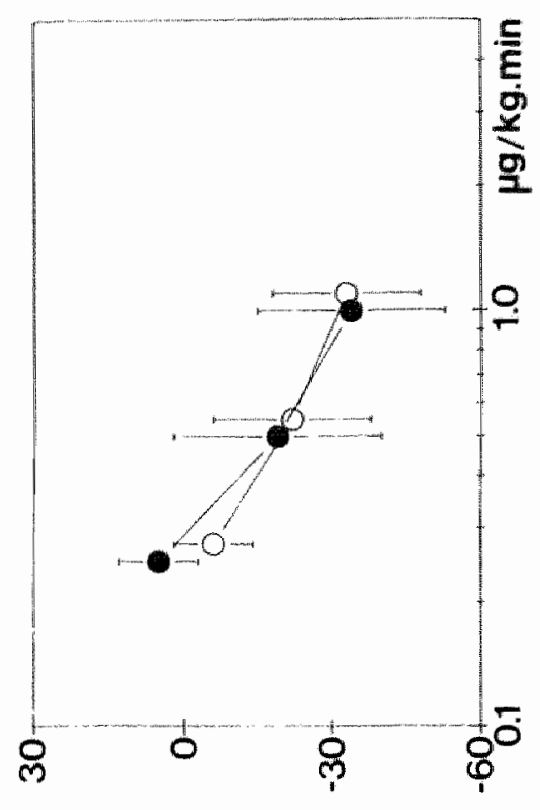

(udq) $\mathbf{y H}^{\circ}$

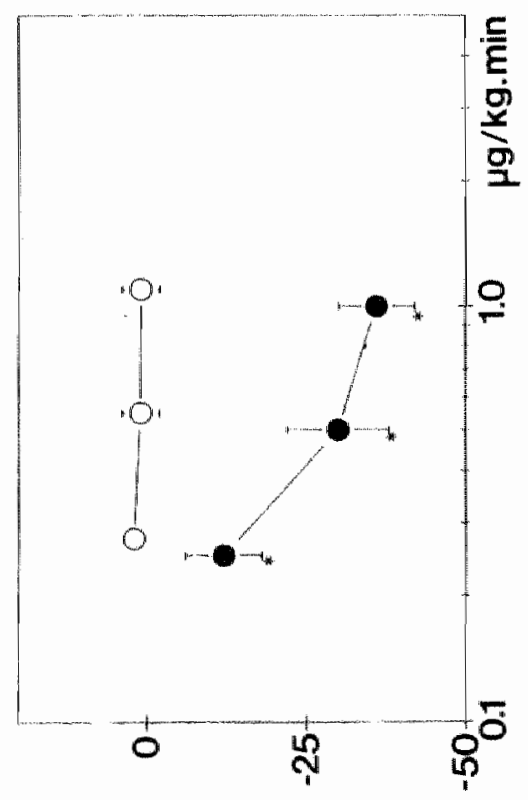

(6Hum) d $d W^{\circ}$
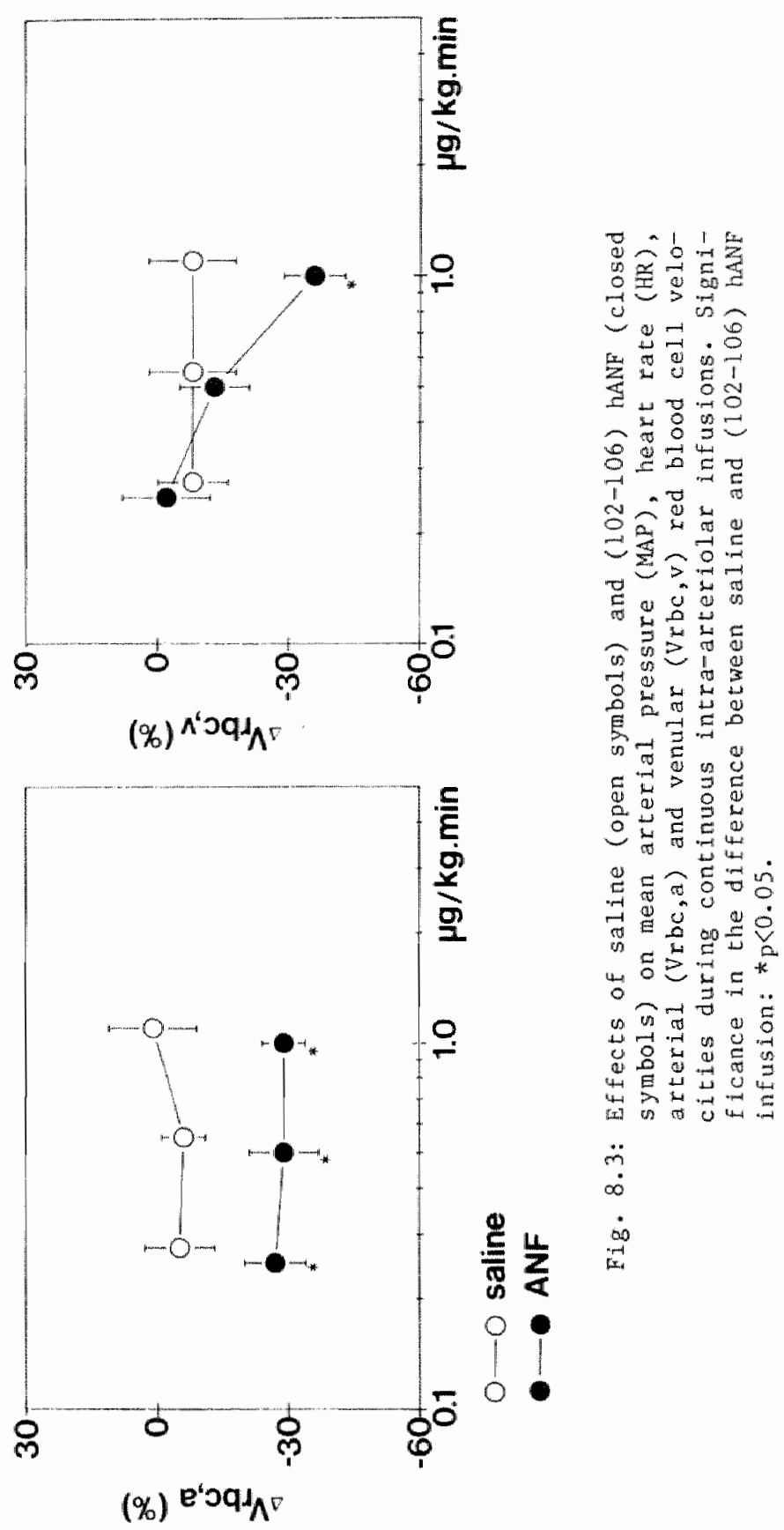

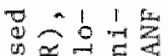
哭程可品 e is 0

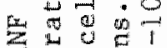
ษ 证:

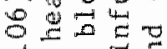
$1 . \nabla=$

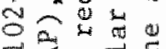
势

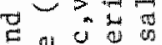
s $=5$ 嵌 00 落出出 F का

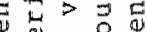
말 每 च ส $=$ o

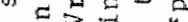
4 o $5 E^{*}$ की 4 त 0 का E 4 L का को 


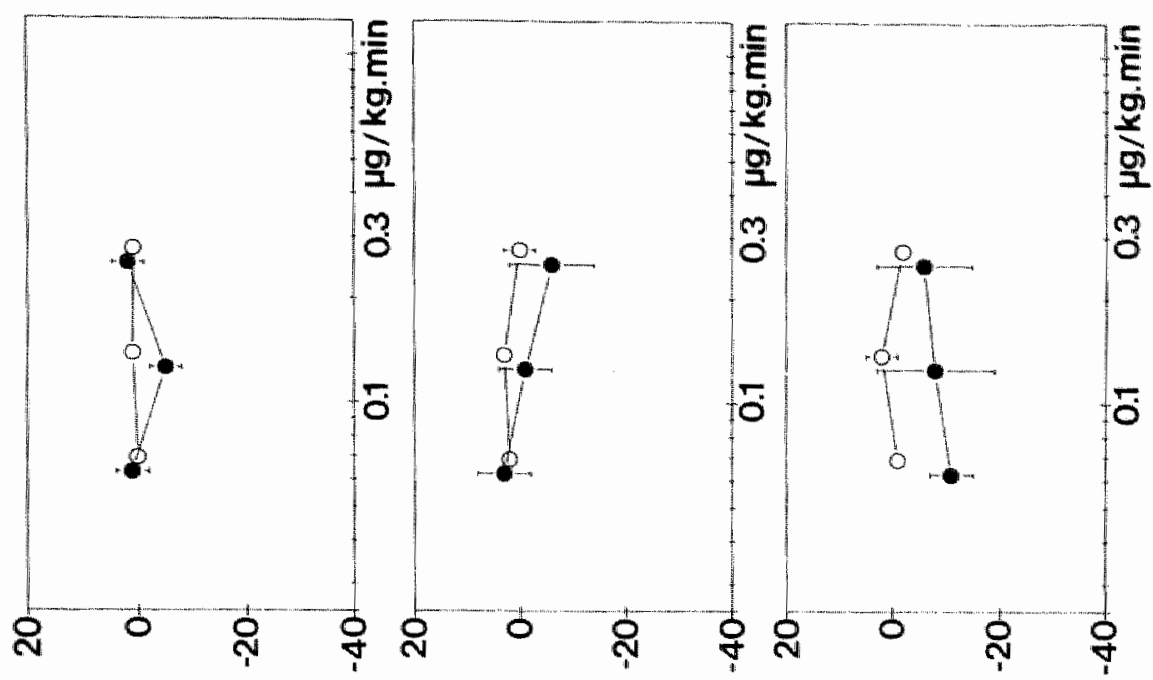

(\%)टへळ

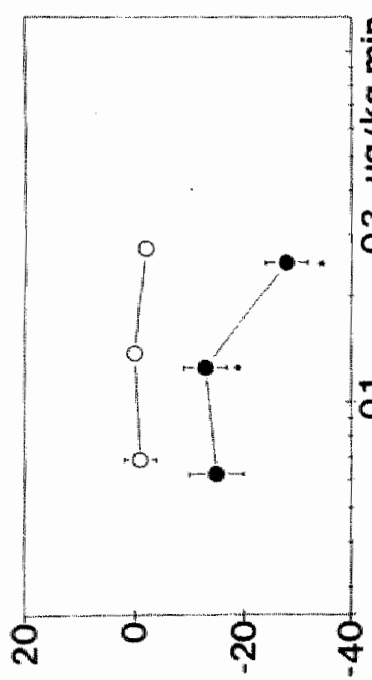

(\%)乙マФ
(\%)ย^๘

(\%) $\triangleright \wedge \varnothing$
구워

टे $\Rightarrow$

的

$\exists \geq$

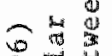

일

$\underset{0}{2}$

$\rightarrow$ 문

$\square$ 出

更

का सम

- ing

$< \pm$

a net

4

E

w

용

o

踏证

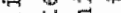

बi

o in

岁范

को

प्र

w

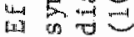

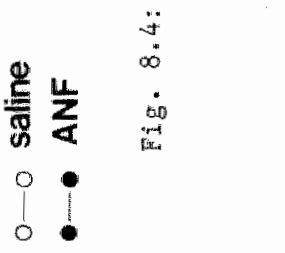


the highest infusion rate. Arteriolar constriction at seweral order levels was observed but this reached statistical significance only for the A2 vessels following 0.125 and $0.25 \mathrm{\mu g} / \mathrm{kg} / \mathrm{min}$ ANF i.a. Venular diameter changes were not seen.

\subsubsection{Effects of $1 . v$. administered AMP on macromolecular leakage}

In none of the experiments, desplte a considerable decrease in MAP' (table 8.2), did ANF affect macromollecular leakage, evidenced by the absence of extravascular fluorescent spots. Notably, plasma leakage did occur when the mesentery preparation was exposed to topically applied histamine. Following topical histamine, the leakage first developed rapidly at the postcapillary venules initially seen as multiple clrcular areas with intense fluorescence. Approximately 5 min after administration, the leakage became massive and the avascular areas of the mesentery were fluorescent as well. Histamine did not have any measurable effect on MAP. Lymph vessels were non-fluorescent both in the control sitwation and following treatment with ANF. Following topical histamine lymph vessels became fluorescent.

Table 8.2: Effects of saline and ANF on MAP and HR in rats used for the study on capillary protein extravasation.

N Start value $\quad 0.5 \quad 2.0 \mu \mathrm{m} / \mathrm{min}$ saline

$\begin{array}{lllll}\text { MAP } & 6 & 125 \pm 5 & -1 \pm 1 & -2 \pm 1 \\ H R & 6 & 322 \pm 8 & 10 \pm 1 & 11 \pm 1\end{array}$

$0.25 \quad 1 \mu g / \mathrm{kg} \cdot \mathrm{mL} \mathrm{In}$ ANF

$\begin{array}{lllrr}\text { MAP } & 8 & 118 \pm 3 & -10 \pm 1 & -26 \pm 4 \\ \text { HR } & 8 & 288+11 & -2 \pm 6 & -9 \pm 9\end{array}$




\subsection{Discussion}

The major objective of this study was to inwestigate the effect of ANF on capillary filtration processes by means of fluorescent macromolecules. The major finding of this study is that systemic infusions of ANF did not cause an enhanced leakage of macromolecules. This finding is important in relation to the effects of ANF on the regulation of blood pressure. Our data suggest that local fluid shifts are not involved in the hypotensive response following atrial natriuretic peptides. The enhanced arteriolar constriction and absence of venular diameter changes following ANT administration are in accordance with earlier observations presented in the previous chapter.

The mesentery has a mique hydraulic condition to study capil1ary filtration because microvascular pressures are higher than in other vascular beds (Bohlen and Gore, 1984). The intestine forms an in-series coupled network system that drains directly into the liver. It is 1 ikely that any change with regard to the altered microvascular permeability should first be reflected by macromolecular leakage in the mesentery.

During systemic infusions of ANF, blood pressure fell. This effect was associated with a diameter reduction of second and third order arterioles. No change of venular diameters was observed while $\mathrm{v}_{\text {rbc }}$ decreased in both arterioles and venules. These observations are in accordance with previous studies (Lappe et a1, 1985; Criscione et al, 1987). In these studies in rats, splanchnic blood flow decreased and vascular resistance increased following administration of atrial natriuretic peptides (APII).

The decrease in cardiac output observed in other studies (Lappe et al, 1985) was explained by lowered cardiac filling pressures and venous return possibly by venous dilation. Under resting conditions (skeletal muscle), venules have a considerable vascular tone (Damon and Duling, 1986). Thus, assuming that also mesenteric venules have a resting tone our data do not corroborate this hypothesis although it still remains possible that larger venules or veins more downstream are involved and exhibit dilation.

The hemodynamic effects of atrial peptides depend on the mode of 
the Ir adminftratlon. Lappe et al (1986) recently showed that in consclous rats atrlal peptides given as a bolus injection decreased renal and splanchic vascular resistance. If a comparable blood pressure reduction was achieved by sustained infusions, regional vascular resistances increased. It is as yet unknown what the primary under1ying mechanism is. This vasoconstriction appeared to be mediated through an increased sympathetic tome rather than through a direct wasoconstrictor action of the peptide because symathetic denervation abollshed the response (Lappe et al, 1985). This fits well in our obgervations demonstrating an arteriolar constriction during continuous infusions of ANF".

To avold the possible Involvement of systemic (reflex) effects, local drug administration was performed. During local infusion, no evidence was obtained for any vasorelaxant effect. The most prominent feature was an actual decrease in artertalar diameter of second order arterioles. ANF falled to cause a venodilation in this preparation also.

An unexpected finding was that low-dose local infusion of ANF decreased blood pressure. This may be related to a possibly excitatory action of atrial peptides on chemosensitive receptors within the splanchnic bed. These receptors may elicit inhibiting afferent signals towards the cardiopulmonary region or the central nervous system (Longhurst, 1984). Secondly, it is concelvable that atrial peptides could interfere with the secretion and action of waso-active peptides of the gastro-intestinal tract (Burnstock and Griffith, 1983). Third1y, the effect might be attributed to the unique pharmacological properties of ANE. In the previous chapter, it was found that local administration of low dose APII did not Iower systemic blood pressure. the design of the present experiments does not allow any conclusions to the nature of the differential effects.

It was hypothesized that atrial peptides are inwolved in the regulation of flutd and electrolyte balance of peripheral tissues. This could be a potential mechanism for the hypotensive action of atrial natriuretic peptides, promoting an increased caplliary filtration. In order to demonstrate an effect of ANF on microvascular permeability, macromolecular leakage was studied. Even the highest doses 
failed to cause an enhanced leakage nor did an enhanced protein transport by 1 ymph vessels occur, indicating that ANF does not promote fluid and protein shifts towards the extravascular space in this part of the circulation. Theoretically, an increased caplllary protein leakage may be achieved by an increased number of perfused capillaries without any change of microvascular permeability of individual capillaries. However, capillary recruitment has not been demonstrated for the mesentery and does hardly occur in the intestine (Bohlen, 1983; Harper et a1, 1985).

Recenty it was demonstrated that the gastro-intestinal tract possesses specific hïgh affinity binding sites for atrial natriuretic peptides (Mantyh et al, 1986). The intestine is involved in fluid and electrolyte reabsorption (Granger et al, 1984) and could be a primary site of action for atrial peptides thus influencing hydrostatic and oncotic pressures. An increased interstitial volume may result in an increased hydrostatic tissue pressure. This should preferentially drive fluid into the lymphatics because the hydraulic conductance of these vessels is greater than that of capillarles (Granger et al, 1984). Since the lymph vessels we studied orlginate close to the intestinal wall and were non-fluorescent, the hypothesis of a specific effect of ANF upon intestinal fluid and protein homeostasis has to be abandoned.

In conclusion, continuous infusion of ANF resulted in a dose-dependent blood pressure decrease. The hypotensive effect cauld not be explained by a direct vasodilatory effect on mesenteric microvessels nor by en enhanced vascular capillary flltration within the same tissue. It remains to be established whether the blood pressure decrease can be explained by a direct effect on larger vessels and/or other tissues.

\section{8. $5^{\circ}$ References}

Atlas SA, Kleinert HD, Camargo MJ, Januszewlcz A, Sealey JE, Laragh JH, Schilling W, Lewicki JA, Johnson LK, Maack T. Puriflcation, sequencing and synthesis of natriuretic and vaso-active rat 
atrial peptide. Nature (Lond) $309,717-719,1984$.

Hollaz J, Wussberger J, Waeber B, Bruner HR. Clinical pharmacology of atrial natriuretic $(3-28)$ eicosahexapeptide. J Hypert suppl 2, $101-108,1986$.

Bohlen HG. Intesintal incrovascular adaptation during maturation of spontaneously hypertensive rats. Hypertension $5,739-745,1983$.

Bohlen HG, Gore RW. Microvascular pressures in the small intestine. In: Physiology of the intestinal circulation (eds: Shepherd $A P$, Granger DN). Raven Press, New York, 1984, pp 249-260.

Burnstack $G$, Griffith SG. Innervation of licrovascular smooth muscle. Prog Appl Mlcracirc 3, 19-39, 1983.

Cantin $M$, Genest $J$. The heart and the atrial narriuretic factor. Endocr Rev 6, 107-127, 1985.

Crisclone $L$, Burdet $R$, Hänni $H$, Kamber $\mathbb{B}$, Truog $A$, Hofbauer $K G$. Systemic and regional hemodynamic effects of atriopeptin II in anesthetized rats. J Cardlowase Pharmacol 9, 135-141, 1987.

Damon DN, Duling BR. Venular reactivity in the hamster cheeck pouch and cremaster muscle. Microvasc Res 31, 379-383, 1986.

DeBold AJ, Borenstein HB, Veres AT, Sonnenberg H. A rapid and potent natriuretic response to intravenous injection of atrial myocardlal extracts in rats. Life Sci $28,89-94,1981$.

Declerck F, Van Gorp L, Beetens J, Reneman RS. Platelet-medlated vascular permeability in the rat: a predominant role for 5-hydrotryptamine. Thromb Res 38, 321-339, 1985.

Flückiger JP, Waeber $B$, Matsueda $G$, Delaloye $B$, Nussberger J, Brunner HR. Effect of atrlopeptin III om hematocrit and volemia of nephrectomized rats. Am J Physiol 251, H880-H883, 1986.

Garcia $R$, Thibault $G$, Cantin M, Genest J. Effect of purified atrial natriuretic factor and rabbit vascular strilps and vascular beds. Am J Physiol 247, R34-R39, 1984.

Granger DN, Ulrich $M$, Parks DA, Harper SL. Transcapillary exchange during intestinal fluid adsorption. In: Physiology of the intestinal circulation (eds: Shepherd AP, Granger DN). Raven press, New York, 1984, pp 211-221.

Harper SL, Bohlen HG, Granger DN. Vaso-active agents and the mesenteric microcirculation. Am J Physiol 249, G309-G315, 1985.

Lappe RW, Todt JA. Mechanism of action of vasoconstrictor responses to atrlopeptine II in conscious SHR. Am J Physiol 36, 1205-1215, 1985 .

Lappe RW, Smits JFM, Todt JA, Debets JJ, Wendt RL. Fallure of atriopeptin II to cause arterial vasodilation in the consclous rats. C1rc Res 56, 606-612, 1985.

Lappe RW, Todt JA, Wendt RL. Hemodynamic effects of infusion versus bolus adninistration of atrial natiuretic factor. Fypertension $8,866-873,1986$.

Longhurst IC, Cardfovascular reflexes of gastro-intestinal origin. In: Physiology of the intestinal circulation (eds: Shepherd AP, Granger DN). Raven press, Wew York, 1984, pp 165-177.

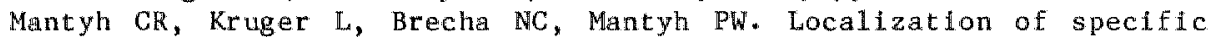
binding sites for atrial matriuretic factor in peripheral tissues of the guinea pig, rat and human. Hypertension 8, 712-721, 1986.

Needleman P, Adans SP, Cole BR, Currle MG, Geller DM, Michwener ML, Saper CB, Schwartz D, Standaert DG. Atriopeptines as cardiac 
hormones. Hypertension 7, 469-482, 1985.

Pegram BL, Kardow MB, Trippodo MC, Cole FE, Macphee AA. Atrial extract: hemodynamics in Wistar-Kyoto and spontaneously hypertensive rats. Am J Physiol 249, 11265-H271, 1985.

Smits JFM, Debets JJM, Van Essen H, Lappe RW. Acute reduction of cardiac filling pressures by atriopeptin II in conscious SHR. Naunyn Schmiedeberg"s Arch Pharmacol 329 (supp1), 253, 1985.

Sugawara A, Nakao K, Morri W, Sakamoto $M$, Horri $K$, Shimokura $M$, Kiso $Y$, Nishimura K, Ban T, Kimara M, Yamori Y, Kangawa K, Matsuo H, Imura H. Significance of alpha-human atrial natriuretic polypeptide as a hormone in humans. Hypertension 8 (suppl 1), 151-155, 1986.

Thompson LP, Webb RC. Vascular responsiveness to atrlopeptine III in mineralocorticoid hypertensive rats. Hypertension 8 (suppl 1), $146-150,1986$. 
9.

In the previous chapters experimental data have been presented about microvascular changes during the development and malintenance of spontaneous hypertension as well as on the effects of neurogenic and humoral influences on microvascular dynamics under these circumstances.

The development of high blood pressure in spontaneously hypertensive rats (SHR) has been explained on the basis of a renal mechanism to retain fluid leading to volume-loading or a primary change in vascular resistance (for references see chapter 1). Since the developmental phase of spontaneous hypertension is characterized by an uneven fractional distribution of flow to the major organs, the question has been raised whether the increased vascular resistance is distributed uniformly over the vascular bed. Although whole-organ experiments have provided evidence that resistance is predominantly increased in the terminal part of the circulation the necessity for microvascular studies is obvious.

Changes in vascular resistance may be caused by structural or functional adjustments of the vascular bed (Bohlen, 1986). Folkow et al (1.983) have hypothetized that changes in vascular morphology should prevent vessels from normal vasodilation and thereby increase the wall thickness to lumen ratio resulting in an increased blood pressure. Although wall thickness was not measured in our study the finding that the maximum diameter obtalned was not different in WKY and SHR in all types of arterioles analyzed suggests that adaptive changes of the vessel wall in muscular tissue do not play a major lnftiating role in the aetiology of spontaneous hypertenston. This has also been found by other investigators (Henrich et al, 1978; Bohlen, 1983; Miller et al, 1987).

The data as obtained in the mesentery and intestine by Henrich and Bohlen, indicate that arteriolar wall bypertrophy may occur, but that hypertrophy is not an obligatory mechanlsm. in the development of hypertension. In another model of hypertenslon, the one-kidney oneclip renal hypertensive rat, the wall thickness to lumen ratlo of 


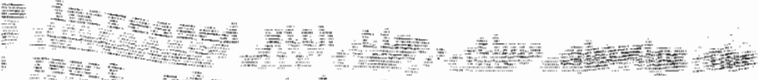

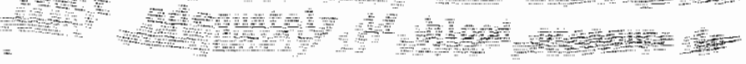

部

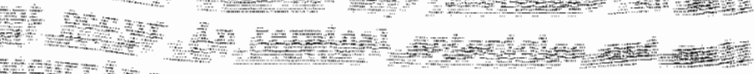

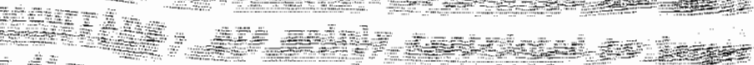

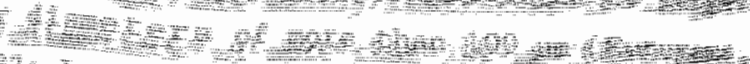
Int

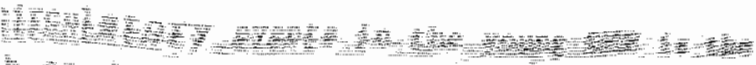
W WhA

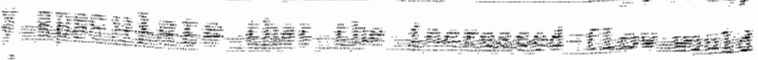
Wy

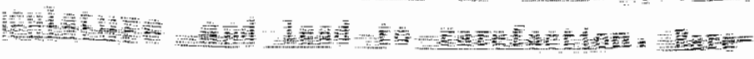
늘

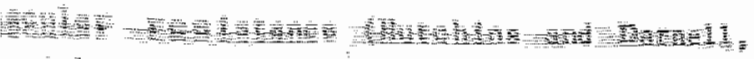

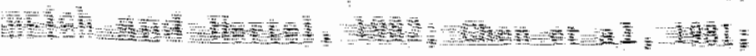
int

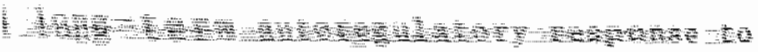

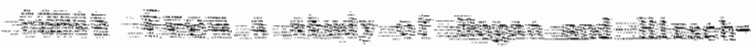

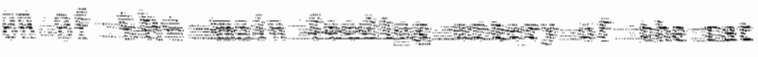
W

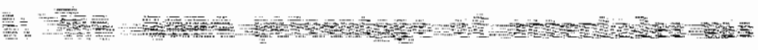

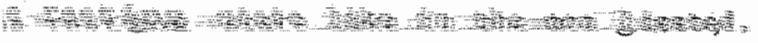
sy counting the number of vessels using ques. They concluded that arteriolar ures modulate arteriolar density. The e For ateriolar rarefaction in the SHR

study further support this concept. In Llary arterioles perfused is diminished ol and vasodilated state. This in favor change 1 in the vascular architecture. inderlying the increased resistance and, $n$ blood pressure, may be a diminished 
growth.

The contribution of oxygen to an elevated total peripheral resistance in SHR has been suggested by Walsh and Tobla (1982) who reported that oxygen has to be available for subclavian wascular resistance to be elevated in young ( 8 weeks old) cord-transsected SuR. In addition, repeated blood flow increases appear to produce an enhanced autoregulatory constrictor response in young and cord-transsected SAR in comparison with WKY. The enhanced response of SHR vessels to oxygen availability (Lombard et al, 1984) suggests that arterioles of the hypertensive animals will increase vascular resistance nore than those of WKY when oxygen avallability is increased. Furthemore, tissue oxygen uptake in the $r a t$ is flow-dependent (Banchero, 1987). Therefore, under conditions where tissue $\mathrm{pO}_{2}$ is not maintained at a relatively low level, local long-term vascular control mechansims could contribute to the elevated vascular resistance in SHR.

The role of oxygen in the development of bypercenston has been known for many years. Exposure to high altitude with low ambient oxygen tensions decreases the prevalence of hypertension in humans or experimental animals and reduces blood pressure to near nomal levels (Marticornes et al, 1969; Banchero, 1975; Ruiz et a1, 1977; prewitt et a1, 1986). Chronic hypoxia elicits microvascular changes assoclated with a reduced vascular resistance, including reduced levels of vasoconstriction and prevention of arteriolar rarefaction (Prewitt et al, 1986). The mechanism by which hypoxia reduces vascular resistance is not fully understood but a number of experiments points towards the role of adenosine, an endogenous vaso-active metabolite with anglogenetic activity (Banchero, 1975; Toraling et a1, 1978, 1980; Mattfeld and Hall, 1983; Hudlicka et al, 1984), an altered sodlum metabollsan (Behm et al, 1984), an altered catechol amine metabolism (Barbarash et al, 1982) or may be related to a metabolic adaptation in the sHk (Henley and Tucker, 1987).

In the adult SHR with a normal distribution of cardiac output Evenwel et al, 1983), arterioles wth a diameter of $80-150$ 2m, which are responsiblle for a considerable part of the increased resistance, did exhibit reduced diameters as compared to WKY. During the ma1ntenance phase of spontaneous hypertenston vascular resistance is in- 
creased in the temtral vascular bed because of a lower number of precapillary arterioles and a smaller lumen size of larger arterioles. as compared to WKY. This may have important consequences for the development of future antihypertensive drugs if a similar mechanisa occurs in human essential hypertension. Because the basic abnormality in spontaneous hypertension seems to be a diminthed vascular growth, one may peculate that new antihypertensive drugs should promate vasoproliferation and in this way lower vascular restatance on the long run. Further investigations are required to explore this hypothesis.

In addition to morphometric studies of the microcirculation in SHR, this thesis Eacussed on neurogenic and homonal influences on the microcirculation. An increased sympathetic drive has often been suggested to be one of the major events leading to arteriolar constriction and chronic hypertension (Abboud, 1982; 1984). Our data do not confirm this hypothesis, since no evidence was found for an early arteriolar constriction in SHR. This does not exclude an enhanced sympathetic activity in speciflc organs, e.g. the heart or kidneys. Heart rate was markedly elevated in the young $S H R$. An elevated heart rate at this age has been attributed to an enhanced activity of the sympathetic nervous system (Smith and Hutchins, 1979; Evenwell et al, 1983).

The studies, In which noradrenaline was applied via different vascular routes to adult rats, ind lcate marked differences in sensitivity along the vascular tree within one vascular bed as well as differences in sensitivity of different parallel coupled microvascular beds. This thesis was not designed to fully unravel pharmacological heterogenelty with the microcirculation. But so far, the experiments point at a potentially important direction for future cardiowascular pharmacological research *

The final aspect studied in this thests was the influence of atrial natriuretic factors (ANE) on microcirculatory dynamics. Previous in vitro studies, using isolated blood vessels, and in vivo macrocirculatory studies in intact animals produced conflicting results as to the vascular effects of ANF. On the one hand, several authors (for references see chapter 1) have suggested a vasodilatory 
effect of ANF, whereas others claim that ANF has no direct effects on resistance vessels. Our microcirculatory studies do not support the concept of $\mathrm{ANF}$ as a circulating vasodilatory substance. A second aspect of $A N F$ activity, as deriwed from macrocirculatary studies, is its effects on body fluid dynamics. Hematocrit and plasma volume measurements in severa1 species suggest that ANF may cause a shift of fluid from the intra to the extravascular fluld compartment. Our studies indicate that ANF does not cause albumin leakage in the mesenteric microcirculation. Although this does not exclude a transcapillary water flux, the data indicate that other mechanisws than transcapillary fluid shifts should be considered to explain the hematocrit changes observed by others.

In sumary, this thesis has dealt with different physlological, pathological and phamacological aspects of the microcirculation in a genetic animal model of hypertension. The studies indicate that the microcirculatory approach can provide new perspectives for studies on the pathophysiology and therapy of hypertension.

\subsection{References}

Abboud FM. The sympathetic system in hypertension. State-of-the-art review. Hypertension 4 (supp1.2), 208-225, 1982.

Abboud FM. The sympathetic nervous system in hypertension. Clin Exp Hypert Theor Pract A6, 43-60, 1984.

Banchero N. Capillary density of skeletal muscle in dogs exposed to sinulated altitude. Proc Soc Exp Biol Med 148, 435-439, 1975.

Banchero N. Cardiovascular responses to chronfc hypoxta. Ann Rev Physial 49, 465-476, 1987.

Barbarash NA, Dvurechenskaya GY, Volina EV, Berdsheva LV, Putintseva TG, Manukin BN, Meelson FZ. Effect of adapation to high althtude hypoxia on catecholamine netabolism in spontaneously hypertensive rats. Bull Exp Med 93, 24-52, 1982.

Behm $R$, Fonig $A$, Griethe $M$, Schmidt $M$, Schnelder P. Sustalned suppression of voluntary sodium intake of spontaneously hypertensive rats (SHR) in hypobaric hypoxia. Blomed Hochin Acta 7 , $975-985,1.984$. $975-985,1984$.
Bohlen HG. Intestinal microvascular adaption during maturation of
spontaneously hypertensive rats. Hypertension 5, 739-745, 1983 .

Bohlen H. Localization of vascular resistance changes during hypertension. Hypertension $8,181-183,1986$.

Brayden JE, Halpern $W$, Brann LR. Biochemical and mechanlcal properties of resistance arteries from normotenstve and hypertensive rats. 
Hypertension 5, 17-25, 1983.

Chen IIH, Rrewlt RL, Dowell RF. Microvascular rarefaction in spontaneously hypertensive rat cremaster muscle. Am J Physiol 241, H306-H310, 1981.

Evenwel RT, Kasbergen CM, Struyker Boudier HAJ. Central and regional hemodynamics and plasma volume distribution during the development of spontaneous hypertension in rats. Clin Exp Hypert A5, $1511-1536,1983$.

Furuyama $M$. Hometrical investigations of arteries in reference to artertal hypertenston. Tohoku J Exp Med 76, 388-414, 1962.

Haack. DW, Schaffer JJ, Simpson JG. Comparison of cutaneous microvessels from spontaneously hypertensive, normotensive Wistar-kyoto and nomal Wistar rats. Proc Soc Exp Biol Med 164, 453-458, 1980.

Henley WN, Tucker A. Hypoxic moderation of systemic hypertension in the spontaneouslly hypertensive rat. Am J Physiol 252, R554-R561, 1987.

Henrich $H$, Hertel $H$, Assmann $R$. Structural differences in the mesentery microcirculation between normotensive and spontaneously hypertensive rats. Pflugers Arch 375, 1.53-159, 1978.

Hentich $H$, Hertel RF. Microvascular hemodynanics in spontaneous hypertension (ed: Henrich H). Hans Huber Publishers, Bern, 1982, pp $21-39$.

Hogan $k D$, Hirschmann L. Arteriolar proliferation in the rat cremaster muscle as a long-term autoregulatory response to reduced perfuston. Microvasc Res 27, 290-296, 1984 .

Hudlicka 0 , Tyler KR, Wright AJA, Zlada AMAR. Growth of capillaries in skeletal muscle. Prog Appl Microcirc 5, 44-61, 1984.

Hutchins PM, Datrell AE. Observation of a decreased number of small arterioles in spontaneously hypertensive rats. Circ Res 34 (supp1 I), 161-165, 1974.

Hutchins PM, Roddick VL. Dusseau JW. Correlation of blood pressure and rarefaction of small arterioles in back-crossed spontaneously hypertensive rats. Microvasc Res $21,246,1981$.

Lee RMKW. Vascular changes at the prehypertensive phase in the mesenteric arteries from spontaneously hypertensive rats. Blood Vesgels $22,105-126,1983$.

Lombard JH, Hess ME, Steklel W. Neural and local control of arterioles in SHR. Hypertension 6, 530-535, 1984 .

Marticornes E, Rulz L, Severino J, Galvez J, Penaloza D. Systemic blood pressure in white men born at sea level: changes after long resldence at high altitudes. Am J Cardiol 23, 364-368, 1969.

Mattfeldt $T$, Hall G. Dipyridamole induced capllary endothelial cell prollferation in the rat heart - a morphometric investigation. Cardiovasc Res 17, 229-237, 1983.

Miller BG, Connors BA, Bohlen HG, Evan AP. Cell and wall morphology of: intestinal arterioles from 4-6 and $17-19$ week old Wistar-Kyoto and spontaneously hypertensive rats. Hypertension 9, 59-68, 1987.

Prewtt RL, Chen IIH, Dowell RF. Microvascular alterations in the one-kidney, one-clip renal hypertensive rat. Am J Physiol 246, H728-H732, 1984.

Prewitt RL, Cardoso SS, Wood WB. Prevention of arteriolar rarefaction 
In the spontameously hypertensive rat by exposure to simulated high altitude. J Hypert $4,735-740,1986$.

Ruiz L, Penaloza D. Altitude and hypertension. Mayo Clin Prac 52, $442-445,1977$.

Smith TL, Hutchins PW. Central hemodynamics in the developmental stage of spontaneous hypertension $\mathbb{t}$ the unanesthetized rat. Hypertension $1,508-517,1979$.

Tornling $G$, Unge $G$, Skoog $L$, Ljungqvist $A$, Carlsson $S$, Adolfsson $J$. Proliferative activity of myocardial capillary wall cells in dipyridamole-treated rats. Cardiovasc Res $12,692-695,1978$.

Tornling $G$, Adolfsson $J$, Unge $G$, Ljungquist A. Capillary neoliormation in skeletal muscle of dipyridamole-treated rats. Arzneim Forsch $30,791-792,1980$.

Walsh GM, Tobia AJ. Vascular pressure flow analysis in normal and hypoxemic spontameously hypertensive rats. Clin Exp Hypert Theor Pract A4, 445-460, 1982 . 

10. SUMMARY

Spontaneous hypertension in rats is hemodynamically characterlized by an increased peripheral resistance. However, the mechanism(s) by which the peripheral resistance is increased remain(s) unresolved. Control of vascular resistance occurs predominantly at the level of small arteries and arterioles. The aim of the present thesis was to investigate microvascular changes during the developmental phase as well as during the established phase of hypertension in a hypertensive model, the spontaneously hypertensive rat (SHR). Moreover, neurogenic and hormonal influences on the microcirculation were investigated to get more insight into the blood pressure regulation at this levell of the circulation in SHR.

In the genera 1 introduction (chapter 1) current concepts on the aetiology of spontaneous hypertension are described. Although the nature of spontameous hypertension is multifacetted, two main mechanisms can be distingulshed. These concepts point towards the primary role of the kidneys or to primary vascular changes, initiating and maintaining the increased vascular resistance and thus blood pressure. Furthermore, a brief survey of the present major literature on microvasular changes in spontaneous hypertension is given. In section 1.7, the existing experimental microvascular data are synthetized into a hypothesis.

Chapter 2 describes the materials and the methods used in the experiments. Beslde basic surglcal techniques, different preparations for microvascular studies in anesthetized animals are descrlbed as well as a recently developed preparation which allows microcirculatory studies in conscious rats.

In chapter 3 the functional and structural vasculat differences between hypertensive and normotensive control rats were studied in young rats (5-6 weeks). This age was chosen because after 5-6 weeks blood pressure starts to rise rapidly. Studies were performed on the cremaster muscle, which is a striated muscle and is morphologically considered to be a skeletal muscle, despite functional differences. Arteriolar diameters and vasodilating capacity were not different in 
SHR and WKY control rats. In the SHR dimished arteriolar and capllary dengites were found. This was also observed following maximal vasodllation suggesting a lower flow carrying capacity in the SHR.

In chapter 4 merovascular alterations in the rat dorsal cutaneous muscle were investlgated. The study was performed in adult conscious rats. A comparison was made between arteriolar and venular dianeters of spontaneously hypertensive and nomotensive rats. Large arterioles in the SHR had diameters smaller than comparable vesseis in the normotensive rats, whlle no differences were observed beween precapillary arterloles in both groups. Venular dianeters were equal or slightly larger in SHR as compared to normotensive control animals.

An increased Bympathetic drive has been often suggested to be one of the major events leading to arteriolar constriction and chronic hypertension. In chapter 5 the effects of sympathetic stimulation and exogenously applied adrenerglc agents on microvascular dynamics are reported. The study was performed on the mesenteric microcirculation. In a number of experiments, the interrelationship between macro and microcirculatory events was studied. The results indicate that exogenous application of adrenergic and other vasoconstrictors or neurogenlc stimuli produce an overall increase in total peripheral resistance with microvascular responses which differ both qualitatively and quantitatively, depending on the way in which the stimulus is applied.

In chapter 6 the regional hemodynamics in conscious rats and in rats anesthetized with pentobarbital or an alpha-chloralose-urethane mixture were compared. These anesthetics were chosen based on their frequent use in microvascular studies. The regional responses were studled following systemic application of differently acting vasopressor substances, 1 ke phenylephrine, noradrenaline and angiotensin II. The depressant activity of pentobarbital was more pronounced for the triated muscle bed while alpha-chloralose-urethane primarily affected the splanchnic bed.

Several authors have suggested a vasodilatory effect of ANF, whereas others claim that ANF has no direct effect on resistance vessels. Therefore, in chapter 7 the in-vivo effects of atriopeptin II (APII) on mesenteric microvessels were studied. Systemically applied APII caused a blood pressure decrease, parallelled by an arteriolar 
constriction within the mesentery microvascular bed. No evidence was obtained for venular dilation, suggesting that larger vessels of other vascular beds are responsibile for the blood pressure decrease. Local. infusion of the drug into the target organ also did not induce arteriolar or venular dilation.

In chapter 8, the effect of another atrial natriuretic factor (102-126 haNF) on macromolecular leakage within the mesentery wicrocirculation was studied. Following systemic application of 102-126 hAll blood pressure decreased while no leakage occurred, indicating that fluid shifts (and thus a reduced effective circulating blood volume) are probably not responsible for the blood pressure decrease of 102-126 hANF. 


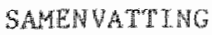

Hoewel ut vele studies blijkt dat spontane hypertensie gekenmerke wordt door een verhoogde perifere valtweerstand, zijn de mechaalsmen die hieraan ten grondslag liggen nog onbekend. De regulering van de watweerstand wind voornamelljk plaats op het nivo van kleine arterien en arteriolen.

In deze dissertatie werden de mikrovaskulaire veranderingen tijdens de ontwkkelingsfase en de stablele fase van hypertensie bestudeerd in een diermodel, namelijk de spontaan hypertensieve rat (SHR). Bovendien werden neurogene en humorale faktoren bestudeerd, warvan bekend is dat zij de conus van mikrovaten kunnen beinvloeden en daamee de bloeddruk. Deze studfes werden verricht om meer inzicht te krijgen 1 n de regulering van de weerstand en daarmee van de bloeddruk bij spontane hypertensie.

In de algemene inleiding (hoofdstuk 1) worden de huidige opvattingen over de zlekteoorzaak van spontane hypertensie beschreven. Hoewel de oorzalk van spontane hypertensie vele facetten kent, zijn er twee bellangrijke mechanismen beschreven. Het eerste konsept gat uit van de roll van de nier, terwijl het tweede konsept vooral primaire veranderingen van het vaatstelsel verantwoordelifk acht voor zowel het initieren als in stand houden van de verhoogde perifere weerstand en dus de bloeddruk. Verder wordt in dit hoofdstuk een kort overzicht gegeven van de belangrijkste literatuur op het gebied wan mikrovaskulatre veranderingen tijdens spontane hypertensie. In paragraaf 1.7 worden de expertmentele gegevens vervat in een hypothese.

In hoofdstuk 2 worden de materialen en methoden die in de verschillende experfmenten gebruikt zijn beschreven. Nast basale chirurgische technleken wordt vooral aandacht besteed aan verschillende mikrovaskulajre preparacen bij verdoofde dieren. Oak wordt een preparaat beschreven dat recent ontwikkeld is en het mogelijk maakt om bij wakkere diecen mikrocirkulatoire studies te verrichten.

In hoofdstuk 3 worden de funktionele en strukturele vaskulaire verschillen tussen hypertensieve ratten en nomotensieve kontroleratten beschreven. De studie werd verricht bij jonge ratten $(5-6$ 
weken). Deze leeftijd werd gekozen ondat het bekend is dat vanaf deze leeftijd de bloeddruk juist dan sterk gat stijgen. Als preparat werd gekozen voor de cremasterspier, een dwarsgestreepte spier. zowel de arteriolaire diameter als het dilaterend vermogen is niet verschllend in SHR en WKY. In de spontaan hypertensieve rat werd ten lagere arteriolaire en kapillaire dichtheid gevonden. Dit werd ook gevonden na maximale vaatverwijding. Het spiervaatbed van de spontaan hypertensieve rat is dan blijkbaar niet in stat om een extra aantal vaten te openen om daarmee de bloedstroom door het vaatbed te verhogen. Het onderliggende mechanisme verantwoordelijk voor de witelndelijke verhoogde weerstand in de spontaan hypertensleve rat is een lagere arteriolaire en kapillaire dichtheid.

In hoofdstuk 4 worden tikrovaskulaire veranderingen beschreven in de huidspler in de rug van de rat. De stude werd verricht bij wakkere volwassen dieren. Er werd een vergelijking gemaakt tussen arteriolaire en venulaire diameters van spontaan hypertensieve en normotensieve ratten. Grote arteriolen verantwoordelijk voor een aanzfenlijk deel van de perifere weerstand bif de spontaan hypertensieve rat toonden kleinere diameters dan overeenkomstige vaten bif normotensieve ratten. De diameters van prekapillaire arteriolen verschilden niet in beide groepen, terwijl de venulaire diameters in de spontaan hypertensieve rat lets groter waren dan overeenkomstige vaten bij nomotensieve kontrole-dieren.

Men neemt aan dat een verhoogde sympathische tonus leidt tot een arteriolaire konstriktie en daarmee chronische hypertensie. In hoofdstuk 5 worden de effekten beschreven van sympathische stimulering en exogeen toegediende adrenerge stoffen op de hemodynamiek van de mikrocirkulatie. De studie werd utgevoerd op het mesenterium van de rat. In een aantal experimenten werd de relatie beschreven tussen makro- en mikrocirkulato ire veranderingen. De resultaten laten zien dat na exogene toedlening van adrenerge en andere vasokonstriktors of na neurogene stimulatie de totale perifere weerstand stight. Mikrovaskulaire effekten verschillen ten opzichte van de makrovaskulaire effekten afhankelijk van de wijze warop gestimuleerd wordt. Dee effekten verschillen zowel in kwantitatief als kwalitatlef opzicht.

In hoofdstuk 6 wordt de regionale hemodynamika vam wakkere die- 
ren vergeleken thet die in deren verdoofd met pentabarbital of met een alpha-chloralose-urethan mengsel. Deze anesthetika werden gekozen op basls wan hun frekment gebruik voar mikrovaskulaire studies. De regionale effekten werden bestudeerd na systemische toediening van verschllend werkzame vasopressorsubstanties, zoals fenylefrine, noradrenaline en anglotensine. II. Pentobarbital bleek selektief de reaktivitelt van het splerbed te verminderen, terwijl alfa-chloralose-urethaan meer de reaktiviteit van het darmbed verminderde.

Tenslotte werd de invloed bestudeerd van "atrial natriuretic Factor" (ANF) op de mikrocirktulatolre hemodynamika. Litatuurgegevens zljn tegenstrijdig voor wat betreft de vaskulaire effekten van ANF. Zowel een (arterlolaire) dilatatie als konstriktie worden gerapporteerd. In hoofdstuk 7 worden de in-wivo effekten beschreven van atriopeptine II (API) op de mikrovaten van het mesenterium. Systemisch toegediend APII verlaagde de bloeddrut, gepaard gaande met een arteriolaire konstriktie. Er werden geen direkte aanwijzingen gevonden voor venulaire dilatatie. Na lokale toediening van de stof in het doelorgaan trad arterlolalre konstriktie op, zonder venulaire dilatatie.

In hoofdstuk 8 worden de effekten beschreven van 102-126 hANF op de makromolekulaire lekkage van het mesenterium bij de rat. Ma systemische toedlening van de stof daalt de bloeddruk, terwijl geen makromolekulaire lekkage optreedt. Dit duidt er op dat een toegenomen perffeer watertransport in het darmbed naar het interstitium (en dus een afgenomen effektief cirkulerend bloedvolume) waarschijnijjk geen bijdrage levert aan het bloeddrukverlagende effekt van 102-1.26 hANF. 
19 navember 1956

$1969-1975$

$1975-1981$

$1982-1987$
Geboren te Heerlien

At heneum-b gevolgd aam het Bernardinus kollege te Heerlen.

Tijdens middelbare schoolperiode na Nederlandse selektie deelname an de "4th and 6 th European Philips contest for young scientists and inventors" in respektievelijk 1972, Eindhoven, en 1974, Aken, West-Duitstand. Ontwing in 1974 een prijs voor een studie getiteld "An envirommental study on snalls" (prof. dr. H.B.G. Casimir, destijds hoofd Philips Research).

Geneeskunde gestudeerd aan de Rijksuniversiteit Limburg te Maastricht

Tijdens het $3 e$ en 4 e studiejaar werkzam geweest als student-assistent in het laboratorium voor mikrocirkulatie (vakgroep Fysiologie; begeleider $\mathrm{dr}$. C.J. Tangelder, hoofd prof. dr. R.S. Renernan).

Het artsexamen werd met goed gevolg afgelegd in juni 1981.

In dienst getreden als wetenschappelijk ass 1 tent bij de vakgroep farmakologle (hoofd prof. dr. H.A.J. Struyker Boudier). Tljdens de eerste 2 jaren werkzam geweest op het gebled van de renale zenuwen en de betekents daarvan bij het ontstaan van spontane hypertensie binnen het laboratorlum voor dierexperimentele farmakologie (dr. J.F.M. Snits). Ontving voor dit werk in 1985 een prijs van de Revlon Health Care Group in de vorn van een rels- 
betus.

De experimenten warop het huldige proefschrift gebaseed is, zijn tot stand gekomen In de periode december 1983 - december 1986 en hoofdzakelijk uitgevoerd binnen het mikrocirkulatie-1aboratorium (dr. D. W. SLat).

In 1986 gedurende een halfjar werkzam geweest in het mikrocirkulatielaboratorium van prof. dr. P.M. Hutchins en prof. dr. T.L. Sulth te Winston-Salem N.C., U.S.A. (Wake Forest University, The Bowman Gray School of Medicine).

Vanaf 1987 Assistent in opleiding op de afdeling Inwen-
dige Geneeskunde wan het Akadenisch Ziekenhuis
Mastricht (hoofd opleiding prof. dr. J.
Flendrig). 


\section{LIST OF PUBLICATIONS}

\section{Full papers}

Smits JFM, Le Noble LML, Kleinfans JCS. Role of afferent and efferent renal nerves in blood pressure control. In: Adrenergic blood pressure regulation. Proceedings of a symposium (eds: WH Birkenhager, Folkow B, Struyker Boudier HAJ). Excerpta Medica, Afasterdam, 1985, pp 67-75.

Le Noble LML, Lappe RW, Brody MJ, Struyker Boudier HAJ, Smits JEM. Selective efferent chemical sympathectomy of rat kidneys. Am J Physiol 249, R496-R502, 1985.

Le Noble LML, Janssen BJA, Lappe RW, Brody MJ, Struyker Boudier HAJ, Smits JFM. Pharmacological evidence for rapid destruction of efferent renal nerves in rats by intrarenal infusion of 6-hydroxydopamine. J Hypert supp1 3, 137-140, 1986.

Struyker Boudier HAJ, Kleinjans JCS, Le Noble LML, Nievelstein MMN, Smits JFM. Rate-controlled cardiovascular drug administration and action. In: Rate-controlled drug administration and action. CRC Press, Boca Raton, USA, 1986, pp $1.72-199$.

Le Noble LML, Struyker HAJ, Smits JFM. Differential effects of general anesthetics on regional vasoconstrictor responses in the rat. Arch Int Pharmacodyn, 1987 (in press).

Le Noble LML, Tangelder GJ, Slaaf DW, Smits JFM, Struyker Boudier HAJ. Sympathetic adrenergic stimulation of the microcirculation: a combined macro- and microcirculatory study. Pflugers Arch, 1987 (in press).

Le Noble LML, Slaaf DW, Tangelder GJ, Struyker Boudier HAJ, Van Essen $H$, Smits JFM. In-vivo effects of synthetic atrlopeptin II (APII) on mesenteric microvessels of SHR. (submitted).

Le Noble LML, Slaaf DW, Tangelder GJ, Struyker Boud ler HAJ, Reneman RS. Regulation of perfusion of skeletal muscle during the early phase of spontaneous hypertension in rats: a functional morphometric study (in preparation).

Le Noble LML. Slaaf DW, Struyker Boudier HAJ, Snits JIM. Evaluation of macromolecular leakage as a possible mechantsm for the blood pressure lowering effect of $1.02-126 \mathrm{hANF}$ (In preparation).

Le Noble LML, Smith TL, Lynch $C D$, Hutchins PM. Cutaneous muscle microcirculation in aduit conscious normotenstue and spontaneously hypertensive rats (in preparation).

\section{Abstracts}

Le Noble LML, Kasbergen CM, Smlts JEM, Struyker Boudier HAJ. The influence of sympathetic nerve activity on renal function in the rat. Arch Int Physiol Biochem 2, 91, 1983.

Le Noble LML and Kasbergen CM. Intrarenal Infusion of 6-hydroxy-dopamine (6-OHDA) as a novel method for renal sympathet lc denervation in rats. Naunyn Schmiedeberg" ${ }^{n}$ Arch Pharmacol 322 (suppl) R19, 1983. 
Le Noble LML, Kasbergen CM, Saits JFM, Struyker Boudier HAJ. Efferent renal sympathetic denervation in rats by low-dose intrarenal. 6-hydroxydopamine infusion. Proc. $24 \mathrm{th}$ Dutch Fed Meeting, 1983.

Le Moble LML, Smits JFM, Struyker Boudier HA.J. Dissociation between chemical and functional indices for renal sympathectomy after intrarenal 6-hydroxydopamine. Pharmaceut Gkbl Sci Ed 5, 266, 1983.

Le Noble LML, Sints JFM, Slaaf DW, Tangelder GI, Struyker Boudier HAJ. Pffects of anesthesia on regional and nicrocirculatory hemodynamic effects of vasopressor substances in the rat. Int J Micracirc C1in Exp 3, 314, 1984.

Le Noble LML, Smite JFM, Slaaf DW, Tangelder GJ, Struyker Boudier HAJ. The influence of vasopressor substances and anesthesia on microcirculatory hemodynamics in the rat mesentery. Pharmaceut Wb1 Sci Ed 6, 226, 1984 .

Le Noble LML, Smits JFM, Struyker Boudier HAJ. Selective efferent denervation of rat kidneys. Ric Sci Educ Perman suppl 49, abstr nr $301,1985$.

Struyker Boudier $H$, Smits J, Nievelstein $H$, Le Moble J, Janssen B. Antihypertensfve drugs: renal sites of action. Naunyn Schmiedeberg" A Arch Pharmacol 330 (supp1): R4, 1985.

Smits FJM, Le Noble LML, Nievelstein HMNW, Struyker Boudier HAJ. Pharmacology of the microcirculation. Naunyn Schmiedeberg's Arch Pharmacol 330 (suppl), R1, 1985.

La Noble L, Tangelder $G$, Slaaf $D$, Smits J. Microvascular effects of synthetic atriopeptin II (APII) in rat mesentery. Fed Proc 45 , $894,1986$.

Le Noble LML, Tangelder GJ, Slaaf DW, Struyker Boudier HAJ. Vasomotion and arteriolar recruitment in cremaster muscle of anesthetized rats. Int J Microcirc Clin Exp 5, 220, 1986.

Le Noble LML, Slaaf DW, Tangelder GJ, Van Essen $\mathbb{H}$, Struyker Boudier HAJ, Smits JFM. Microcirculatory changes and plasma leakage in rat mesentery during infusion of atrial natriuretic factors (ANF). Pharmaceut Wbl Sci Ed 8, 274, 1986.

Daemen MJAP, Debets JJ, Le Noble LML, Smits JFM. Hemodynamic effects of atrial natriuretic factors (ANF) in experimental animals. Proc Br Pharmacol Soc, C76, 1986.

Le Noble $I$, Lynch $C$, Smith $T$, Hutchins $P$. Skeletal muscle microcirculation in adult, consclous, normotensive Wistar-Kyoto (WKY) and spontaneously hypertensive rats (SHR). Fed Proc 46, 21.4, 1987.

Smits J, Le Noble J, Van Essen H, Slaaf D. Microcirculatory effects of synthetlc atrial natriuretic factor (hANF; WY 47.663) in rat mesentery. Fed Proc 46, 1142, 1987.

Je Noble LML, Van Essen H, Slaaf DW, Tangelder GJ, Struyker Boudier HAJ. Arteriolar alterations during the early phase of spontaneous hypertension in rat cremaster muscle. Naunyn Schmiedeberg"s Arch Pharmacol 335 (supp 1), 269, 1987.

Smits J, Le Noble J, Van Essen H, Slaaf DW. Human atrial natriuretic factor (h-ANF; WY 47.663) does not increase capillary protein extravasation in rat mesentery. Ric Sci Educ Perman suppl 58, abster ne 537, 1987. 
Aan de uiteindelijke realisatie van dit proefschrift heb lik met veel plezier gewerkt. Het behoeft geen betoog dat proefschriften niet het werk zijn van een persoon. Het doen van wetenschappelijk onderzoek betekent een kontinue uitdaging warwoor een goede sfeer en social werkklimat nodig zijn. Hiervoor will ik allen danken met wile ik in deze periode heb samengewerkt. De samenwerking met medewerkers wan verschillende disciplines binnen thet mikrocirkulatie-laboratorium betekende een extra stimulans voor mij.

In de eerste plats wil ik mijn promotores, prof. dr. H.A.J. Struyker Boudier en prof. dr. R.S. Reneman, bedanken. Beste Harry, ik ben je dankbaar voor de keuze binmen het ondewwerp hypertensie en je vertrouwen in voorgestelde experimenten. In het bijzonder waardeer ik het feit dat je valk bereid was tijdens de uitvoering van experimenten aanwezig te zijn ondanks je drukke werkzamheden. Prof. dr. R.S. Reneman wil ik bedanken voor de begeleiding en kritische analyse van de morfometrische experimenten, vooral tijdens de latste fase van het onderzoek.

De beide co-promotores, dr. D.W. Slaaf en dr. J.F.M. Snits, wil $i k$ bedanken voor hun inspanningen om mij een goede wetenschappelijke scholing te geven en hun suggesties tijdens het schrijven van het proefschrift. In het bijzonder waardeer ik Dick Slaaf voor zijn enthousiasme om mijn ideeën en konsepten, op zijn inmiddels bekende manier, steeds weer op hun (on)juistheid te toetsen.

Bijzondere steun heb ik gehad aan dr. G.J. Tangelder. Beste Geert-Jan, ik bewonder je vindingrijkheid en vooral je vermogen om steeds opnieuw problemen die woor mij welhaast onoplosbaar leken, hanteerbiar te maken.

De beide referenten, prof. dr. F.T. Bosman en prof. dr. M.A.D.H. Schalekamp, dank ik voor de naumgezette wijze warop zij het manuskript gelezen hebben.

Rinus Alewijnse wil ik bedanken voor zijn voortreffelljke elektronische ondersteuning.

De medewerkers van de mechanika-werkplats zijn van grote bete- 
Kenis geweest voor de technische reallsatle van de mikroskoopopste1ling en orgaanbaden. Hun steun en daadwerkelijke thzet soms tijdens experimenten wardeer ik ten zeerste.

Helma van Essen en Sabrina van Velzen bedank lik voor hun uitmuntende ondexsteuning tijdens het uitvoeren van de experimenten en hun bulp bij het maken van de velle tekeningen.

In particular I would like to thank $\mathrm{dr}$. Tom Smith and prof. Phillp Hutchins, not only for offering lab facilities and support during my experiments but also for their hospitality and their efforts to make my stay in Winston-Salem, NC, a pleasant and fruitful one.

En tenslotte wll ik EIs Geurts en Mia Hogenboom bedanken voor al het typewerk en voor het korrigeren wan soms onleesbare passages van de manuskripten. 